\title{
Evaluating the potential effect of the increased importance of the impact component in the Research Excellence Framework of the UK
}

\begin{abstract}
Mehmet Pinar ${ }^{\mathrm{a}}$, Emre Unlu ${ }^{\mathrm{b}}$

The UK's research excellence framework (REF) is a system that is intended to evaluate the quality of the research produced by the higher education institutes (HEIs) in the UK in three areas: quality of research outputs, the impact of this research beyond academia, and the research environment. For the next REF, the funding bodies have reviewed the importance of the three assessment elements and decided to increase the weight of "impact" to $25 \%$ (from 20\% in REF2014) and decrease the weight of "outputs" to $60 \%$ (from 65\% in REF2014). This paper first examines the relevance of some factors for the quality of impact submissions in REF2014 and finds that larger submissions and institutes with higher external research income received better impact scores in the REF. This paper then examines the unit of assessments (UoAs) and HEIs that benefitted from the inclusion of the impact agenda as part of REF2014 by examining the distribution of the quality-related research (QR) funding in the 2017-2018 period and finds that the QR funding gap among different UoAs tend to decrease but the gap among HEIs in most of the UoAs increased. With the increased importance of impact agenda as a criterion for funding bodies, it is expected that research income will be concentrated in fewer universities in the future with the increased importance of non-academic impact. This paper also discusses some of the gaming strategies and long-term investment priorities that HEIs may engage in based on the new submission rules of the next REF.
\end{abstract}

Keywords: Impact; Research assessment systems; Research excellence framework; Research funding distribution

Acknowledgements. We gratefully acknowledge the helpful comments of the two anonymous reviewers. The authors would like to thank seminar participants at Edge Hill University for useful suggestions and comments. We also thank Chris Hughes for his very detailed feedback on the manuscript. We are grateful to the Research Investment Fund of Edge Hill University for financial support.

This is the authors' accepted manuscript for the article: Pinar, M., Unlu, E. (2019) "Evaluating the potential effect of the increased importance of the impact component in the Research Excellence Framework of the UK", British Educational Research Journal, forthcoming. The final publication is available at: https://doi.org/10.1002/berj.3572

\footnotetext{
${ }^{a}$ Corresponding author: Business School, Edge Hill University, St Helens Road, Ormskirk, L39 4QP, Lancashire, United Kingdom. Email: mehmet.pinar@edgehill.ac.uk

${ }^{\mathrm{b}}$ Business School, Edge Hill University, St Helens Road, Ormskirk, L39 4QP, Lancashire, United Kingdom. Email: emre.unlu@edgehill.ac.uk
} 


\section{Introduction}

Performance-based university research funding systems have become popular in recent decades (see e.g., Bridges, 2009; Hicks, 2012; Rebora and Turri, 2013 for evaluation of different performancebased research funding systems). The OECD has identified a clear international trend towards more competitive funding with the introduction of performance-based elements in core institutional funding (OECD, 2010). The UK's Research Excellence Framework (REF) is one of the most highly developed research performance assessment mechanisms, performance-based used to evaluate the quality of the research produced by the higher education institutes (HEIs) in the UK. The quality of research outputs (outputs hereafter), the impact of this research beyond academia (impact hereafter), and the research environment (environment hereafter) of the UK HEIs were evaluated in 36 subject-based unit of assessments (UoAs) in REF2014 where outputs, impact and environment elements were given 65\%, $20 \%$, and $15 \%$ importance when evaluating the overall quality of research ${ }^{1}$. These three assessment criteria are then used by the funding bodies to allocate the mainstream quality-related research $(\mathrm{QR})$ funding across the UoAs and HEIs in the UK. QR funding is an important element of the UK's 'dual funding' system for research, allocating funding directly to HEIs for them to invest in pursuit of their institutional research strategies.

The positive effect of university research on firm, industry, regional, and economic and social performance has been long examined (see e.g., Cohen et al., 2002; Cowan and Zinovyeva, 2013; Perkman et al., 2013; Szücs, 2018 among many others) promoting an expectation upon academia to engage with non-academic audiences to have a wider societal and economic impact. Hence, the impact agenda is now also reflected in the allocation of QR funding via REF2014 and by the assessment of pathways to impact plans and increased use of so-called "challenge-led" research funding streams.

Since the inclusion of the impact agenda as part of the REF, there is a stream of literature that highlight the challenges and issues that the impact agenda imposes on academia (see e.g., Penfield et al. (2014) for a detailed review of the impact component of the REF and methodologies and frameworks that have been employed globally to assess research impact and some of the challenges in evaluating impact). Some of the key challenges of the evaluation of the impact agenda were about the uncertainty of the way it is evaluated and its effect on the academic disciplines. For instance, Sayer (2015) argues that peer review evaluation of impact in the REF is likely to be biased as the reviewers lack clear guidance on how to assess the research elements Manville et al. (2015) were commissioned by the funding bodies to evaluate the assessment process of the impact element of REF submission and highlighted various challenges that panel members faced during the evaluation process (e.g., some panel members thought that they did not have the expertise to evaluate some of the impact element and some

\footnotetext{
${ }^{1}$ This paper evaluates the impact performances of 36 UoAs in the REF2014. However, the next REF exercise will consist of 34 UoAs (see https://www.ref.ac.uk/about/units-of-assessment/ for the new UoAs that will be used in the next REF submissions).
} 
others had difficulty in distinguishing the quality of impact). . Furthermore, Smith et al. (2011) examine the potential effect of the impact agenda on academic independence (or academic autonomy) as evaluation of impact may be used to impose the type of research that academics should carry to generate so-called socially or economically beneficial research outcomes. Similarly, researchers in some of the disciplines (e.g., chemistry, physics and mathematics) were concerned that their researchmight be redirected to show economic benefit, which would narrow their research focus (Manville et al., 2015; Watermeyer). Overall, there exists a substantial discussion about the way that impact can (should) be evaluated and potential challenges, issues, and uncertainty around it (see e.g., Samuel and Derrick, 2015). Even though there exists a lot of uncertainty around impact evaluation, the weighting (importance) of impact element is to be increased to $25 \%$ and the weighting (importance) of output element is decreased to 60\% in the next REF exercise, REF2021 (see point 26 of REF, 2019) ${ }^{2}$. Even though there is an extensive conceptual and empirical research devoted towards evaluating the effect of impact agenda on academic staff members, different UoAs and institutions, to our knowledge, there is no empirical analysis that evaluates how increased importance of impact agenda is likely to affect the distribution of research income across universities and subject areas.

To examine which unit of assessments and institutes were the main beneficiaries (losers) after the inclusion of impact agenda in the REF, we examine the mainstream QR funding distribution in 2017-2018 period by using the newly proposed weights for its allocation (i.e., 60\%, 25\%, and 15\% of the total QR funding is distributed based on the performance of HEIs in output, impact, and environment elements, respectively). It should be noted that our aim in here is not to predict how the QR funding will be distributed in REF2021 with the increased importance of impact element but to examine which unit of assessments and HEIs were the ones that performed relatively better (worse) in the impact element in the REF2014 compared to output one and discuss how inclusion of the impact agenda affected the research income distribution among different subject areas and HEIs.

The rest of the paper is organized as follows. Section 2 provides information on the evaluation of research quality in the UK. Section 3 provides the details of how the mainstream QR funding is distributed. Section 4 evaluates the relevance of submission size and external research income for the quality of impact case studies. Section 5 examines which units of assessment and HEIs were the ones that performed relatively better (worse) in the impact element in the REF2014 compared to the output element by redistributing QR funding using the newly proposed weights. We also discuss some potential tactical implications for HEIs in section 5 and finally, section 6 concludes the paper and offers some policy implications.

\footnotetext{
${ }^{2}$ When the impact element was first introduced in REF2014, the weight (importance) of the research outputs in all panels was decreased except panel G (see http://www.rae.ac.uk/panels/ for weights given to each element in Research Assessment Exercise in 2008). Similarly, from REF2014 to REF2021, the weight of research outputs was decreased by $5 \%$ when the weight of the impact element was increased by $5 \%$. In other words, the importance was shifted from research outputs to impact element over the last implementation of the REF.
} 


\section{Evaluation of research excellence in the UK}

The REF is the current system that evaluates the quality of research conducted by the HEIs of the UK. The joint team of four education-funding bodies, namely Research England (formerly HEFCE), the Scottish Funding Council, the Higher Education Funding Council for Wales, and the Department for the Economy of Northern Ireland, conduct this evaluation in order to determine the distribution of QR research funds.

Since the introduction in 1986 of the Research Selectivity Exercise (the predecessor to the Research Assessment Exercise - the RAE), there have been major changes in the assessment of research quality and the way the funding has been distributed (see e.g., Shattock, 2012 for a thorough discussion on the evolution of research assessment exercises). In 2014, REF replaced RAE, which was lastly conducted in 2008, by removing esteem indicators and introducing a new element for the assessment of the research quality in non-academic impact. UK HEIs place a lot of importance to the REF exercise as not only HEIs receive their share of QR funding per year based on their performances in this exercise, but it also affects their rankings in the university league tables ${ }^{3}$. Given the fact that the university rankings also affect students' choice of university to attend (Horstschräer, 2012; Broecke, 2015; Gibbons et al., 2015) and the ability of universities to attract highly productive researchers (see e.g., Hicks, 2009), the REF exercise also indirect impact on other activities of the HEIs. Therefore, the performance of HEIs in the REF not only affects their QR research funding over the period between two REF exercises (e.g., QR research funding between 2015-2016 and 2021-2022 period) but also their ranking within the similar period, which can then affect the student enrollment levels and the type of staff members they attract. Hence, the evaluation of research quality has important implications for HEIs. In the next subsections, we provide details of how the REF was implemented in 2014 and then discuss the changes that are expected to be introduced in the next REF evaluation.

\subsection{Evaluation of research excellence in 2014}

During the REF 2014 process, HEIs made submissions in each of the research areas they wished to be assessed, chossing from the available 36 UoAs. An expert sub-panel evaluated the quality of research submitted in each UoA under the guidance of four main panels. The main panels in the REF consist of medicine, health and life sciences (panel A), physical sciences, engineering and mathematics (panel B), social sciences (panel C), arts and humanities (panel D). The panels include senior researchers, international members and research users, people outside academia who use research in their organization or professional activity. 36 sub-panels evaluating the submissions' quality had a total of 1052 panel members and assessors, including academics and research users and specialist advisors ${ }^{4}$.

\footnotetext{
${ }^{3}$ For example, the complete university guide league tables use research quality in their rankings, which is constructed based on the REF outcomes.

${ }^{4}$ Further details about the REF in 2014 can be accessed via http://www.ref.ac.uk/2014/.
} 
Each UoA submission was evaluated according to their performance in research outputs, research environment, and their non-academic impact, which contribute $65 \%, 15 \%, 20 \%$ to the overall evaluation performance, respectively. The evaluations were performed according to the published "panel criteria and working methods", which differed across different panels and UoAs (see REF, 2011a for further details) to reflect broad disciplinary variations. After the evaluations, each main panel and its sub-panels generated a report detailing how they had applied the criteria.

The research output was assessed according to 'originality, rigour and significance, which can be described as the ability to make a difference through knowledge and thinking in the academic field or application beyond the academic field'. The impact element was evaluated in terms of its 'reach and significance'. Here, 'significance' refers to the research's ability to influence or enhance the policies or practices of non-academic organizations. In the assessment of impact, research users play an important role to ensure that the assessment criteria are able to capture effectively the wider impact of UK research. Lastly, REF evaluated the extent to which the research environment was conducive to the production of excellent research and its effective distribution and implementation. Thus, the research environment is evaluated based on its 'sustainability and vitality'. Finally, assessors in each sub-panel (UoA) classify the overall quality profile of submitted material under each of the three elements (output, impact, and environment) as either $4 *$ (i.e., world-leading quality), $3 *$ (i.e., internationally excellent but falls short of the highest standards of excellence), $2 *$ (quality that is recognized internationally), $1 *$ (quality that is recognized nationally), and unclassified (i.e., quality that falls below the standard of nationally recognized work).

\subsection{Changes in the weight allocation across three elements}

During preparations for REF2014 the UK higher education funding bodies had suggested that the weight for the impact element for REF 2014 should be $25 \%$ in order for it to be taken seriously by all the key stakeholders, and to demonstrate the benefits of research. However, as the impact assessment was introduced for the first time in REF2014, and its weight was set at $20 \%$ with the intention of increasing it in subsequent assessments (see REF, 2011b).

After REF2014, with the success of impact (as shown by Lord Stern's independent review, see Stern, 2016) and the feedback from the participant HEIs, Lord Stern suggested that the weight of research output should stay at $65 \%$ while environment and impact should be evaluated together with impact weight at least $20 \%$. Following the consultation from the four UK higher education funding bodies about the proposed approach of implementing Lord Stern's views (REF, 2017a), the final guidance of submissions for the REF 2021 was published with the weight of the impact increased to $25 \%$ and the weight of output decreased to $60 \%$ while the weight of the environment stayed the same (REF, 2019).

\section{Mainstream QR funding distribution}




\subsection{Mainstream QR funding distribution based on REF 2014 results}

After the assessment of the REF 2014 returns, these REF results have been used to allocate QR research funding across the UK HEIs. For instance, Research England allocated a total of $£ 1.6$ billion QR funding to English HEIs in the 2017-2018 period. 2015-2016 year was the first year of funding allocations based on the new weights on the three elements of research (outputs, impact, and environment), with the submissions that are rated $4 *$ (world-leading) given four times as much funding to that rated 3* (internationally excellent), and no QR research funding is given to submissions that are classified $2 *$ or below 5 .

Even though Research England distributes a total of $£ 1.6$ billion QR funding to English HEIs in 2017-2018 period, here we will only use the mainstream QR funding in our analysis as this portion of the funding is distributed solely based on the REF 2014 performance of HEIs, whereas other portions of the QR funding have other sets of criteria for their distribution. The mainstream $\mathrm{QR}$ funding is distributed based on quality (i.e., the assessed quality of outputs, impact case studies and research environment in REF 2014), the volume of submission and relative cost of research in different UoAs (subject areas) ${ }^{6}$. First, the whole mainstream QR funding is split into three pots according to the contribution of the three elements of research assessed in the REF (i.e., outputs, impact and environment) where $£ 157.0, £ 210.7, £ 684.7$ million were distributed in the environment, impact and output pots, respectively ${ }^{7}$. Research funding in each pot is then distributed across four main panels based on the eligible volume of research (which is based on the proportion of internationally-excellent and world-leading quality of research) and subject cost weights attached to each UoA (as conducting research in some subjects is more expensive $)^{8}$. Finally, given the subject cost weights, the eligible volume of research and quality of research (e.g., world-leading and internationally-excellent research receive a weight ratio of $4: 1$ and the research rated as nationally excellent or below are not given any

\footnotetext{
${ }^{5}$ Details on how annual funding is distributed by the Research England can be accessed via http://www.hefce.ac.uk/funding/annallocns/

${ }^{6}$ Interested readers referred to https://re.ukri.org/research/how-we-fund-research/for the details of how Research England distributes funding across different UoAs and HEIs.

${ }^{7}$ In this paper, we avoid the additional funding distributed based on London weighting in order to compare the funding allocation across the UoAs, panels, and HEIs, solely based on quality, not where the HEIs are located.

${ }^{8}$ Details of the research cost weight for each UoA are given in herehttps://webarchive.nationalarchives.gov.uk/20180405130324/http://www.hefce.ac.uk/funding/annallocns/17 18/research/.
} 
QR funding), mainstream QR funding is distributed across different UoAs of HEIs, and therefore to the HEIs ${ }^{9}$.

\subsection{Mainstream QR funding distribution based on REF 2014 performances with the proposed new weights}

Even though it is relatively hard to understand how the QR funding is distributed across HEIs due to many changing factors (see e.g., Kelly, 2016 for detailed analysis on this), each qualifying submission generates a certain percentage of the funding from the environment, impact and output pots. For instance, based on the volume and quality of research produced in the clinical medicine UoA of the University of Birmingham, this UoA brought this university $£ 625,628, £ 982,472$, and £2,728,672 from the environment, impact, output pots of mainstream QR research funding in the 2017-2018 period. These amounts to roughly $0.40 \%, 0.47 \%$, and $0.40 \%$ of the total funds distributed in the environment, impact, and output pots, respectively ${ }^{10}$. Since the subject costs, volume and quality of research are already known, one can easily allocate additional QR funding in each pot to the respective UoAs based on the percentage of funding they receive in each pot. For instance, if an additional $£ 1$ million is planned to be distributed in each pot, the University Birmingham would have received roughly $£ 4,000, £ 4,700$, $£ 4,000$ more from the environment, impact, and output pots based on the research performance of the medical medicine UoA in the REF 2014 submission, respectively.

Based on the explanation above, it is straightforward to calculate the changes in mainstream QR funding distribution if one were to reallocate some of the funding from one pot to another. In this exercise, we reallocate $5 \%$ of the total mainstream $Q R$ funding from output to impact pot (i.e., $£ 52,665,551.5)$. In other words, the total mainstream QR funding in environment pot will be the same as before. However, total funding distributed in impact (output) pot will be $£ 52,665,551.5$ more (less). This reallocation of total funds across different pots would increase (decrease) the QR funding received by some of the panels, UoAs, and HEIs. For instance, this reallocation of funds from output to impact pot would increase the funds received by the University of Birmingham based on the research performance of the clinical medicine UoA by $£ 35,720^{11}$. Since the funding in each pot is distributed based on each UoA's relative performance in the respective research element, the relative quality of research impact achieved by the clinical medicine unit of the University of Birmingham is higher than

\footnotetext{
${ }^{9}$ The detailed stages followed by Research England to allocate mainstream QR funding to four main panels, UoAs and HEIs are explained between paragraphs 120 and 136 in HEFCE (2017). We do not provide these detailed stages to preserve space.

${ }^{10}$ The percentage of funding that is received by clinical medicine of the Birmingham University from environment, impact, output pots are calculated as follows: (£625,628 / 157,996,659) x 100, (£982,472/ $£ 210,662,204) \times 100$, and $(£ 2,728,672 / £ 684,652,158) \times 100$, respectively.

11 This is calculated as follows: (£982,472 / £210,662,204) x £52,665,551.5+(£2,728,672/ £684,652,158) x $£ 52,665,551.5$.
} 
their relative quality in research outputs, which led to a higher $\mathrm{QR}$ research funding generated by this UoA after reallocation of funds based on the newly proposed weights. Obviously, reallocation of funds based on new weights across three elements of research would lead to higher QR funding generation by some panels, UoAs, and HEIs and less by some others. In the next section, we will offer the details of how this reallocation of funds across different elements affect QR funding obtained by different panels, UoAs, and HEIs.

\section{Some quantitative determinants of quality of impact}

In this section, we will examine the association of some quantitative factors with the assessed quality of non-academic impact in the REF2014, which will provide some explanation on how the increased importance of impact may affect the behaviour of institutes and research income inequality among subject areas and HEIs.

\subsection{Size of submissions and quality of impact case studies}

There are various areas where the size of the unit of assessment may play a role in the quality of the assessed impact case studies. Firstly, the size of a given unit provides a good proxy for the number and quality of research collaborations and research groups within the unit of assessment. For instance, Larivière et al. (2015) found that unit size plays a significant role in the number of collaborations and scientific impact. Secondly, relatively larger departments are likely to benefit from economies of scale where there is the possibility of staff engaging in more scholarly activities and other types of research activities. Thirdly, larger departments tend to have better infrastructure and facilities and that there may be more non-academic staff members that work towards evidencing impact and impact activities (e.g., larger departments may hire administrative staff members that support the preparation of the impact case studies as they have a larger budget available for such activities). For instance, Mryglod et al. (2013) suggested that larger departments achieved relatively higher scores in RAE2008 thanks to their access to expensive and sophisticated equipment. To examine whether the size of the unit of assessment played any role in the assessed quality of impact, we collected the number of FTE staff submitted and the assessed quality of impact element of each submission. We measure the assessed quality of the impact case studies of a given submission by the grade point average (GPA) of the impact element by multiplying the proportion of research activity attributed to each quality category by the sub-panel with the respective weights given to each quality profile categories: unclassified $=0,1^{*}=1,2^{*}=2,3^{*}=3$ and $4^{*}=4^{12}$. Figure 1 shows the associations between submission size and the assessed quality of the impact case studies in panels A, B, C and D. We find that relatively larger submissions in all panels tend to

\footnotetext{
${ }^{12}$ For instance, if $20 \%, 30 \%$ and $50 \%$ of the impact case studies of a given submission were rated as $2 *, 3 *$ and $4^{*}$, respectively, then the GPA of the assessed quality of impact element of this unit would be 3.3 (i.e., $0.2 \times 2+0.3 \times 3+0.5 \times 4)$.
} 
achieve higher GPA scores in impact elements where the effect of submission size is higher in panels B and C (i.e., the fitted lines in Panels B and C are steeper than the ones in panels A and D).

<Insert Figure 1 approximately here>

\subsection{External research income generation and quality of impact case studies}

Beyond the importance of impact agenda for the mainstream QR funding, other significant funding initiatives (e.g., the non-QR elements of the Global Challenges Research Fund and Industrial Strategy Challenges Fund, and funding allocated by the UK research councils also prioritised the nonacademic impact in their allocation of funds. Gunn and Mintrom (2016) reviewed the European Union (EU), Netherlands, and the United Kingdom funding systems and suggested that impact generation has become one of the criteria in the choice of allocation of the research grants. To examine whether the external research income generation has any association with the assessed quality of the impact case studies, we obtained the total amounts of external research income and research income-in-kind between the period 1 August 2008 to 31 July 2013 for each submission from the environment submissions of the REF 2014. We standardize the total external research income generated by each submission with the department size (i.e., total external research income per FTE) and Figure 2 presents the association between the external research income per FTE and the assessed quality of impact submissions (i.e., GPAs of the assessed quality) in four main panels. We find that the effect of external research income per FTE on GPA levels was relatively higher in panels B and C where submissions with higher external research income per FTE tend to achieve relatively higher GPA levels in impact element. This positive relationship is potentially due to the fact that most of the external research income generated by these units were associated with well-planned impact agendas, which then resulted in the better-quality impact case studies.

\section{$<$ Insert Figure 2 approximately here>}

\section{Increased importance of the impact agenda and its implications}

\subsection{Distribution of QR funding across UoAs and four main panels}

In this subsection, we evaluate the allocation of research funding in 2017-2018 period if one were to distribute QR funding based on the decisions taken on the REF2021 where the $25 \%$ of the QR funding will be distributed in impact pot, and the $60 \%$ of the QR research funding will be distributed in output pot and the remaining $15 \%$ of the funds will be distributed in environment pot. We carried out this exercise to identify the UoAs that had relatively better (worse) performance in impact element than that of in output one in the REF2014.

Table 1 offers QR funding distribution across UoAs and four main panels in 2017-2018 period based on the REF 2014 and REF 2021 weight allocations across the three elements of research and total gains and losses of each UoA and panel if one were to distribute the funding based on the REF 2021 
weight allocation compared to the REF2014 one. The main UoA that would have gained additional funding with the proposed change is clinical medicine with an additional $£ 1.8$ million allocated to this UoA. Similarly, Public Health, Health Services and Primary Care UoA would have generated £446k more with the increased impact weight. On the other hand, the main UoAs whose performance would have generated relatively less QR income with the higher weight on wider impact agenda would be biological sciences, mathematical sciences, and physics where total funding received by these UoAs would have declined by roughly $£ 788 \mathrm{k}, £ 543 \mathrm{k}$, and $£ 454 \mathrm{k}$, respectively. This finding is in line with the relative positions of the fields in terms of their performances in output and impact. The best performers in impact agenda are the clinical medicine and Public Health, Health Services and Primary Care as they generate the highest QR funding per FTE from the impact pot, whereas they rank $11^{\text {th }}$ and $12^{\text {th }}$ positions in terms of their output performance, respectively. On the other hand, mathematics, physics and biological sciences ranked in 2nd, 3rd and 5th in QR funding per FTE from output pot but ranked in 9th, 11th and 15th positions in terms of QR funding per FTE they received from the impact pot, respectively. Overall, QR funding inequality among UoAs is relatively high in output compared to impact where FTE-weighted Gini coefficients were 0.15 and 0.12 , respectively suggesting that the increased importance of the impact agenda decreases the QR funding inequality among the UoAs.

<Insert Table 1 approximately here>

When we examine the performance of four main panels [i.e., Panel A (Medicine, health and life sciences), Panel B (Physical sciences, engineering and mathematics), Panel C (Social Sciences), and Panel D (Arts and humanities) consisting UoAs between 1 and 6, 7 and 15, 16 and 26, and 27 and 36 , respectively], we find that panels $\mathrm{A}, \mathrm{C}$, and D would have received $£ 858.5 \mathrm{k}, £ 718.8 \mathrm{k}$, and $£ 436.2 \mathrm{k}$ more funding if impact (output) pot had 5\% more (less) of the total mainstream QR funding. On the other hand, Panel B (Physical sciences, engineering and mathematics) would have received roughly £2 million less if more weight (importance) was given to impact agenda. Like the case above, we find that the gap between the panels is decreased with the inclusion of the impact agenda since the FTE-weighted Gini coefficients were higher in QR funding distribution in the output pot than the one in the impact pot. In sum, we find that the inclusion of the impact agenda to the REF evaluation decreased the QR funding gap between four main panels, which would have been higher if the assessment was only based on the research outputs and environment. When we look at the income inequality among HEIs within a given UoA, we find that inequality among the HEIs would have been higher in 28 UoAs with the newly proposed weights (see Table 2 for the details). In other words, the research income inequality among HEIs in most of the subject areas increased with the inclusion of impact agenda in the REF evaluation (area studies being the most affected one). Whereas, inequality across HEIs in 7 UoAs would decrease with the reallocation of funds (i.e., the inclusion of impact agenda as part of the evaluation decreased the gap between HEIs in these units of assessments). Overall, our findings suggest that the inequality across HEIs within UoA is likely to increase with the increased importance of wider impact agenda. It 
should be noted that the changes in inequality measures are relatively small since only $5 \%$ of the total mainstream funding is reallocated from output to impact pot. However, the direction of the inequality would give us guidance about the effect if one were to reallocate 10 or 15 percent funding from output to impact pot.

\section{$<$ Insert Table 2 approximately here>}

Lower QR funding generation by some UoAs and panels as a result of REF2021 weights applied to REF2014 performances may be attributable to various factors. Firstly, it is possible that impact on a non-academic community is observed in longer periods in some subject areas such as physics and mathematics (e.g., Penfield et al. (2014) discuss some of the challenges of impact evaluation and suggest that impact of some research lags in time). This is something that is acknowledged by Lord Stern's report highlighting that "realising the full impact of research is a continuing and sometimes long-lived process" (Stern, 2016, p. 23), yet there is a clear time frame in which impact and research had to take place to be part of the REF submission. Another explanation would be that the majority of the academic staff members think that links to impact are less straightforward or obvious to evidence in some fields except medical fields (Bornmann, 2013; Manville et al., 2015; Wilkinson, 2019) and carrying out such exercise in REF2014 may have disproportionately disadvantaged some fields. In other words, some of the fields have long adapted societal impact in their research agenda, and potentially these were the fields that obtained relatively higher QR funding after the inclusion of impact agenda to the REF. Similarly, academics in some fields are more concerned about their academic autonomy with the inclusion of impact agenda to the REF (see e.g., Manville et al., 2015) and it is possible that academics in some subject areas may prefer research outputs over impact and vice versa, and an overall tendency of academics may either improve or deteriorate the REF performances of some subject areas. In other words, cultural change in some fields may take time and researchers may resist integrating impact into their research agenda.

\subsection{Distribution of QR funding among English HEIs}

Table 3 lists five main winners and losers with the inclusion of the non-academic impact in the evaluation. Positive (negative) figures in the total gains/losses column suggest that an institution would have received higher (lower) mainstream $\mathrm{QR}$ funds if the $\mathrm{QR}$ funding is distributed based on the decisions taken for the REF 2021 compared to the existing allocation of funds. If the mainstream QR funding was distributed based on the new weights proposed, University College London (UCL hereafter), University of Leeds, University of Manchester, University of Nottingham, and University of Bristol would have experienced the highest increases in their mainstream QR funding with total increases in their funding by $£ 404 \mathrm{k}, £ 288 \mathrm{k}, £ 270 \mathrm{k}, £ 236 \mathrm{k}$, and $£ 231 \mathrm{k}$, respectively. On the other hand, University of Cambridge, University of Warwick, University of Oxford, University of Birmingham, University of Surrey, and University of Exeter would have received $£ 354 \mathrm{k}, £ 246 \mathrm{k}, £ 221 \mathrm{k}, £ 160 \mathrm{k}$, 
$£ 148 \mathrm{k}$, and £138k less of mainstream QR funding if the funding was distributed based on newly proposed weights, respectively. In other words, the institutes mentioned above were the main winners and losers with the inclusion of the societal impact in the REF based on their performances in REF2014. Clearly, the performance of some of the UoAs in these HEIs would generate more QR funding, and some others would generate less with the newly proposed weights highlighting the departments that performed better (worse) in the impact element compared to output one. For instance, performances by the clinical medicine and institute of education of the UCL would have brought $£ 368 \mathrm{k}$ and $£ 101 \mathrm{k}$ more funding with the new way of allocating funds, respectively. Whereas, performances by the biological and mathematical sciences would have brought $£ 117 \mathrm{k}$ and $70 \mathrm{k}$ less of research funding to the UCL, respectively (see Supplementary material for the detailed total funding received across different UoAs for given set of institutes). In light of this, decision-makers at UCL may choose rationally to place more emphasis and support in their long-term investments in research capacity building in the clinical medicine and education units compared to the biological and mathematical sciences units.

<Insert Table 3 approximately here>

Unlike inequality among UoAs and panels, we find that the QR funding income inequality across HEIs was relatively higher in the impact pot than that in output pot where the FTE-weighted Gini coefficients in impact and output pots were 0.182 and 0.157 , respectively. This suggests that the increased importance of non-academic impact would further increase the QR funding inequality among HEIs. First, relatively larger submissions and submissions with larger external income per FTE tend to perform better in impact element (see subsections 4.1 and 4.2). In other words, these two factors contributed to the QR funding inequality among HEIs, where larger institutes and institutes that generated external income tend to obtain relatively higher QR funding. . Secondly, Russell group universities have higher economic impact and more knowledge transfer activities compared to other universities (see e.g., Hewitt-Dundas, 2012; Guerrero et al., 2015) and inclusion of the impact agenda in the REF should benefit Russell group universities and increase the gap between Russell and nonRussell group universities. We find that the research income inequality among Russell and non-Russell group increased with the increased importance of the impact agenda, but the research income inequality among these two groups decreased in some $\mathrm{UoAs}^{13}$.

Overall, we find that the increased importance of impact agenda leads to an increase in the QR income inequality among HEIs where the QR funding is likely to end up in the hands of HEIs that are relatively larger and generate more external research income. Furthermore, not only the increased importance of impact agenda plays a role in the allocation of QR funding to UK HEIs but also strategies, behaviours and cultures of institutes have and will continue to change as a result of the impact agenda.

\footnotetext{
${ }^{13}$ The research income inequality between Russell and non-Russell group universities are increased in 21 UoAs (i.e., UoA 1, 3, 5, 8, 9, 10, 11, 12, 13, 15, 16, 18, 20, 21, 23, 24, 25, 27, 29, 30, and 36) and decreased in other 15 UoAs, and the results are available from authors upon request.
} 
Beyond the inclusion of the impact in the REF, the funders on both sides of the dual funding system prioritise non-academic impact so that they created mechanisms to promote and incentivise it (see e.g., Global Challenges Research Fund and Industrial Strategy Challenges Fund, and UK Research and Innovation among many others). In other words, units that produce impactful research will not only receive higher QR funding but also will generate higher external research income (and higher external research income then produces impactful research, see subsection 4.2), which would then further increase the inequality among HEIs. It has also been found that granted research proposals tend to generate higher citation impact at their international research fronts than those whose submissions were rejected (Van Leeuwen and Moed, 2012) and submissions to the RAE in 2008 with higher external research income obtained better research environment evaluation (Taylor, 2011). In other words, the increased importance of the impact agenda has major implications beyond the QR funding allocations where the importance of impact agenda is higher than the proposed 25\% considering the positive spillover effects of impactful research (i.e., higher external research grants, better research outputs and environment).

\subsection{Some potential implications for the HEIs}

Knowing which of those UoAs performed relatively better (worse) in impact element, some HEIs may choose to place more emphasis on the UoAs that performed worse in impact element to improve their positions. On the other hand, one can also argue that university administrators may follow the logic of the REF exercise by allocating more resources to the most efficient users (i.e., more of central funding is allocated to the UoAs that are likely to generate better performance in the impact case studies) ${ }^{14}$. This strategic move is also in line with the economic theory of investing more in a given sector in which there is higher marginal expected return compared to other sectors. Hence, if the marginal expected return of a given UoA (return here is the $\mathrm{QR}$ funding) is higher than the other ones, the economic theory would suggest that more resources should be allocated to the former UoA compared to the other ones. Hence, decision-makers may choose to allocate relatively more central funding to UoAs that performed relatively better in REF 2014 exercise and increase the size of the submission in these UoAs (see section 4.1 where relatively larger submission achieved higher impact scores) and decrease the size of the submissions that performed relatively weaker. For instance, Greenhalgh and Fahy (2015) examined the impact case study submissions to the Public Health, Health Services and Primary Care UoA and found that the institutions made a strategic decision to submit more quantitative empirical studies in this unit of assessment and did not to submit impact case studies where impact is relatively harder to capture (see e.g., Wilkinson, 2019). Johnston and Reeves (2017) examined the Economics and Econometrics submissions of HEIs to the assessment periods in 1992, 1996, 2001,

\footnotetext{
${ }^{14}$ For instance, Bloch et al. (2014) show that previous external research grant holders are more likely to obtain grants in the future and that it is possible that the subject areas that performed better in the previous REF exercise will also do a better job in the next REF return.
} 
2008 and 2014 and found that research groups that perform below universities' expectations are pulled out of the next submission periods. In the previous implementation of the research excellence assessments, institutes were allowed not to return any submissions in some fields where there was a limited research activity and/or the quality of research perceived to be low quality. However, with the implementation of the universal REF (i.e., all research active staff members are required to be returned in the next REF submission, see REF (2019) for the details), institutes have to return submissions in UoAs where there are research active staff members. However, HEIs may choose to relocate some of the staff members from the UoAs where the impact case study submissions are likely to be rated lower to the UoAs in which impact case studies are likely to be rated higher to decrease the number of impact case study submissions of UoAs that have relatively weaker impact case studies. Furthermore, the design of funding distribution may encourage more of joint submissions to the next REF to benefit from economies of scale (see e.g., Docampo et al., 2015 for discussion of mergers of HEIs to move in the rankings) as larger institutes tend to perform better in generating non-academic impact and can do a better diversification of different priorities of research.

Another important change from REF2014 to the next REF exercise is the number of case studies required in submissions. The number of impact case studies required in each submission is determined by the number full-time equivalent (FTE) of staff returned in the submissions. In the REF 2014 submissions, units were required to submit two impact case studies if the submitting unit has less than 14.99 staff, and an additional impact case study was required for additional 10 staff returned and so on (see REF, 2011a for the details). On the other hand, the thresholds set for the number of required impact case studies are changed for the next REF exercise. Units are now required to submit two impact case studies if the submitting unit has less than 19.99 staff, and an additional impact case study was required for additional 15 staff returned up to 109.99 staff, and an additional impact case study is required for additional 50 staff beyond 110 staff (see REF, 2019 for the details). This would be a major change for the behaviour of institutes in their decisions about the submissions as the required impact case studies per FTE submitted is downgraded. For instance, in the previous REF submission, there were 20, 32, 64 and 57 units in panels A, B, C and D where the number of staff submitted were between 15 and 19.99 and these units submitted three impact case studies to the REF2014, but these units would have returned only two impact studies based on the rules set for the next REF exercise. Since the larger institutes performed relatively better in generating impact in the REF2014, lowered number of impact case studies required for submissions may potentially scale down the differences in impact performances between smaller and larger institutes. However, we would still expect that these thresholds set for returning a different number of impact case studies to play an important role. For instance, if a unit has 36 research active staff members to be returned for the next REF exercise, this would require four impact case studies to be returned by this unit assuming all staff are returned under this unit. However, if decisionmakers think that this unit has only three strong impact case studies (this would be the decision-makers' 
perception about the quality of the impact case studies) and cannot produce a fourth impact case study, they may choose to decrease the number of submitted staff in this unit. This could be done by either allocating one staff member from this unit to another one or choosing not to hire any staff member prior the census date (i.e., 31 July 2020 where the information on all staff in the post with significant responsibility for research to be submitted) if one staff member left the institution. One may observe an alternative scenario as follows. For instance, a unit with a size of 30 may have three strong impact case studies (again perceived quality of impact case studies by the institute). In other words, this department is not short of impact case studies for the REF submission. However, this unit may have a shortage of research outputs for the REF return (i.e., 2.5 times the number of FTE submitted), then this department may choose to hire additional research active staff members before the census date of the next REF to meet the required number and quality of research outputs. Hence, by hiring up to four additional research active members (as this would not require the department to return additional impact case study), this department is likely to improve its assessed quality of research in the next REF. In other words, we expect to see the gaming culture of the institutes to continue depending on the number and/or the perceived quality of the impact case studies of a given unit.

The increased importance of impact would also change the hiring and promotion procedures of the institutes. Universities will potentially increase appointment of researchers that are more likely to engage in impact agenda (see e.g., Salter et al., 2017 that identify the type of Business and Management academics that have preference for impact agenda) and may integrate non-academic impact agenda as part of their promotion criteria to increase incentives for researchers to engage with non-academic impact. Furthermore, we expect to see a larger number of research administrators being hired (particularly in larger institutes) to support the preparation of impact case studies. Hiring these additional administrators would not increase the required returns in the next REF (e.g., the number of required research outputs and impact case studies would not be affected by the number of administrators working in an institute) but is likely to improve the assessed quality of impact case studies and the success rates in the external research grant applications.

\section{Conclusions}

UK higher education funding bodies recently decided to increase the importance (weight) of impact agenda for the next REF exercise to encourage universities and academics to engage with more impactful research or do more to try to generate impact from their research. However, how this change is likely to affect the research income gaps among different subject areas and universities is not clear. To understand the potential effect of this change, we first examine the relationships between some quantitative factors and the assessed quality of impact case studies in the REF 2014 evaluation. We find that larger institutes and institutes that generated higher external research income per FTE tend to have more impactful research. We then examined how the distribution of mainstream QR funding across different subject areas and universities would alter if we were to distribute mainstream QR research 
funding in 2017-2018 period with the use of newly proposed weights (i.e., the importance of wider impact and research outputs increased and decreased by 5\%, respectively) where 15\%, $25 \%$ and $60 \%$ of the total mainstream QR funding is distributed based on the performances of HEIs in environment, impact, and output elements of research, respectively. We find that even though the research income gap between subject areas and four main panels decreased with the inclusion of the impact agenda as part of the evaluation, the research income gap among HEIs increased in most of the subject areas after the inclusion of the impact element as part of the evaluation.

Our analysis highlighted some of the subject areas that were more and less successful in generating high impact with their research (e.g., UoAs that are in the Physical sciences, engineering and mathematics panel were less successful in impact element compared to other UoAs). It has been argued that the non-academic impact in these areas is relatively harder to capture (see e.g., Manville et al., 2015; Wilkinson, 2019). Unless there is more engagement of academics with more impactful research or alternative ways of capturing impact in some subject areas, we may expect to see a lower number of submissions in these subject areas or research active staff members in these units may be returned in another unit of assessments.

Beyond the increased importance of the impact agenda in the allocation of QR funding, the impact element of research has become important criteria in the allocation of funding by other funding agencies. We also showed that the units with higher external research income per FTE tend to perform better in impact element in the evaluation of the REF. Furthermore, research outputs and environment also tend to be better with the increased external research income generation. Hence, increased impact element will have a spillover effect on the assessed quality of other research elements and that nonacademic impact will play a significant role on future research income distribution among universities and we expect to see increased research income inequality among HEIs where most of the funding being allocated to a fewer number of universities.

\section{References}

Bloch, C., Graversen, E. K., \& Pedersen, H. S. (2014) Competitive research grants and their impact on career performance. Minerva, 52, 77-96.

Bornmann, L. (2013) What is societal impact of research and how can it be assessed? a literature survey, Journal of the American Society for Information Science and Technology, 64(2), 217-233.

Bridges, D. (2009) Research quality assessment in education: Impossible science, possible art? British Educational Research Journal, 35(4), 497-517.

Broecke, S. (2015) University rankings: do they matter in the UK? Education Economics, 23(2), 137161.

Cohen, W.M., Nelson, R.R., Walsh, J.P. (2002) Links and Impacts: The Influence of Public Research on Industrial R\&D. Management Science, 48(1), 1-23. 
Cowan, R., \& Zinovyeva, N. (2013) University effects on regional innovation. Research Policy, 42(3), 788-800.

Docampo, D., Egret, D., \& Cram, L. (2015) The effect of university mergers on the Shanghai ranking. Scientometrics, 104, 175-191.

Gibbons, S., Neumayer, E., \& Perkins, R. (2015) Student satisfaction, league tables and university applications: evidence from Britain. Economics of Education Review, 48, 148-164.

Greenhalgh, T., \& Fahy, N. (2015) Research impact in the community-based health sciences: an analysis of 162 case studies from the 2014 UK research excellence framework. BMC Medicine, 13, 232. https://doi.org/10.1186/s12916-015-0467-4

Guerrero, M., Cunningham, J.A., \& Urbano, D., 2015. Economic impact of entrepreneurial universities' activities: An exploratory study of the United Kingdom. Research Policy, 44(3), 748764.

Gunn, A., \& Mintrom, M. (2016) Higher Education Policy Change in Europe: Academic Research Funding and the Impact Agenda. European Education, 48(4), 241-257.

HEFCE (2017) Guide to funding 2017-18. How HEFCE allocates its funds. Available at https://webarchive.nationalarchives.gov.uk/20180405115730/http://www.hefce.ac.uk/pubs/year/2017/ 201704/ (accessed 05 June 2019).

Hewitt-Dundas, N. (2012) Research intensity and knowledge transfer activity in UK universities. Research Policy, 41(2), 262-275.

Hicks, D. (2009) Evolving regimes of multi-university research evaluation. Higher Education, 57, 393-404.

Hicks, D. (2012) Performance-based university research funding systems. Research Policy, 41(2), 251-261.

Horstschräer, J. (2012) University rankings in action? The importance of rankings and an excellence competition for university choice of high-ability students. Economics of Education Review, 31, 11621176.

Johnston, J., \& Reeves, A. (2017) Assessing research performance in UK universities using the case of the economics and econometrics unit of assessment in the 1992-2014 research evaluation exercises. Research Evaluation, 26(1), 28-40.

Kelly, A. (2016) Funding in English Universities and its relationship to the Research Excellence Framework. British Education Research Journal, 42(4), 665-681.

Larivière, V., Gingras, Y., Sugimoto, C.R., \& Tsou, A (2015) Team size matters: Collaboration and scientific impact since 1900. Journal of the Association for Information Science and Technology, 66(7), 1323-1332.

Mryglod, O., Kenna, R., Holovatch, Y., \& Berche, B. (2013) Absolute and specific measures of research group excellence", Scientometrics, 95(1), 115-127.

Manville, C., Guthrie, S., Henham, ML., Garrod, B., Sousa, S., Kirtley, A., et al. (2015). Assessing impact submissions for REF 2014: An evaluation. Rand Europe. Available at https://www.rand.org/content/dam/rand/pubs/research_reports/RR1000/RR1032/RAND_RR1032.p df (accessed 07 June 2019). 
OECD, 2010. Performance-Based Funding for Public Research in Tertiary Education Institutions: Workshop Proceedings. OECD Publishing, Paris. http://dx.doi.org/10.1787/9789264094611-en

Penfield, T., Baker, M., Scoble, R., \& Wykes, M., (2014) Assessment, evaluations, and definitions of research impact: a review. Research Evaluation, 23(1), 21-32.

Perkmann, M., Tartari, V., McKelvey, M., Autio, E., Broström, A., D’Este, P., et al., 2013. Academic engagement and commercialisation: A review of the literature on university-industry relations.

Research Policy, 42(2), 423-442.

Rebora, G., Turri, M., 2013. The UK and Italian research assessment exercises face to face. Research Policy, 42(9), 1657-1666.

REF, 2011a. Assessment framework and guidance on submissions. Available at

https://www.ref.ac.uk/2014/media/ref/content/pub/assessmentframeworkandguidanceonsubmissions/ GOS\%20including\%20addendum.pdf (accessed 05 May 2019).

REF, 2011b. Decisions on assessing research impact. Available at

https://www.ref.ac.uk/2014/media/ref/content/pub/decisionsonassessingresearchimpact/01 11.pdf (accessed 05 May 2019).

REF (2014) Results and submissions database. Available at https://results.ref.ac.uk/(S(mevbbiplnrg5u1yebd0vb2dr))/(accessed 10 May 2019).

REF, 2017. Consultation on the second Research Excellence Framework. Available at https://www.ref.ac.uk/media/ref,2021/downloads/REF_2017_02.pdf (accessed 07 June 2019).

REF, 2019. Guidance on submissions. Available at https://www.ref.ac.uk/media/1092/ref guidance on submissions.pdf (accessed 10 June 2019).

Samuel, G.N., \& Derrick, G.E. (2015) Societal impact evaluation: Exploring evaluator perceptions of the characterization of impact under the REF2014. Research Evaluation, 24, 229-241.

Salter, A., Salandra, R., \& Walker, J. (2017) Exploring preferences for impact versus publications among UK business and management academics. Research Policy, 46(10), 1769-1782

Sayer D. (2015) Rank Hypocrisies: The Insult of the REF. Los Angeles, CA: Sage.

Shattock, M. (2012) Making Policy in British Higher Education 1945-2011. Berkshire: McGraw-Hill.

Smith, S., Ward, V., \& House, A. (2011) 'Impact' in the proposals for the UK's Research Excellence Framework: Shifting the boundaries of academic autonomy. Research Policy, 40(10), 1369-1379.

Stern, L. (2016) Building on success and learning from experience. In: Department for Business, E.I.S. (Ed.), An Independent Review of the Research Excellence Framework, HMO, London.

Szücs, F. (2018) Research subsidies, industry university cooperation and innovation. Research Policy, 47(7), 1256-1266.

Taylor, J. (2011) The Assessment of Research Quality in UK Universities: Peer Review or Metrics? British Journal of Management, 22(2), 202-217.

Van Leeuwen, T.N. \& Moed, H.F. (2012). Funding decisions, peer review, and scientific excellence in physical sciences, chemistry, and geosciences. Research Evaluation, 21, 189-198.

Watermeyer, R. (2016) Impact in the REF: issues and obstacles. Studies in Higher Education, 41(2), 199-214. 
Wilkinson, C. (2019) Evidencing impact: a case study of UK academic perspectives on evidencing research impact. Studies in Higher Education, 44(1), 72-85.

Tables and figures and supplementary material provided below. 


\begin{tabular}{|c|c|c|c|c|}
\hline $\begin{array}{l}\text { UoA } \\
/ \\
\text { Panel }\end{array}$ & Unit of assessments / Panels & $\begin{array}{l}\text { QR funding } \\
(15-20-65)\end{array}$ & $\begin{array}{l}\text { QR funding } \\
(15-25-60)\end{array}$ & $\begin{array}{c}\text { Total } \\
\text { gains/losses }\end{array}$ \\
\hline 1 & Clinical Medicine & $£ 95,606,821$ & $£ 96,787,656$ & $£ 1,180,835$ \\
\hline 2 & Public Health, Health Services and Primary Care & $£ 37,988,245$ & $£ 38,434,414$ & $£ 446,169$ \\
\hline 3 & Allied Health Professions, Dentistry, Nursing and Pharmacy & $£ 61,360,345$ & $£ 61,125,398$ & $-£ 234,947$ \\
\hline 4 & Psychology, Psychiatry and Neuroscience & $£ 57,057,862$ & $£ 57,168,624$ & $£ 110,762$ \\
\hline 5 & Biological Sciences & $£ 62,031,270$ & $£ 61,243,194$ & $-£ 788,076$ \\
\hline 6 & Agriculture, Veterinary and Food Science & $£ 17,322,390$ & $£ 17,466,190$ & $£ 143,800$ \\
\hline $\mathbf{A}$ & Medicine, health and life sciences & $£ 331,366,933$ & $£ 332,225,475$ & $£ 858,542$ \\
\hline 7 & Earth Systems and Environmental Sciences & $£ 31,341,264$ & $£ 31,294,389$ & $-£ 46,875$ \\
\hline 8 & Chemistry & $£ 34,228,285$ & $£ 33,963,220$ & $-£ 265,065$ \\
\hline 9 & Physics & $£ 46,862,421$ & $£ 46,408,249$ & $-£ 454,172$ \\
\hline 10 & Mathematical Sciences & $£ 55,248,376$ & $£ 54,705,672$ & $-£ 542,704$ \\
\hline 11 & Computer Science and Informatics & $£ 47,250,105$ & $£ 46,965,481$ & $-£ 284,624$ \\
\hline 12 & Aeronautical, Mechanical, Chemical \& Manufacturing Engineering & $£ 31,645,605$ & $£ 31,619,354$ & $-£ 26,251$ \\
\hline 13 & Electrical and Electronic Engineering, Metallurgy and Materials & $£ 29,743,308$ & $£ 29,515,529$ & $-£ 227,779$ \\
\hline 14 & Civil and Construction Engineering & $£ 8,829,813$ & $£ 8,789,565$ & $-£ 40,248$ \\
\hline 15 & General Engineering & $£ 58,793,890$ & $£ 58,668,100$ & $-£ 125,790$ \\
\hline $\mathbf{B}$ & Physical sciences, engineering \& mathematics & $£ 343,943,067$ & $£ 341,929,559$ & $-£ 2,013,508$ \\
\hline 16 & Architecture, Built Environment and Planning & $£ 16,688,132$ & $£ 16,704,951$ & $£ 16,819$ \\
\hline 17 & Geography, Environmental Studies and Archaeology & $£ 33,889,463$ & $£ 33,889,463$ & $£ 0$ \\
\hline 18 & Economics and Econometrics & $£ 13,125,747$ & $£ 13,047,211$ & $-£ 78,536$ \\
\hline 19 & Business and Management Studies & $£ 44,329,664$ & $£ 44,435,942$ & $£ 106,278$ \\
\hline 20 & Law & $£ 21,485,109$ & $£ 21,481,055$ & $-£ 4,054$ \\
\hline 21 & Politics and International Studies & $£ 17,357,242$ & $£ 17,498,955$ & $£ 141,713$ \\
\hline 22 & Social Work and Social Policy & $£ 16,752,655$ & $£ 16,904,928$ & $£ 152,273$ \\
\hline 23 & Sociology & $£ 9,426,742$ & $£ 9,509,761$ & $£ 83,019$ \\
\hline 24 & Anthropology and Development Studies & $£ 7,761,774$ & $£ 7,839,235$ & $£ 77,461$ \\
\hline 25 & Education & $£ 20,704,843$ & $£ 20,823,127$ & $£ 118,284$ \\
\hline 26 & Sport and Exercise Sciences, Leisure \& Tourism & $£ 13,403,896$ & $£ 13,509,394$ & $£ 105,498$ \\
\hline $\mathbf{C}$ & Social Sciences & $£ 214,925,267$ & $£ 215,644,023$ & $£ 718,756$ \\
\hline 27 & Area Studies & $£ 7,298,915$ & $£ 7,348,473$ & $£ 49,558$ \\
\hline 28 & Modern Languages and Linguistics & $£ 18,547,759$ & $£ 18,565,185$ & $£ 17,426$ \\
\hline 29 & English Language and Literature & $£ 29,822,042$ & $£ 29,770,112$ & $-£ 51,930$ \\
\hline 30 & History & $£ 26,349,422$ & $£ 26,270,227$ & $-£ 79,195$ \\
\hline 31 & Classics & $£ 6,478,459$ & $£ 6,510,687$ & $£ 32,228$ \\
\hline 32 & Philosophy & $£ 8,654,452$ & $£ 8,647,240$ & $-£ 7,212$ \\
\hline 33 & Theology and Religious Studies & $£ 5,306,445$ & $£ 5,329,654$ & $£ 23,209$ \\
\hline 34 & Art and Design: History, Practice and Theory & $£ 26,569,816$ & $£ 26,840,334$ & $£ 270,518$ \\
\hline 35 & Music, Drama, Dance and Performing Arts & $£ 20,879,310$ & $£ 21,009,054$ & $£ 129,744$ \\
\hline 36 & Comm., Cultural \& Media Studies, Library \& Information Man. & $£ 13,169,134$ & $£ 13,220,999$ & $£ 51,865$ \\
\hline D & Arts and humanities & $£ 163,075,754$ & $£ 163,511,965$ & $£ 436,211$ \\
\hline \multicolumn{5}{|c|}{$\begin{array}{l}\text { Notes: QR funding (15-20-65) and QR funding (15-25-60) columns give total funding distributed across UoAs based on the } \\
15 \%, 20 \% \text {, and 65\% weights, and } 15 \%, 25 \% \text {, and 60\% weights, given to the environment, impact and output, respectively. Tota } \\
\text { gains/losses are the differences between QR funding (15-20-65) and QR funding (15-25-60) columns. Panels A, B, C and D } \\
\text { consist of UoAs between } 1 \text { and } 6,7 \text { and } 15,16 \text { and } 26 \text {, and } 27 \text { and 36, respectively. }\end{array}$} \\
\hline
\end{tabular}




\begin{tabular}{|c|c|c|c|}
\hline Unit of assessments & $\begin{array}{c}\text { Gini } \\
(15-20-65)\end{array}$ & $\begin{array}{c}\text { Gini } \\
(15-25-60)\end{array}$ & $\Delta$ Gini \\
\hline Clinical Medicine & 0.0919 & 0.0891 & -0.0020 \\
\hline Public Health, Health Services and Primary Care & 0.1078 & 0.1040 & -0.0038 \\
\hline Allied Health Professions, Dentistry, Nursing and Pharmacy & 0.1889 & 0.1924 & +0.0035 \\
\hline Psychology, Psychiatry and Neuroscience & 0.1930 & 0.1909 & -0.0021 \\
\hline Biological Sciences & 0.1400 & 0.1407 & +0.0007 \\
\hline Agriculture, Veterinary and Food Science & 0.1478 & 0.1477 & -0.0001 \\
\hline Earth Systems and Environmental Sciences & 0.1473 & 0.1469 & -0.0004 \\
\hline Chemistry & 0.1496 & 0.1510 & +0.0014 \\
\hline Physics & 0.1043 & 0.1088 & +0.0045 \\
\hline Mathematical Sciences & 0.1685 & 0.1738 & +0.0053 \\
\hline Computer Science and Informatics & 0.2789 & 0.2818 & +0.0029 \\
\hline Aeronautical, Mechanical, Chemical and Manufacturing Engineering & 0.1473 & 0.1517 & +0.0044 \\
\hline Electrical and Electronic Engineering, Metallurgy and Materials & 0.1941 & 0.1975 & +0.0034 \\
\hline Civil and Construction Engineering & 0.1805 & 0.1823 & +0.0018 \\
\hline General Engineering & 0.2239 & 0.2272 & +0.0033 \\
\hline Architecture, Built Environment and Planning & 0.2237 & 0.2275 & +0.0038 \\
\hline Geography, Environmental Studies and Archaeology & 0.1919 & 0.1942 & +0.0023 \\
\hline Economics and Econometrics & 0.2589 & 0.2598 & +0.0009 \\
\hline Business and Management Studies & 0.2317 & 0.2280 & -0.0037 \\
\hline Law & 0.2255 & 0.2318 & +0.0063 \\
\hline Politics and International Studies & 0.2332 & 0.2332 & 0.0000 \\
\hline Social Work and Social Policy & 0.2741 & 0.2772 & +0.0031 \\
\hline Sociology & 0.1352 & 0.1400 & +0.0046 \\
\hline Anthropology and Development Studies & 0.1220 & 0.1247 & +0.0027 \\
\hline Education & 0.2568 & 0.2632 & +0.0064 \\
\hline Sport and Exercise Sciences, Leisure and Tourism & 0.3052 & 0.3065 & +0.0013 \\
\hline Area Studies & 0.1506 & 0.1595 & +0.0089 \\
\hline Modern Languages and Linguistics & 0.1085 & 0.1098 & +0.0013 \\
\hline English Language and Literature & 0.1789 & 0.1848 & +0.0059 \\
\hline History & 0.1553 & 0.1589 & +0.0036 \\
\hline Classics & 0.1258 & 0.1283 & +0.0025 \\
\hline Philosophy & 0.1784 & 0.1826 & +0.0042 \\
\hline Theology and Religious Studies & 0.1935 & 0.2000 & +0.0065 \\
\hline Art and Design: History, Practice and Theory & 0.2062 & 0.2096 & +0.0034 \\
\hline Music, Drama, Dance and Performing Arts & 0.2531 & 0.2516 & -0.0015 \\
\hline Comm., Cultural and Media Studies, Library \& Information Management & 0.2328 & 0.2393 & +0.0065 \\
\hline \multicolumn{4}{|c|}{$\begin{array}{l}\text { Notes: Gini (15-20-65) column represents FTE-weighted Gini coefficient when } 15 \%, 20 \% \text {, and } 65 \% \text { of the QR } \\
\text { funding is distributed in environment, impact, and output pots, respectively. Gini }(15-25-60) \text { column represents FTE- } \\
\text { weighted Gini coefficient when } 15 \%, 25 \% \text {, and } 60 \% \text { of the QR funding is distributed in environment, impact, and } \\
\text { output pots, respectively. } \Delta \text { Gini represents the change in inequality among HEIs with the increased weight of impact. }\end{array}$} \\
\hline
\end{tabular}




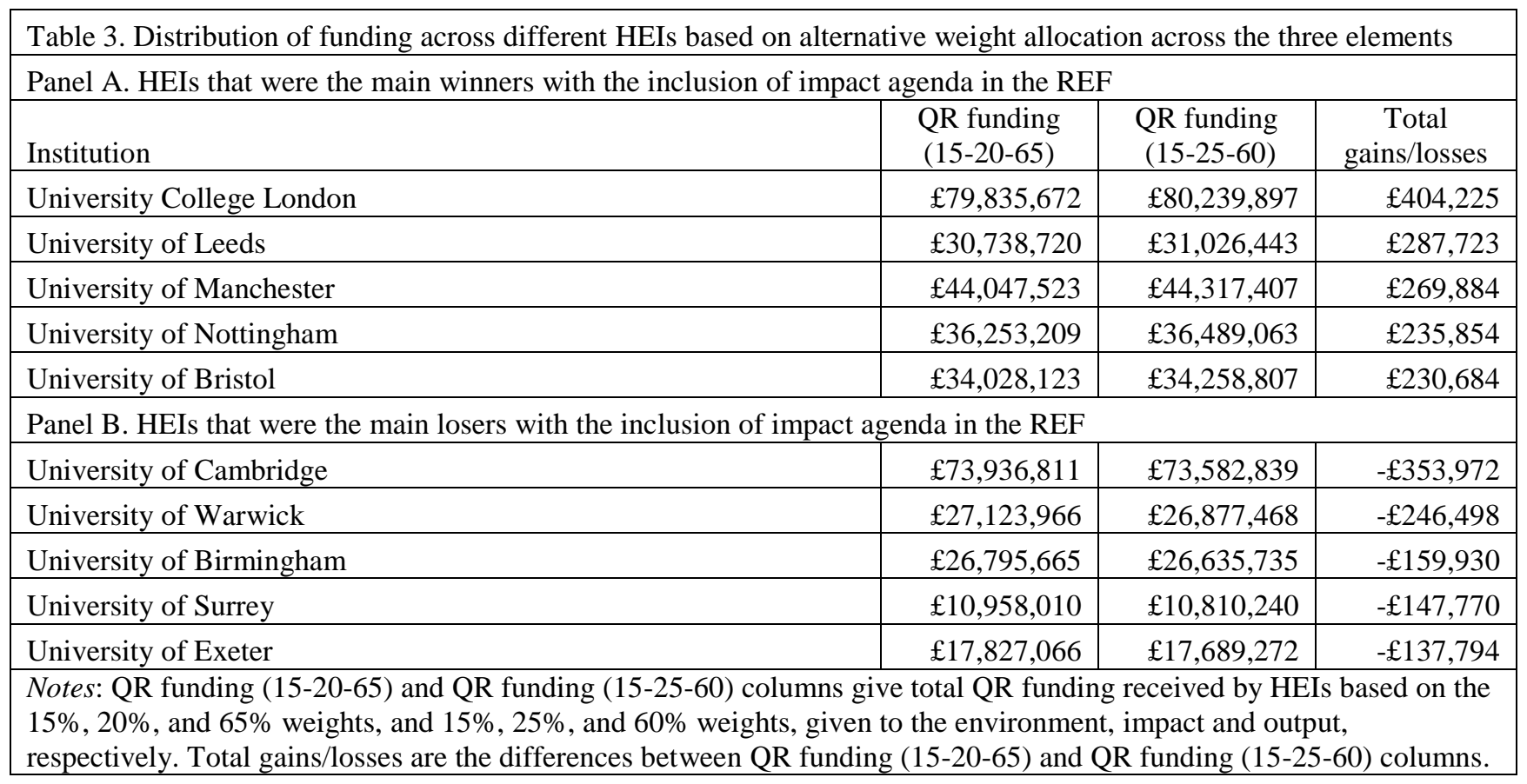



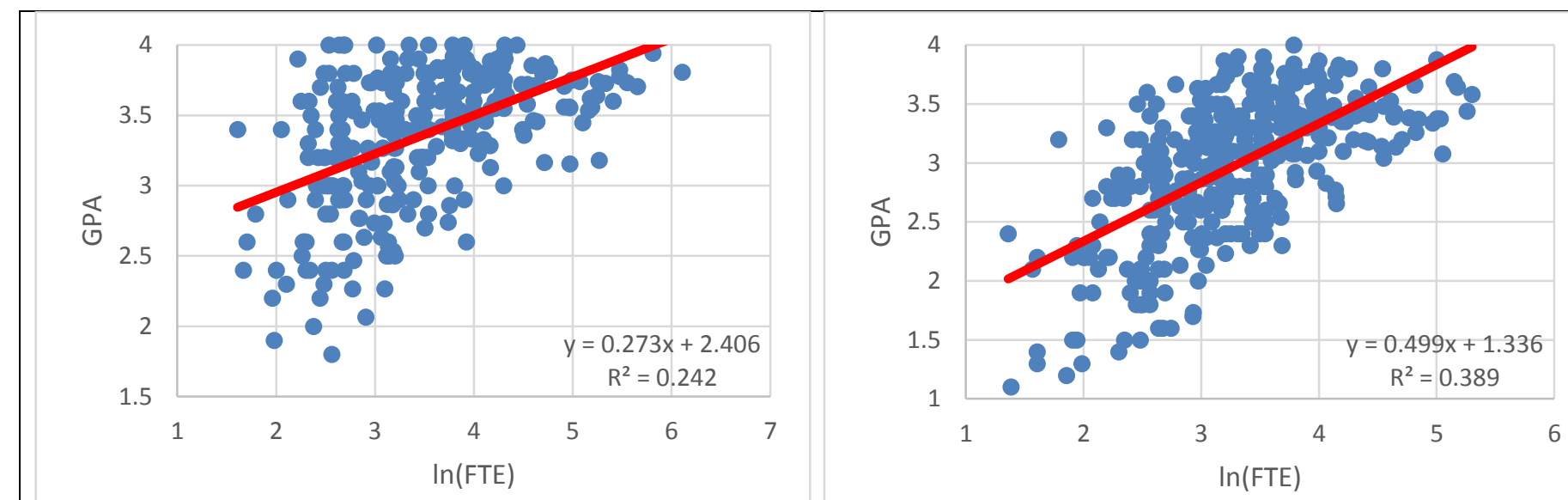

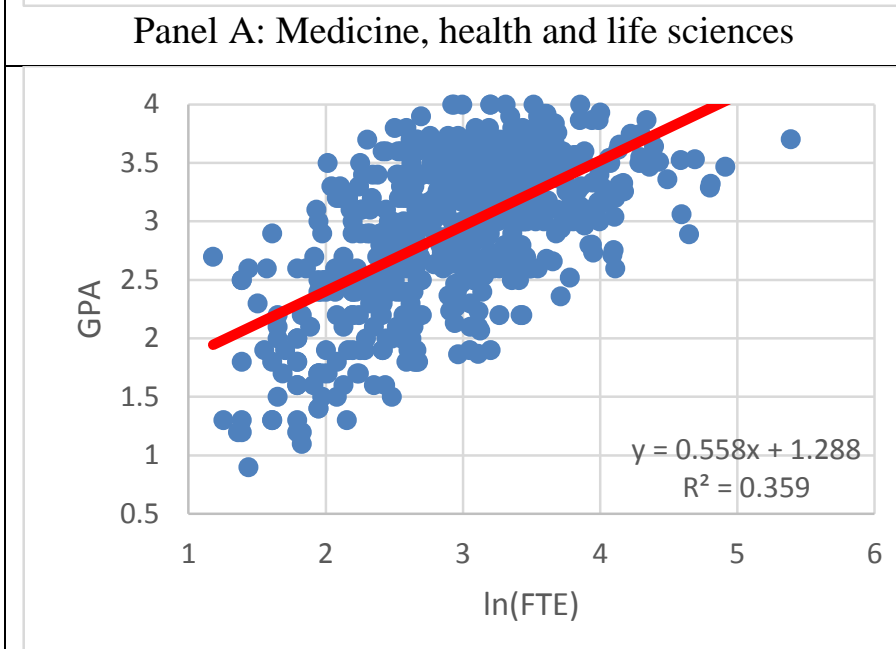

Panel C: Social Sciences
Panel B: Physical sciences, engineering and mathematics

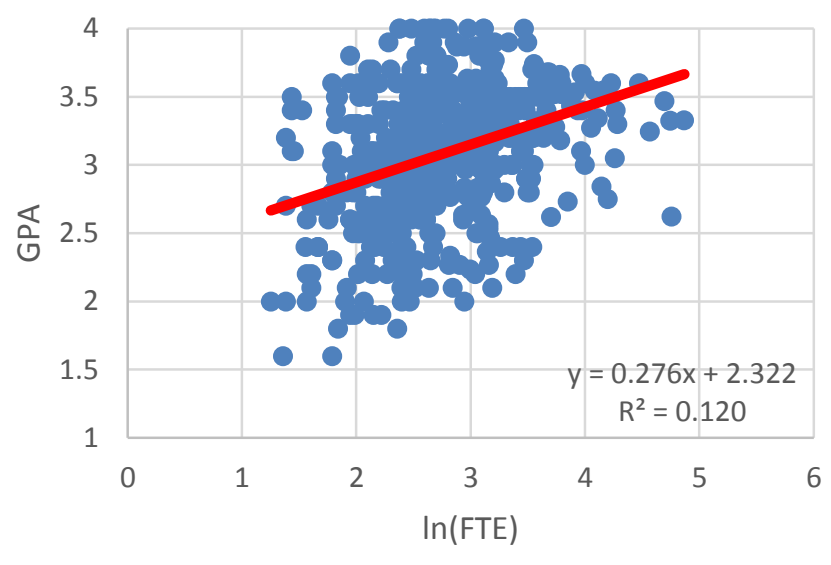

Panel D: Arts and humanities

Figure 1. Scatterplots of impact GPA and submission size (measured in natural logarithm) in Panels A, B, C and D

Notes: 17, 18, 27 and 25 submissions that are found to be outliers based on standardized residuals followed by simple regression estimations from Panels A, B, C and D, which are dropped from the analysis. Red-line highlights the fitted regression line. 


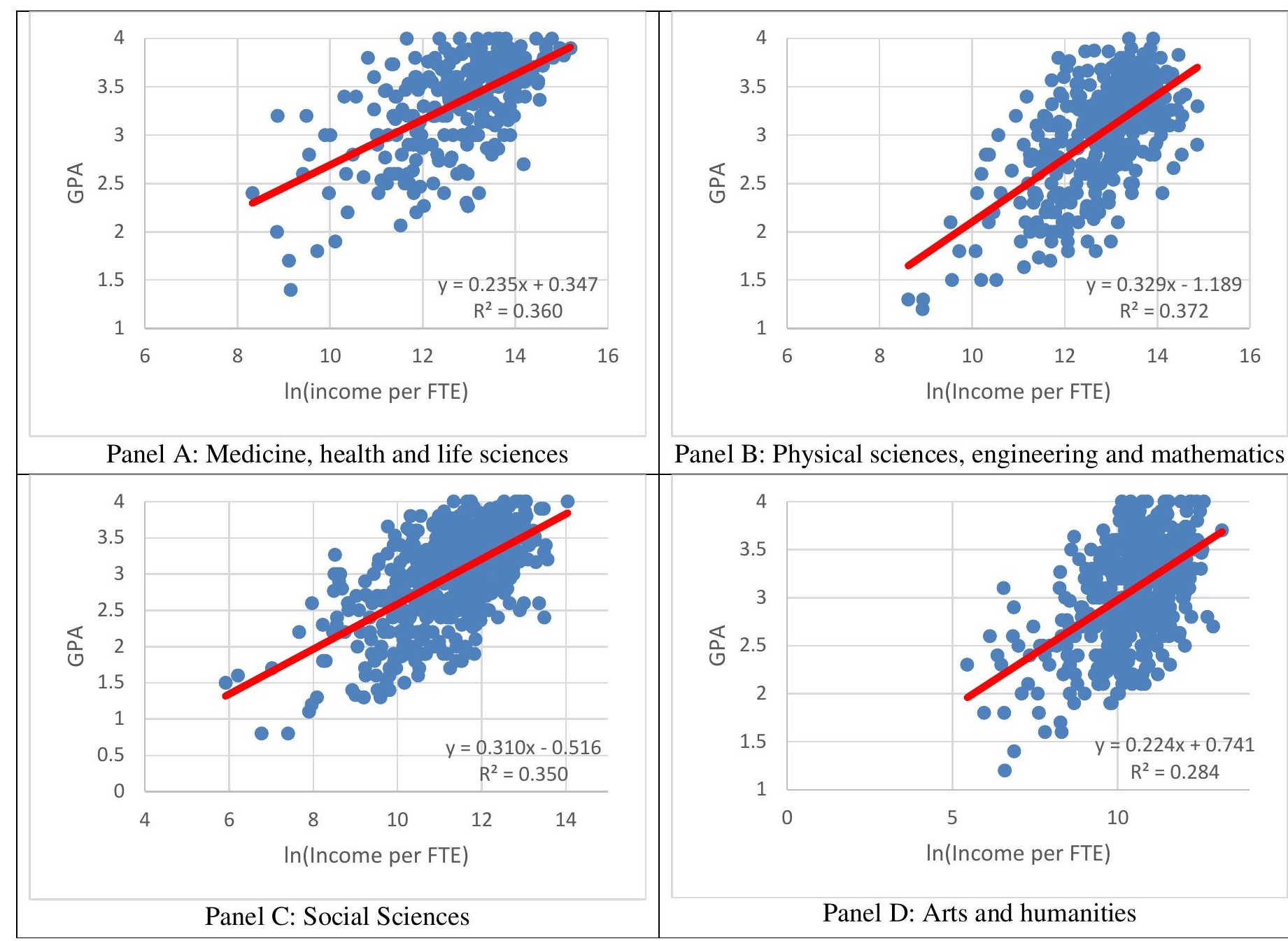

Figure 2. Scatterplots of impact GPA and external research income per FTE (measured in natural logarithm) in Panels A, B, C and D

Notes: 19, 22, 31 and 26 submissions that are found to be outliers based on standardized residuals followed by simple regression estimations from Panels A, B, C and D, which are dropped from the analysis. Red-line highlights the fitted regression line. 
Supplementary material. Distribution of mainstream QR funding to each UoA across all HEIs when alternative weights are given to research outputs, impact agenda and research environment elements

Institution

Unit of assessment (UOA)

Anglia Ruskin University

Anglia Ruskin University

Anglia Ruskin University

Anglia Ruskin University

Anglia Ruskin University

Anglia Ruskin University

Anglia Ruskin University

Anglia Ruskin University

Anglia Ruskin University

Anglia Ruskin University

Anglia Ruskin University

Anglia Ruskin University

Anglia Ruskin University

Anglia Ruskin University

Anglia Ruskin University

Aston University

Aston University

Aston University

Aston University

Aston University

Aston University

Aston University

Bath Spa University

Bath Spa University

Bath Spa University

Bath Spa University

Bath Spa University

Bath Spa University

Birkbeck College

Birkbeck College

Birkbeck College

Birkbeck College

Birkbeck College

Birkbeck College

Birkbeck College

Birkbeck College

Birkbeck College

Birkbeck College

Birkbeck College

Birkbeck College

Birkbeck College

Birkbeck College

Birmingham City University

Birmingham City University
Mainstream QR funding with 15-20-65

$£ 210,408$

$£ 175,981$

$£ 35,621$

$£ 53,635$

$£ 69,188$

$£ 260,554$

$£ 115,037$

$£ 39,883$

$£ 84,539$

$£ 15,547$

$£ 136,741$

$£ 37,325$

$£ 117,961$

$£ 150,497$

$£ 92,963$

$£ 2,169,404$

$£ 376,560$

$£ 583,471$

$£ 556,681$

$£ 838,728$

$£ 211,835$

$£ 245,265$

$£ 80,174$

$£ 266,390$

$£ 29,149$

$£ 176,966$

$£ 220,694$

$£ 83,961$

$£ 1,091,877$

$£ 781,081$

$£ 335,014$

$£ 540,129$

$£ 230,282$

$£ 273,590$

$£ 429,620$

$£ 227,119$

$£ 399,246$

$£ 380,214$

$£ 523,203$

$£ 735,064$

$£ 231,837$

$£ 413,026$

$£ 156,019$

$£ 76,149$
Mainstream QR funding with 15-25-60

Additional gains/losses

$£ 210,160$

$£ 163,073$

$£ 33,442$

$£ 54,904$

$£ 63,995$

$£ 261,174$

$£ 115,298$

$£ 39,195$

$£ 78,747$

$£ 14,609$

$£ 131,044$

$£ 34,620$

$£ 116,841$

$£ 164,075$

$£ 88,213$

$£ 2,145,810$

$£ 387,548$

$£ 581,646$

$£ 550,971$

$£ 837,795$

$£ 209,886$

$£ 260,403$

$£ 77,086$

$£ 256,438$

$£ 29,698$

$£ 167,120$

$£ 232,441$

$£ 81,661$

$£ 1,099,640$

$£ 766,702$

$£ 336,619$

$£ 511,154$

$£ 224,085$

$£ 269,465$

$£ 423,418$

$£ 227,551$

$£ 403,293$

$£ 383,212$

$£ 511,121$

$£ 729,316$

$£ 229,354$

$£ 426,671$

$£ 159,831$

$£ 83,124$ 


\begin{tabular}{|c|c|c|c|c|}
\hline Birmingham City University & 16 & $£ 61,083$ & $£ 58,030$ & $-£ 3,053$ \\
\hline Birmingham City University & 19 & $£ 41,378$ & $£ 45,048$ & $£ 3,670$ \\
\hline Birmingham City University & 20 & $£ 24,736$ & $£ 25,082$ & $£ 346$ \\
\hline Birmingham City University & 22 & $£ 22,477$ & $£ 24,527$ & $£ 2,050$ \\
\hline Birmingham City University & 25 & $£ 66,861$ & $£ 61,811$ & $-£ 5,050$ \\
\hline Birmingham City University & 29 & $£ 207,106$ & $£ 208,562$ & $£ 1,456$ \\
\hline Birmingham City University & 34 & $£ 631,260$ & $£ 656,109$ & $£ 24,849$ \\
\hline Birmingham City University & 35 & $£ 304,719$ & $£ 315,017$ & $£ 10,298$ \\
\hline Birmingham City University & 36 & $£ 112,991$ & $£ 112,090$ & $-£ 901$ \\
\hline Bishop Grosseteste University & 25 & $£ 35,112$ & $£ 32,411$ & $-£ 2,701$ \\
\hline Bishop Grosseteste University & 29 & $£ 11,099$ & $£ 10,737$ & $-£ 362$ \\
\hline Bishop Grosseteste University & 30 & $£ 11,606$ & $£ 11,082$ & $-£ 524$ \\
\hline Bournemouth University & 3 & $£ 336,148$ & $£ 322,617$ & $-£ 13,531$ \\
\hline Bournemouth University & 4 & $£ 174,049$ & $£ 162,844$ & $-£ 11,205$ \\
\hline Bournemouth University & 15 & $£ 178,709$ & $£ 182,475$ & $£ 3,766$ \\
\hline Bournemouth University & 17 & $£ 424,257$ & $£ 415,108$ & $-£ 9,149$ \\
\hline Bournemouth University & 19 & $£ 214,863$ & $£ 234,014$ & $£ 19,151$ \\
\hline Bournemouth University & 26 & $£ 334,798$ & $£ 335,473$ & $£ 675$ \\
\hline Bournemouth University & 34 & $£ 302,656$ & $£ 316,917$ & $£ 14,261$ \\
\hline Bournemouth University & 36 & $£ 476,517$ & $£ 488,748$ & $£ 12,231$ \\
\hline Brunel University London & 2 & $£ 206,644$ & $£ 214,838$ & $£ 8,194$ \\
\hline Brunel University London & 3 & $£ 888,892$ & $£ 857,910$ & $-£ 30,982$ \\
\hline Brunel University London & 4 & $£ 360,593$ & $£ 381,123$ & $£ 20,530$ \\
\hline Brunel University London & 7 & $£ 371,776$ & $£ 394,382$ & $£ 22,606$ \\
\hline Brunel University London & 10 & $£ 455,693$ & $£ 456,140$ & $£ 447$ \\
\hline Brunel University London & 11 & $£ 737,134$ & $£ 708,563$ & $-£ 28,571$ \\
\hline Brunel University London & 12 & $£ 1,127,222$ & $£ 1,093,095$ & $-£ 34,127$ \\
\hline Brunel University London & 15 & $£ 1,251,316$ & $£ 1,240,201$ & $-£ 11,115$ \\
\hline Brunel University London & 18 & $£ 101,113$ & $£ 100,749$ & $-£ 364$ \\
\hline Brunel University London & 19 & $£ 599,062$ & $£ 589,501$ & $-£ 9,561$ \\
\hline Brunel University London & 20 & $£ 238,525$ & $£ 229,436$ & $-£ 9,089$ \\
\hline Brunel University London & 21 & $£ 322,856$ & $£ 323,907$ & $£ 1,051$ \\
\hline Brunel University London & 22 & $£ 253,917$ & $£ 255,374$ & $£ 1,457$ \\
\hline Brunel University London & 23 & $£ 125,550$ & $£ 121,789$ & $-£ 3,761$ \\
\hline Brunel University London & 24 & $£ 107,398$ & $£ 107,647$ & $£ 249$ \\
\hline Brunel University London & 25 & $£ 161,855$ & $£ 157,564$ & $-£ 4,291$ \\
\hline Brunel University London & 26 & $£ 792,773$ & $£ 803,875$ & $£ 11,102$ \\
\hline Brunel University London & 29 & $£ 293,951$ & $£ 281,741$ & $-£ 12,210$ \\
\hline Brunel University London & 34 & $£ 244,234$ & $£ 260,303$ & $£ 16,069$ \\
\hline Brunel University London & 35 & $£ 344,005$ & $£ 348,745$ & $£ 4,740$ \\
\hline Brunel University London & 36 & $£ 178,150$ & $£ 168,328$ & $-£ 9,822$ \\
\hline Buckinghamshire New University & 3 & $£ 48,013$ & $£ 45,418$ & $-£ 2,595$ \\
\hline Buckinghamshire New University & 19 & $£ 15,961$ & $£ 17,179$ & $£ 1,218$ \\
\hline Buckinghamshire New University & 26 & $£ 10,414$ & $£ 10,073$ & $-£ 341$ \\
\hline Buckinghamshire New University & 34 & $£ 131,243$ & $£ 132,637$ & $£ 1,394$ \\
\hline Canterbury Christ Church University & 3 & $£ 176,680$ & $£ 173,248$ & $-£ 3,432$ \\
\hline Canterbury Christ Church University & 6 & $£ 98,099$ & $£ 90,553$ & $-£ 7,546$ \\
\hline Canterbury Christ Church University & 21 & $£ 30,305$ & $£ 27,974$ & $-£ 2,331$ \\
\hline
\end{tabular}




\begin{tabular}{|c|c|c|c|c|}
\hline Canterbury Christ Church University & 25 & $£ 166,003$ & $£ 163,086$ & $-£ 2,917$ \\
\hline Canterbury Christ Church University & 26 & $£ 245,536$ & $£ 252,769$ & $£ 7,233$ \\
\hline Canterbury Christ Church University & 29 & $£ 79,210$ & $£ 76,980$ & $-£ 2,230$ \\
\hline Canterbury Christ Church University & 30 & $£ 115,175$ & $£ 112,025$ & $-£ 3,150$ \\
\hline Canterbury Christ Church University & 33 & $£ 47,480$ & $£ 46,838$ & $-£ 642$ \\
\hline Canterbury Christ Church University & 35 & $£ 172,419$ & $£ 169,467$ & $-£ 2,952$ \\
\hline Canterbury Christ Church University & 36 & $£ 85,670$ & $£ 81,716$ & $-£ 3,954$ \\
\hline City, University of London & 3 & $£ 1,786,290$ & $£ 1,810,801$ & $£ 24,511$ \\
\hline City, University of London & 4 & $£ 468,996$ & $£ 458,563$ & $-£ 10,433$ \\
\hline City, University of London & 10 & $£ 425,955$ & $£ 425,331$ & $-£ 624$ \\
\hline City, University of London & 11 & $£ 655,378$ & $£ 671,862$ & $£ 16,484$ \\
\hline City, University of London & 15 & $£ 1,176,353$ & $£ 1,153,197$ & $-£ 23,156$ \\
\hline City, University of London & 18 & $£ 156,709$ & $£ 154,464$ & $-£ 2,245$ \\
\hline City, University of London & 19 & $£ 1,806,754$ & $£ 1,805,107$ & $-£ 1,647$ \\
\hline City, University of London & 20 & $£ 252,121$ & $£ 244,037$ & $-£ 8,084$ \\
\hline City, University of London & 21 & $£ 145,474$ & $£ 141,262$ & $-£ 4,212$ \\
\hline City, University of London & 23 & $£ 280,054$ & $£ 283,078$ & $£ 3,024$ \\
\hline City, University of London & 35 & $£ 244,322$ & $£ 243,982$ & $-£ 340$ \\
\hline City, University of London & 36 & $£ 449,827$ & $£ 460,450$ & $£ 10,623$ \\
\hline Courtauld Institute of Art & 34 & $£ 1,180,817$ & $£ 1,164,097$ & $-£ 16,720$ \\
\hline Coventry University & 3 & $£ 473,814$ & $£ 459,305$ & $-£ 14,509$ \\
\hline Coventry University & 4 & $£ 213,256$ & $£ 225,055$ & $£ 11,799$ \\
\hline Coventry University & 7 & $£ 167,666$ & $£ 162,045$ & $-£ 5,621$ \\
\hline Coventry University & 10 & $£ 190,847$ & $£ 184,013$ & $-£ 6,834$ \\
\hline Coventry University & 11 & $£ 141,666$ & $£ 147,379$ & $£ 5,713$ \\
\hline Coventry University & 15 & $£ 278,951$ & $£ 266,626$ & $-£ 12,325$ \\
\hline Coventry University & 19 & $£ 154,542$ & $£ 166,367$ & $£ 11,825$ \\
\hline Coventry University & 21 & $£ 76,389$ & $£ 80,201$ & $£ 3,812$ \\
\hline Coventry University & 34 & $£ 735,009$ & $£ 777,744$ & $£ 42,735$ \\
\hline Cranfield University & 6 & $£ 543,491$ & $£ 567,731$ & $£ 24,240$ \\
\hline Cranfield University & 12 & $£ 4,933,063$ & $£ 4,876,394$ & $-£ 56,669$ \\
\hline Cranfield University & 19 & $£ 704,329$ & $£ 724,643$ & $£ 20,314$ \\
\hline De Montfort University & 3 & $£ 463,169$ & $£ 475,324$ & $£ 12,155$ \\
\hline De Montfort University & 11 & $£ 425,445$ & $£ 411,295$ & $-£ 14,150$ \\
\hline De Montfort University & 15 & $£ 207,426$ & $£ 200,619$ & $-£ 6,807$ \\
\hline De Montfort University & 16 & $£ 331,970$ & $£ 330,705$ & $-£ 1,265$ \\
\hline De Montfort University & 19 & $£ 256,100$ & $£ 266,547$ & $£ 10,447$ \\
\hline De Montfort University & 20 & $£ 65,862$ & $£ 63,456$ & $-£ 2,406$ \\
\hline De Montfort University & 22 & $£ 211,129$ & $£ 222,226$ & $£ 11,097$ \\
\hline De Montfort University & 29 & $£ 195,351$ & $£ 199,363$ & $£ 4,012$ \\
\hline De Montfort University & 30 & $£ 132,792$ & $£ 145,650$ & $£ 12,858$ \\
\hline De Montfort University & 34 & $£ 413,307$ & $£ 419,116$ & $£ 5,809$ \\
\hline De Montfort University & 35 & $£ 245,422$ & $£ 242,933$ & $-£ 2,489$ \\
\hline De Montfort University & 36 & $£ 231,746$ & $£ 222,511$ & $-£ 9,235$ \\
\hline Edge Hill University & 3 & $£ 137,274$ & $£ 139,504$ & $£ 2,230$ \\
\hline Edge Hill University & 4 & $£ 186,943$ & $£ 176,287$ & $-£ 10,656$ \\
\hline Edge Hill University & 11 & $£ 1,473$ & $£ 1,841$ & $£ 368$ \\
\hline Edge Hill University & 17 & $£ 55,447$ & $£ 54,316$ & $-£ 1,131$ \\
\hline
\end{tabular}




\begin{tabular}{|c|c|c|c|c|}
\hline Edge Hill University & 20 & $£ 83,346$ & $£ 85,274$ & $£ 1,928$ \\
\hline Edge Hill University & 22 & $£ 99,834$ & $£ 95,224$ & $-£ 4,610$ \\
\hline Edge Hill University & 25 & $£ 79,572$ & $£ 85,734$ & $£ 6,162$ \\
\hline Edge Hill University & 26 & $£ 162,086$ & $£ 169,628$ & $£ 7,542$ \\
\hline Edge Hill University & 29 & $£ 111,715$ & $£ 105,109$ & $-£ 6,606$ \\
\hline Edge Hill University & 30 & $£ 60,652$ & $£ 61,274$ & $£ 622$ \\
\hline Edge Hill University & 35 & $£ 34,880$ & $£ 35,872$ & $£ 992$ \\
\hline Edge Hill University & 36 & $£ 103,387$ & $£ 103,611$ & $£ 224$ \\
\hline Falmouth University & 34 & $£ 104,860$ & $£ 100,004$ & $-£ 4,856$ \\
\hline Falmouth University & 35 & $£ 253,368$ & $£ 263,068$ & $£ 9,700$ \\
\hline Goldsmiths' College & 4 & $£ 740,371$ & $£ 750,502$ & $£ 10,131$ \\
\hline Goldsmiths' College & 11 & $£ 408,331$ & $£ 414,310$ & $£ 5,979$ \\
\hline Goldsmiths' College & 21 & $£ 89,100$ & $£ 83,993$ & $-£ 5,107$ \\
\hline Goldsmiths' College & 22 & $£ 66,269$ & $£ 62,804$ & $-£ 3,465$ \\
\hline Goldsmiths' College & 23 & $£ 495,164$ & $£ 482,519$ & $-£ 12,645$ \\
\hline Goldsmiths' College & 24 & $£ 195,338$ & $£ 198,524$ & $£ 3,186$ \\
\hline Goldsmiths' College & 25 & $£ 120,013$ & $£ 114,142$ & $-£ 5,871$ \\
\hline Goldsmiths' College & 29 & $£ 361,112$ & $£ 354,269$ & $-£ 6,843$ \\
\hline Goldsmiths' College & 30 & $£ 149,865$ & $£ 144,761$ & $-£ 5,104$ \\
\hline Goldsmiths' College & 34 & $£ 569,355$ & $£ 575,839$ & $£ 6,484$ \\
\hline Goldsmiths' College & 35 & $£ 386,827$ & $£ 406,734$ & $£ 19,907$ \\
\hline Goldsmiths' College & 35 & $£ 155,278$ & $£ 152,249$ & $-£ 3,029$ \\
\hline Goldsmiths' College & 36 & $£ 547,592$ & $£ 560,385$ & $£ 12,793$ \\
\hline Guildhall School of Music \& Drama & 35 & $£ 242,218$ & $£ 260,513$ & $£ 18,295$ \\
\hline Harper Adams University & 6 & $£ 246,319$ & $£ 246,242$ & $-£ 77$ \\
\hline Heythrop College & 33 & $£ 209,862$ & $£ 218,415$ & $£ 8,553$ \\
\hline Imperial College London & 1 & $£ 12,125,301$ & $£ 12,330,892$ & $£ 205,591$ \\
\hline Imperial College London & 2 & $£ 2,336,245$ & $£ 2,334,479$ & $-£ 1,766$ \\
\hline Imperial College London & 4 & $£ 1,543,629$ & $£ 1,549,677$ & $£ 6,048$ \\
\hline Imperial College London & 5 & $£ 4,061,897$ & $£ 3,999,633$ & $-£ 62,264$ \\
\hline Imperial College London & 8 & $£ 2,066,553$ & $£ 2,064,641$ & $-£ 1,912$ \\
\hline Imperial College London & 9 & $£ 4,448,706$ & $£ 4,432,616$ & $-£ 16,090$ \\
\hline Imperial College London & 10 & $£ 4,224,819$ & $£ 4,224,110$ & $-£ 709$ \\
\hline Imperial College London & 11 & $£ 2,498,080$ & $£ 2,489,148$ & $-£ 8,932$ \\
\hline Imperial College London & 12 & $£ 7,326,981$ & $£ 7,403,443$ & $£ 76,462$ \\
\hline Imperial College London & 13 & $£ 2,041,669$ & $£ 2,073,565$ & $£ 31,896$ \\
\hline Imperial College London & 13 & $£ 1,652,881$ & $£ 1,645,806$ & $-£ 7,075$ \\
\hline Imperial College London & 14 & $£ 2,539,088$ & $£ 2,539,632$ & $£ 544$ \\
\hline Imperial College London & 15 & $£ 1,452,568$ & $£ 1,455,998$ & $£ 3,430$ \\
\hline Imperial College London & 19 & $£ 1,552,221$ & $£ 1,508,782$ & $-£ 43,439$ \\
\hline King's College London & 1 & $£ 5,273,247$ & $£ 5,265,258$ & $-£ 7,989$ \\
\hline King's College London & 2 & $£ 753,919$ & $£ 763,418$ & $£ 9,499$ \\
\hline King's College London & 3 & $£ 1,881,558$ & $£ 1,862,979$ & $-£ 18,579$ \\
\hline King's College London & 3 & $£ 3,298,722$ & $£ 3,291,079$ & $-£ 7,643$ \\
\hline King's College London & 3 & $£ 1,440,004$ & $£ 1,456,378$ & $£ 16,374$ \\
\hline King's College London & 4 & $£ 7,620,934$ & $£ 7,697,600$ & $£ 76,666$ \\
\hline King's College London & 5 & $£ 2,208,724$ & $£ 2,138,574$ & $-£ 70,150$ \\
\hline King's College London & 9 & $£ 773,886$ & $£ 745,137$ & $-£ 28,749$ \\
\hline
\end{tabular}




\begin{tabular}{|c|c|c|c|c|}
\hline King's College London & 10 & $£ 1,320,424$ & $£ 1,239,136$ & $-£ 81,288$ \\
\hline King's College London & 11 & $£ 1,734,803$ & $£ 1,704,409$ & $-£ 30,394$ \\
\hline King's College London & 15 & $£ 2,072,922$ & $£ 2,120,090$ & $£ 47,168$ \\
\hline King's College London & 17 & $£ 906,463$ & $£ 908,312$ & $£ 1,849$ \\
\hline King's College London & 19 & $£ 698,926$ & $£ 703,368$ & $£ 4,442$ \\
\hline King's College London & 20 & $£ 911,176$ & $£ 920,471$ & $£ 9,295$ \\
\hline King's College London & 21 & $£ 1,794,428$ & $£ 1,841,281$ & $£ 46,853$ \\
\hline King's College London & 23 & $£ 355,757$ & $£ 351,599$ & $-£ 4,158$ \\
\hline King's College London & 25 & $£ 965,656$ & $£ 984,052$ & $£ 18,396$ \\
\hline King's College London & 26 & $£ 441,460$ & $£ 439,452$ & $-£ 2,008$ \\
\hline King's College London & 28 & $£ 688,791$ & $£ 684,315$ & $-£ 4,476$ \\
\hline King's College London & 29 & $£ 1,003,212$ & $£ 1,011,260$ & $£ 8,048$ \\
\hline King's College London & 30 & $£ 923,236$ & $£ 936,678$ & $£ 13,442$ \\
\hline King's College London & 31 & $£ 553,608$ & $£ 555,052$ & $£ 1,444$ \\
\hline King's College London & 32 & $£ 540,201$ & $£ 546,296$ & $£ 6,095$ \\
\hline King's College London & 33 & $£ 524,301$ & $£ 531,233$ & $£ 6,932$ \\
\hline King's College London & 35 & $£ 390,651$ & $£ 382,697$ & $-£ 7,954$ \\
\hline King's College London & 35 & $£ 466,788$ & $£ 469,541$ & $£ 2,753$ \\
\hline King's College London & 36 & $£ 827,111$ & $£ 851,925$ & $£ 24,814$ \\
\hline Kingston University & 3 & $£ 333,570$ & $£ 319,615$ & $-£ 13,955$ \\
\hline Kingston University & 4 & $£ 95,226$ & $£ 90,648$ & $-£ 4,578$ \\
\hline Kingston University & 11 & $£ 163,370$ & $£ 163,283$ & $-£ 87$ \\
\hline Kingston University & 15 & $£ 140,877$ & $£ 134,087$ & $-£ 6,790$ \\
\hline Kingston University & 17 & $£ 106,963$ & $£ 102,384$ & $-£ 4,579$ \\
\hline Kingston University & 19 & $£ 338,830$ & $£ 339,219$ & $£ 389$ \\
\hline Kingston University & 29 & $£ 348,465$ & $£ 378,801$ & $£ 30,336$ \\
\hline Kingston University & 32 & $£ 90,359$ & $£ 89,809$ & $-£ 550$ \\
\hline Kingston University & 34 & $£ 471,238$ & $£ 456,147$ & $-£ 15,091$ \\
\hline Leeds Beckett University & 2 & $£ 85,661$ & $£ 87,815$ & $£ 2,154$ \\
\hline Leeds Beckett University & 4 & $£ 79,876$ & $£ 81,972$ & $£ 2,096$ \\
\hline Leeds Beckett University & 11 & $£ 5,304$ & $£ 6,630$ & $£ 1,326$ \\
\hline Leeds Beckett University & 16 & $£ 218,432$ & $£ 218,243$ & $-£ 189$ \\
\hline Leeds Beckett University & 19 & $£ 44,152$ & $£ 46,844$ & $£ 2,692$ \\
\hline Leeds Beckett University & 22 & $£ 73,801$ & $£ 69,674$ & $-£ 4,127$ \\
\hline Leeds Beckett University & 25 & $£ 54,464$ & $£ 55,014$ & $£ 550$ \\
\hline Leeds Beckett University & 26 & $£ 837,869$ & $£ 847,082$ & $£ 9,213$ \\
\hline Leeds Beckett University & 34 & $£ 23,148$ & $£ 21,367$ & $-£ 1,781$ \\
\hline Leeds Beckett University & 35 & $£ 30,735$ & $£ 28,371$ & $-£ 2,364$ \\
\hline Leeds Beckett University & 36 & $£ 187,469$ & $£ 187,972$ & $£ 503$ \\
\hline Leeds Trinity University & 26 & $£ 7,096$ & $£ 6,550$ & $-£ 546$ \\
\hline Leeds Trinity University & 29 & $£ 21,109$ & $£ 19,485$ & $-£ 1,624$ \\
\hline Leeds Trinity University & 30 & $£ 13,755$ & $£ 13,720$ & $-£ 35$ \\
\hline Leeds Trinity University & 33 & $£ 13,377$ & $£ 13,208$ & $-£ 169$ \\
\hline Leeds Trinity University & 36 & $£ 37,766$ & $£ 34,861$ & $-£ 2,905$ \\
\hline Liverpool Hope University & 4 & $£ 52,166$ & $£ 48,153$ & $-£ 4,013$ \\
\hline Liverpool Hope University & 11 & $£ 48,423$ & $£ 44,698$ & $-£ 3,725$ \\
\hline Liverpool Hope University & 17 & $£ 4,864$ & $£ 4,490$ & $-£ 374$ \\
\hline Liverpool Hope University & 21 & $£ 21,113$ & $£ 19,489$ & $-£ 1,624$ \\
\hline
\end{tabular}




\begin{tabular}{|c|c|c|c|c|}
\hline Liverpool Hope University & 22 & $£ 45,531$ & $£ 42,029$ & $-£ 3,502$ \\
\hline Liverpool Hope University & 25 & $£ 134,925$ & $£ 136,385$ & $£ 1,460$ \\
\hline Liverpool Hope University & 26 & $£ 61,210$ & $£ 56,502$ & $-£ 4,708$ \\
\hline Liverpool Hope University & 29 & $£ 184,983$ & $£ 171,182$ & $-£ 13,801$ \\
\hline Liverpool Hope University & 30 & $£ 63,992$ & $£ 62,433$ & $-£ 1,559$ \\
\hline Liverpool Hope University & 33 & $£ 125,742$ & $£ 122,479$ & $-£ 3,263$ \\
\hline Liverpool Hope University & 35 & $£ 64,526$ & $£ 67,712$ & $£ 3,186$ \\
\hline Liverpool Hope University & 35 & $£ 15,491$ & $£ 15,018$ & $-£ 473$ \\
\hline Liverpool John Moores University & 3 & $£ 602,508$ & $£ 587,614$ & $-£ 14,894$ \\
\hline Liverpool John Moores University & 4 & $£ 135,672$ & $£ 130,123$ & $-£ 5,549$ \\
\hline Liverpool John Moores University & 9 & $£ 683,806$ & $£ 678,342$ & $-£ 5,464$ \\
\hline Liverpool John Moores University & 11 & $£ 90,488$ & $£ 91,412$ & $£ 924$ \\
\hline Liverpool John Moores University & 12 & $£ 144,440$ & $£ 137,087$ & $-£ 7,353$ \\
\hline Liverpool John Moores University & 13 & $£ 111,000$ & $£ 104,485$ & $-£ 6,515$ \\
\hline Liverpool John Moores University & 15 & $£ 140,665$ & $£ 133,024$ & $-£ 7,641$ \\
\hline Liverpool John Moores University & 16 & $£ 173,358$ & $£ 172,914$ & $-£ 444$ \\
\hline Liverpool John Moores University & 20 & $£ 36,063$ & $£ 37,980$ & $£ 1,917$ \\
\hline Liverpool John Moores University & 22 & $£ 81,827$ & $£ 83,097$ & $£ 1,270$ \\
\hline Liverpool John Moores University & 24 & $£ 157,662$ & $£ 160,211$ & $£ 2,549$ \\
\hline Liverpool John Moores University & 25 & $£ 141,194$ & $£ 133,955$ & $-£ 7,239$ \\
\hline Liverpool John Moores University & 26 & $£ 1,370,231$ & $£ 1,380,267$ & $£ 10,036$ \\
\hline Liverpool John Moores University & 29 & $£ 192,901$ & $£ 197,810$ & $£ 4,909$ \\
\hline Liverpool John Moores University & 30 & $£ 57,386$ & $£ 55,764$ & $-£ 1,622$ \\
\hline Liverpool John Moores University & 34 & $£ 126,381$ & $£ 122,368$ & $-£ 4,013$ \\
\hline Liverpool John Moores University & 36 & $£ 133,257$ & $£ 135,381$ & $£ 2,124$ \\
\hline Liverpool School of Tropical Medicine & 1 & $£ 837,921$ & $£ 848,677$ & $£ 10,756$ \\
\hline Liverpool School of Tropical Medicine & 2 & $£ 138,840$ & $£ 139,860$ & $£ 1,020$ \\
\hline London Business School & 19 & $£ 2,787,837$ & $£ 2,729,384$ & $-£ 58,453$ \\
\hline London Metropolitan University & 3 & $£ 181,893$ & $£ 175,561$ & $-£ 6,332$ \\
\hline London Metropolitan University & 10 & $£ 46,875$ & $£ 44,772$ & $-£ 2,103$ \\
\hline London Metropolitan University & 11 & $£ 23,610$ & $£ 21,794$ & $-£ 1,816$ \\
\hline London Metropolitan University & 16 & $£ 87,004$ & $£ 84,338$ & $-£ 2,666$ \\
\hline London Metropolitan University & 19 & $£ 27,714$ & $£ 27,215$ & $-£ 499$ \\
\hline London Metropolitan University & 20 & $£ 4,098$ & $£ 3,783$ & $-£ 315$ \\
\hline London Metropolitan University & 21 & $£ 8,753$ & $£ 8,080$ & $-£ 673$ \\
\hline London Metropolitan University & 22 & $£ 133,958$ & $£ 136,461$ & $£ 2,503$ \\
\hline London Metropolitan University & 25 & $£ 39,678$ & $£ 41,643$ & $£ 1,965$ \\
\hline London Metropolitan University & 27 & $£ 161,995$ & $£ 167,692$ & $£ 5,697$ \\
\hline London Metropolitan University & 34 & $£ 103,763$ & $£ 96,119$ & $-£ 7,644$ \\
\hline London Metropolitan University & 36 & $£ 71,135$ & $£ 70,891$ & $-£ 244$ \\
\hline London School of Hygiene and Tropical Medicine & 1 & $£ 1,721,853$ & $£ 1,763,814$ & $£ 41,961$ \\
\hline London School of Hygiene and Tropical Medicine & 2 & $£ 8,237,922$ & $£ 8,394,584$ & $£ 156,662$ \\
\hline London South Bank University & 3 & $£ 225,282$ & $£ 224,019$ & $-£ 1,263$ \\
\hline London South Bank University & 4 & $£ 72,426$ & $£ 70,892$ & $-£ 1,534$ \\
\hline London South Bank University & 15 & $£ 474,073$ & $£ 473,672$ & $-£ 401$ \\
\hline London South Bank University & 19 & $£ 23,017$ & $£ 24,483$ & $£ 1,466$ \\
\hline London South Bank University & 22 & $£ 159,616$ & $£ 152,793$ & $-£ 6,823$ \\
\hline London South Bank University & 26 & $£ 162,883$ & $£ 166,231$ & $£ 3,348$ \\
\hline
\end{tabular}




\begin{tabular}{|c|c|c|c|c|}
\hline London South Bank University & 36 & $£ 67,654$ & $£ 68,080$ & $£ 426$ \\
\hline Loughborough University & 8 & $£ 378,306$ & $£ 383,633$ & $£ 5,327$ \\
\hline Loughborough University & 9 & $£ 270,710$ & $£ 256,115$ & $-£ 14,595$ \\
\hline Loughborough University & 10 & $£ 777,548$ & $£ 742,969$ & $-£ 34,579$ \\
\hline Loughborough University & 11 & $£ 235,564$ & $£ 237,071$ & $£ 1,507$ \\
\hline Loughborough University & 12 & $£ 3,845,868$ & $£ 3,888,172$ & $£ 42,304$ \\
\hline Loughborough University & 13 & $£ 587,885$ & $£ 583,547$ & $-£ 4,338$ \\
\hline Loughborough University & 14 & $£ 537,112$ & $£ 547,269$ & $£ 10,157$ \\
\hline Loughborough University & 16 & $£ 977,373$ & $£ 985,626$ & $£ 8,253$ \\
\hline Loughborough University & 17 & $£ 402,395$ & $£ 391,853$ & $-£ 10,542$ \\
\hline Loughborough University & 19 & $£ 976,638$ & $£ 967,923$ & $-£ 8,715$ \\
\hline Loughborough University & 22 & $£ 177,107$ & $£ 186,705$ & $£ 9,598$ \\
\hline Loughborough University & 25 & $£ 142,979$ & $£ 142,426$ & $-£ 553$ \\
\hline Loughborough University & 26 & $£ 1,952,444$ & $£ 2,005,247$ & $£ 52,803$ \\
\hline Loughborough University & 27 & $£ 206,501$ & $£ 200,204$ & $-£ 6,297$ \\
\hline Loughborough University & 29 & $£ 287,729$ & $£ 282,113$ & $-£ 5,616$ \\
\hline Loughborough University & 34 & $£ 1,375,524$ & $£ 1,424,464$ & $£ 48,940$ \\
\hline Loughborough University & 36 & $£ 313,547$ & $£ 322,388$ & $£ 8,841$ \\
\hline Loughborough University & 36 & $£ 771,735$ & $£ 769,070$ & $-£ 2,665$ \\
\hline Manchester Metropolitan University & 3 & $£ 1,261,130$ & $£ 1,290,521$ & $£ 29,391$ \\
\hline Manchester Metropolitan University & 7 & $£ 344,212$ & $£ 334,033$ & $-£ 10,179$ \\
\hline Manchester Metropolitan University & 11 & $£ 161,235$ & $£ 162,805$ & $£ 1,570$ \\
\hline Manchester Metropolitan University & 15 & $£ 380,548$ & $£ 369,964$ & $-£ 10,584$ \\
\hline Manchester Metropolitan University & 19 & $£ 271,474$ & $£ 282,187$ & $£ 10,713$ \\
\hline Manchester Metropolitan University & 22 & $£ 145,357$ & $£ 139,287$ & $-£ 6,070$ \\
\hline Manchester Metropolitan University & 23 & $£ 287,018$ & $£ 292,997$ & $£ 5,979$ \\
\hline Manchester Metropolitan University & 25 & $£ 333,159$ & $£ 337,617$ & $£ 4,458$ \\
\hline Manchester Metropolitan University & 29 & $£ 423,063$ & $£ 436,019$ & $£ 12,956$ \\
\hline Manchester Metropolitan University & 30 & $£ 173,074$ & $£ 179,528$ & $£ 6,454$ \\
\hline Manchester Metropolitan University & 32 & $£ 44,559$ & $£ 44,072$ & $-£ 487$ \\
\hline Manchester Metropolitan University & 34 & $£ 824,888$ & $£ 837,826$ & $£ 12,938$ \\
\hline Manchester Metropolitan University & 35 & $£ 97,211$ & $£ 95,230$ & $-£ 1,981$ \\
\hline Middlesex University & 3 & $£ 257,964$ & $£ 254,538$ & $-£ 3,426$ \\
\hline Middlesex University & 4 & $£ 144,749$ & $£ 143,011$ & $-£ 1,738$ \\
\hline Middlesex University & 11 & $£ 705,527$ & $£ 666,754$ & $-£ 38,773$ \\
\hline Middlesex University & 17 & $£ 174,829$ & $£ 190,700$ & $£ 15,871$ \\
\hline Middlesex University & 19 & $£ 494,518$ & $£ 497,938$ & $£ 3,420$ \\
\hline Middlesex University & 20 & $£ 227,726$ & $£ 232,534$ & $£ 4,808$ \\
\hline Middlesex University & 22 & $£ 513,528$ & $£ 535,101$ & $£ 21,573$ \\
\hline Middlesex University & 34 & $£ 465,951$ & $£ 467,749$ & $£ 1,798$ \\
\hline Middlesex University & 35 & $£ 325,788$ & $£ 334,023$ & $£ 8,235$ \\
\hline Middlesex University & 36 & $£ 174,984$ & $£ 172,338$ & $-£ 2,646$ \\
\hline Newman University & 4 & $£ 6,512$ & $£ 6,011$ & $-£ 501$ \\
\hline Newman University & 25 & $£ 63,908$ & $£ 59,084$ & $-£ 4,824$ \\
\hline Newman University & 26 & $£ 10,379$ & $£ 10,187$ & $-£ 192$ \\
\hline Newman University & 29 & $£ 29,983$ & $£ 27,677$ & $-£ 2,306$ \\
\hline Newman University & 30 & $£ 18,423$ & $£ 17,006$ & $-£ 1,417$ \\
\hline Newman University & 33 & $£ 6,141$ & $£ 5,669$ & $-£ 472$ \\
\hline
\end{tabular}




\begin{tabular}{|c|c|c|c|c|}
\hline Norwich University of the Arts & 34 & $£ 116,445$ & $£ 120,278$ & $£ 3,833$ \\
\hline Nottingham Trent University & 3 & $£ 710,197$ & $£ 707,530$ & $-£ 2,667$ \\
\hline Nottingham Trent University & 4 & $£ 448,522$ & $£ 463,242$ & $£ 14,720$ \\
\hline Nottingham Trent University & 11 & $£ 125,492$ & $£ 139,777$ & $£ 14,285$ \\
\hline Nottingham Trent University & 15 & $£ 476,273$ & $£ 465,283$ & $-£ 10,990$ \\
\hline Nottingham Trent University & 16 & $£ 122,099$ & $£ 116,646$ & $-£ 5,453$ \\
\hline Nottingham Trent University & 17 & $£ 46,451$ & $£ 47,187$ & $£ 736$ \\
\hline Nottingham Trent University & 19 & $£ 242,028$ & $£ 242,748$ & $£ 720$ \\
\hline Nottingham Trent University & 20 & $£ 81,332$ & $£ 77,238$ & $-£ 4,094$ \\
\hline Nottingham Trent University & 22 & $£ 71,487$ & $£ 74,435$ & $£ 2,948$ \\
\hline Nottingham Trent University & 25 & $£ 106,376$ & $£ 98,193$ & $-£ 8,183$ \\
\hline Nottingham Trent University & 26 & $£ 70,934$ & $£ 65,684$ & $-£ 5,250$ \\
\hline Nottingham Trent University & 28 & $£ 116,531$ & $£ 116,627$ & $£ 96$ \\
\hline Nottingham Trent University & 29 & $£ 272,323$ & $£ 274,489$ & $£ 2,166$ \\
\hline Nottingham Trent University & 30 & $£ 89,239$ & $£ 90,384$ & $£ 1,145$ \\
\hline Nottingham Trent University & 34 & $£ 311,405$ & $£ 308,502$ & $-£ 2,903$ \\
\hline Nottingham Trent University & 36 & $£ 161,163$ & $£ 158,701$ & $-£ 2,462$ \\
\hline Oxford Brookes University & 3 & $£ 240,866$ & $£ 239,790$ & $-£ 1,076$ \\
\hline Oxford Brookes University & 4 & $£ 180,130$ & $£ 173,905$ & $-£ 6,225$ \\
\hline Oxford Brookes University & 5 & $£ 433,958$ & $£ 435,573$ & $£ 1,615$ \\
\hline Oxford Brookes University & 11 & $£ 323,880$ & $£ 319,005$ & $-£ 4,875$ \\
\hline Oxford Brookes University & 15 & $£ 371,287$ & $£ 355,203$ & $-£ 16,084$ \\
\hline Oxford Brookes University & 16 & $£ 638,786$ & $£ 647,500$ & $£ 8,714$ \\
\hline Oxford Brookes University & 17 & $£ 144,160$ & $£ 135,684$ & $-£ 8,476$ \\
\hline Oxford Brookes University & 19 & $£ 240,124$ & $£ 246,629$ & $£ 6,505$ \\
\hline Oxford Brookes University & 20 & $£ 36,604$ & $£ 34,950$ & $-£ 1,654$ \\
\hline Oxford Brookes University & 21 & $£ 121,508$ & $£ 126,999$ & $£ 5,491$ \\
\hline Oxford Brookes University & 25 & $£ 89,536$ & $£ 82,909$ & $-£ 6,627$ \\
\hline Oxford Brookes University & 29 & $£ 237,421$ & $£ 229,226$ & $-£ 8,195$ \\
\hline Oxford Brookes University & 30 & $£ 479,856$ & $£ 469,059$ & $-£ 10,797$ \\
\hline Oxford Brookes University & 32 & $£ 42,222$ & $£ 39,164$ & $-£ 3,058$ \\
\hline Oxford Brookes University & 34 & $£ 78,363$ & $£ 75,169$ & $-£ 3,194$ \\
\hline Oxford Brookes University & 35 & $£ 220,627$ & $£ 226,600$ & $£ 5,973$ \\
\hline Oxford Brookes University & 36 & $£ 72,130$ & $£ 67,095$ & $-£ 5,035$ \\
\hline Queen Mary University of London & 1 & $£ 4,994,766$ & $£ 5,016,386$ & $£ 21,620$ \\
\hline Queen Mary University of London & 2 & $£ 736,734$ & $£ 740,875$ & $£ 4,141$ \\
\hline Queen Mary University of London & 3 & $£ 1,173,575$ & $£ 1,163,353$ & $-£ 10,222$ \\
\hline Queen Mary University of London & 5 & $£ 723,896$ & $£ 708,439$ & $-£ 15,457$ \\
\hline Queen Mary University of London & 8 & $£ 444,681$ & $£ 424,906$ & $-£ 19,775$ \\
\hline Queen Mary University of London & 9 & $£ 699,549$ & $£ 671,400$ & $-£ 28,149$ \\
\hline Queen Mary University of London & 10 & $£ 914,877$ & $£ 887,244$ & $-£ 27,633$ \\
\hline Queen Mary University of London & 11 & $£ 1,232,922$ & $£ 1,224,388$ & $-£ 8,534$ \\
\hline Queen Mary University of London & 13 & $£ 599,014$ & $£ 584,735$ & $-£ 14,279$ \\
\hline Queen Mary University of London & 13 & $£ 735,088$ & $£ 724,359$ & $-£ 10,729$ \\
\hline Queen Mary University of London & 15 & $£ 1,017,106$ & $£ 1,012,296$ & $-£ 4,810$ \\
\hline Queen Mary University of London & 17 & $£ 894,878$ & $£ 884,418$ & $-£ 10,460$ \\
\hline Queen Mary University of London & 18 & $£ 380,369$ & $£ 373,489$ & $-£ 6,880$ \\
\hline Queen Mary University of London & 19 & $£ 489,060$ & $£ 499,270$ & $£ 10,210$ \\
\hline
\end{tabular}




\begin{tabular}{|c|c|c|c|c|}
\hline Queen Mary University of London & 20 & $£ 638,933$ & $£ 627,407$ & $-£ 11,526$ \\
\hline Queen Mary University of London & 21 & $£ 272,657$ & $£ 267,747$ & $-£ 4,910$ \\
\hline Queen Mary University of London & 28 & $£ 228,496$ & $£ 226,491$ & $-£ 2,005$ \\
\hline Queen Mary University of London & 28 & $£ 587,929$ & $£ 585,294$ & $-£ 2,635$ \\
\hline Queen Mary University of London & 29 & $£ 1,081,321$ & $£ 1,088,258$ & $£ 6,937$ \\
\hline Queen Mary University of London & 30 & $£ 803,993$ & $£ 816,107$ & $£ 12,114$ \\
\hline Queen Mary University of London & 35 & $£ 655,051$ & $£ 664,155$ & $£ 9,104$ \\
\hline Roehampton University & 3 & $£ 220,391$ & $£ 208,425$ & $-£ 11,966$ \\
\hline Roehampton University & 4 & $£ 236,128$ & $£ 241,481$ & $£ 5,353$ \\
\hline Roehampton University & 19 & $£ 21,701$ & $£ 21,711$ & $£ 10$ \\
\hline Roehampton University & 23 & $£ 148,571$ & $£ 155,983$ & $£ 7,412$ \\
\hline Roehampton University & 24 & $£ 118,899$ & $£ 114,422$ & $-£ 4,477$ \\
\hline Roehampton University & 25 & $£ 224,900$ & $£ 213,274$ & $-£ 11,626$ \\
\hline Roehampton University & 28 & $£ 122,589$ & $£ 129,660$ & $£ 7,071$ \\
\hline Roehampton University & 29 & $£ 234,807$ & $£ 224,519$ & $-£ 10,288$ \\
\hline Roehampton University & 30 & $£ 157,855$ & $£ 154,456$ & $-£ 3,399$ \\
\hline Roehampton University & 33 & $£ 70,337$ & $£ 66,317$ & $-£ 4,020$ \\
\hline Roehampton University & 35 & $£ 466,835$ & $£ 462,100$ & $-£ 4,735$ \\
\hline Roehampton University & 35 & $£ 246,283$ & $£ 249,503$ & $£ 3,220$ \\
\hline Roehampton University & 36 & $£ 217,876$ & $£ 219,558$ & $£ 1,682$ \\
\hline Rose Bruford College of Theatre and Performance & 35 & $£ 60,672$ & $£ 58,593$ & $-£ 2,079$ \\
\hline Royal College of Music & 35 & $£ 348,357$ & $£ 365,628$ & $£ 17,271$ \\
\hline Royal Holloway, University of London & 4 & $£ 854,632$ & $£ 848,148$ & $-£ 6,484$ \\
\hline Royal Holloway, University of London & 5 & $£ 522,303$ & $£ 505,629$ & $-£ 16,674$ \\
\hline Royal Holloway, University of London & 7 & $£ 826,936$ & $£ 828,395$ & $£ 1,459$ \\
\hline Royal Holloway, University of London & 9 & $£ 654,998$ & $£ 638,759$ & $-£ 16,239$ \\
\hline Royal Holloway, University of London & 10 & $£ 420,820$ & $£ 436,312$ & $£ 15,492$ \\
\hline Royal Holloway, University of London & 11 & $£ 865,536$ & $£ 845,133$ & $-£ 20,403$ \\
\hline Royal Holloway, University of London & 17 & $£ 743,176$ & $£ 754,018$ & $£ 10,842$ \\
\hline Royal Holloway, University of London & 18 & $£ 300,619$ & $£ 300,403$ & $-£ 216$ \\
\hline Royal Holloway, University of London & 19 & $£ 685,779$ & $£ 679,198$ & $-£ 6,581$ \\
\hline Royal Holloway, University of London & 21 & $£ 288,346$ & $£ 290,000$ & $£ 1,654$ \\
\hline Royal Holloway, University of London & 28 & $£ 474,441$ & $£ 480,264$ & $£ 5,823$ \\
\hline Royal Holloway, University of London & 29 & $£ 551,658$ & $£ 551,950$ & $£ 292$ \\
\hline Royal Holloway, University of London & 30 & $£ 541,756$ & $£ 558,798$ & $£ 17,042$ \\
\hline Royal Holloway, University of London & 31 & $£ 95,399$ & $£ 90,938$ & $-£ 4,461$ \\
\hline Royal Holloway, University of London & 35 & $£ 425,749$ & $£ 420,620$ & $-£ 5,129$ \\
\hline Royal Holloway, University of London & 35 & $£ 566,376$ & $£ 551,551$ & $-£ 14,825$ \\
\hline Royal Holloway, University of London & 36 & $£ 303,940$ & $£ 302,520$ & $-£ 1,420$ \\
\hline Royal Northern College of Music & 35 & $£ 270,847$ & $£ 286,009$ & $£ 15,162$ \\
\hline Sheffield Hallam University & 3 & $£ 435,891$ & $£ 419,976$ & $-£ 15,915$ \\
\hline Sheffield Hallam University & 5 & $£ 187,640$ & $£ 179,339$ & $-£ 8,301$ \\
\hline Sheffield Hallam University & 13 & $£ 398,797$ & $£ 387,469$ & $-£ 11,328$ \\
\hline Sheffield Hallam University & 16 & $£ 510,044$ & $£ 513,294$ & $£ 3,250$ \\
\hline Sheffield Hallam University & 19 & $£ 47,230$ & $£ 47,959$ & $£ 729$ \\
\hline Sheffield Hallam University & 25 & $£ 150,398$ & $£ 143,985$ & $-£ 6,413$ \\
\hline Sheffield Hallam University & 26 & $£ 524,753$ & $£ 530,440$ & $£ 5,687$ \\
\hline Sheffield Hallam University & 29 & $£ 211,685$ & $£ 208,078$ & $-£ 3,607$ \\
\hline
\end{tabular}




\begin{tabular}{|c|c|c|c|c|}
\hline Sheffield Hallam University & 30 & $£ 235,673$ & $£ 227,660$ & $-£ 8,013$ \\
\hline Sheffield Hallam University & 34 & $£ 699,305$ & $£ 715,054$ & $£ 15,749$ \\
\hline Sheffield Hallam University & 36 & $£ 346,924$ & $£ 353,143$ & $£ 6,219$ \\
\hline Southampton Solent University & 15 & $£ 30,927$ & $£ 28,548$ & $-£ 2,379$ \\
\hline Southampton Solent University & 26 & $£ 9,589$ & $£ 8,851$ & $-£ 738$ \\
\hline Southampton Solent University & 34 & $£ 77,975$ & $£ 71,977$ & $-£ 5,998$ \\
\hline Southampton Solent University & 36 & $£ 26,946$ & $£ 25,030$ & $-£ 1,916$ \\
\hline St Mary's University, Twickenham & 25 & $£ 53,914$ & $£ 49,767$ & $-£ 4,147$ \\
\hline St Mary's University, Twickenham & 26 & $£ 90,989$ & $£ 84,528$ & $-£ 6,461$ \\
\hline St Mary's University, Twickenham & 29 & $£ 83,189$ & $£ 76,790$ & $-£ 6,399$ \\
\hline St Mary's University, Twickenham & 30 & $£ 33,192$ & $£ 30,679$ & $-£ 2,513$ \\
\hline St Mary's University, Twickenham & 32 & $£ 12,119$ & $£ 14,185$ & $£ 2,066$ \\
\hline St Mary's University, Twickenham & 33 & $£ 33,561$ & $£ 33,929$ & $£ 368$ \\
\hline St Mary's University, Twickenham & 36 & $£ 43,331$ & $£ 40,717$ & $-£ 2,614$ \\
\hline St. George's, University of London & 1 & $£ 1,153,407$ & $£ 1,170,613$ & $£ 17,206$ \\
\hline St. George's, University of London & 2 & $£ 351,222$ & $£ 355,143$ & $£ 3,921$ \\
\hline Staffordshire University & 4 & $£ 113,585$ & $£ 125,906$ & $£ 12,321$ \\
\hline Staffordshire University & 11 & $£ 12,188$ & $£ 12,753$ & $£ 565$ \\
\hline Staffordshire University & 15 & $£ 82,599$ & $£ 79,482$ & $-£ 3,117$ \\
\hline Staffordshire University & 19 & $£ 41,979$ & $£ 41,241$ & $-£ 738$ \\
\hline Staffordshire University & 25 & $£ 80,993$ & $£ 74,763$ & $-£ 6,230$ \\
\hline Staffordshire University & 26 & $£ 189,880$ & $£ 197,324$ & $£ 7,444$ \\
\hline Staffordshire University & 34 & $£ 29,333$ & $£ 31,822$ & $£ 2,489$ \\
\hline Staffordshire University & 36 & $£ 61,354$ & $£ 58,701$ & $-£ 2,653$ \\
\hline Teesside University & 3 & $£ 270,770$ & $£ 274,720$ & $£ 3,950$ \\
\hline Teesside University & 11 & $£ 159,544$ & $£ 147,271$ & $-£ 12,273$ \\
\hline Teesside University & 15 & $£ 190,700$ & $£ 187,850$ & $-£ 2,850$ \\
\hline Teesside University & 19 & $£ 38,853$ & $£ 38,751$ & $-£ 102$ \\
\hline Teesside University & 22 & $£ 154,645$ & $£ 157,411$ & $£ 2,766$ \\
\hline Teesside University & 29 & $£ 58,751$ & $£ 57,378$ & $-£ 1,373$ \\
\hline Teesside University & 30 & $£ 134,080$ & $£ 135,134$ & $£ 1,054$ \\
\hline Teesside University & 34 & $£ 78,350$ & $£ 84,886$ & $£ 6,536$ \\
\hline Arts University Bournemouth & 34 & $£ 118,206$ & $£ 113,138$ & $-£ 5,068$ \\
\hline Institute of Cancer Research & 1 & $£ 2,544,249$ & $£ 2,573,727$ & $£ 29,478$ \\
\hline Institute of Cancer Research & 5 & $£ 1,563,302$ & $£ 1,547,734$ & $-£ 15,568$ \\
\hline London School of Economics and Political Science & 10 & $£ 795,879$ & $£ 760,297$ & $-£ 35,582$ \\
\hline London School of Economics and Political Science & 17 & $£ 1,192,073$ & $£ 1,179,586$ & $-£ 12,487$ \\
\hline London School of Economics and Political Science & 18 & $£ 1,684,777$ & $£ 1,683,556$ & $-£ 1,221$ \\
\hline London School of Economics and Political Science & 19 & $£ 2,348,493$ & $£ 2,338,058$ & $-£ 10,435$ \\
\hline London School of Economics and Political Science & 20 & $£ 1,673,963$ & $£ 1,685,139$ & $£ 11,176$ \\
\hline London School of Economics and Political Science & 21 & $£ 1,724,953$ & $£ 1,717,866$ & $-£ 7,087$ \\
\hline London School of Economics and Political Science & 22 & $£ 1,590,379$ & $£ 1,596,913$ & $£ 6,534$ \\
\hline London School of Economics and Political Science & 23 & $£ 492,600$ & $£ 489,263$ & $-£ 3,337$ \\
\hline London School of Economics and Political Science & 24 & $£ 334,108$ & $£ 323,112$ & $-£ 10,996$ \\
\hline London School of Economics and Political Science & 24 & $£ 415,664$ & $£ 426,983$ & $£ 11,319$ \\
\hline London School of Economics and Political Science & 27 & $£ 512,453$ & $£ 527,458$ & $£ 15,005$ \\
\hline London School of Economics and Political Science & 30 & $£ 873,801$ & $£ 866,610$ & $-£ 7,191$ \\
\hline London School of Economics and Political Science & 32 & $£ 339,263$ & $£ 340,608$ & $£ 1,345$ \\
\hline
\end{tabular}




\begin{tabular}{|c|c|c|c|c|}
\hline London School of Economics and Political Science & 36 & $£ 426,929$ & $£ 434,131$ & $£ 7,202$ \\
\hline Open University & 3 & $£ 393,774$ & $£ 381,755$ & $-£ 12,019$ \\
\hline Open University & 7 & $£ 1,282,488$ & $£ 1,250,653$ & $-£ 31,835$ \\
\hline Open University & 10 & $£ 363,042$ & $£ 341,535$ & $-£ 21,507$ \\
\hline Open University & 11 & $£ 725,204$ & $£ 694,356$ & $-£ 30,848$ \\
\hline Open University & 13 & $£ 414,897$ & $£ 399,836$ & $-£ 15,061$ \\
\hline Open University & 17 & $£ 309,350$ & $£ 304,958$ & $-£ 4,392$ \\
\hline Open University & 19 & $£ 251,893$ & $£ 259,505$ & $£ 7,612$ \\
\hline Open University & 22 & $£ 234,326$ & $£ 234,328$ & $£ 2$ \\
\hline Open University & 23 & $£ 533,644$ & $£ 550,942$ & $£ 17,298$ \\
\hline Open University & 24 & $£ 323,325$ & $£ 327,489$ & $£ 4,164$ \\
\hline Open University & 25 & $£ 1,015,883$ & $£ 1,041,582$ & $£ 25,699$ \\
\hline Open University & 29 & $£ 267,673$ & $£ 273,916$ & $£ 6,243$ \\
\hline Open University & 30 & $£ 243,188$ & $£ 247,887$ & $£ 4,699$ \\
\hline Open University & 31 & $£ 127,620$ & $£ 133,136$ & $£ 5,516$ \\
\hline Open University & 32 & $£ 50,631$ & $£ 49,355$ & $-£ 1,276$ \\
\hline Open University & 33 & $£ 73,028$ & $£ 68,878$ & $-£ 4,150$ \\
\hline Open University & 34 & $£ 569,734$ & $£ 561,674$ & $-£ 8,060$ \\
\hline Open University & 35 & $£ 336,065$ & $£ 336,141$ & $£ 76$ \\
\hline Royal Academy of Music & 35 & $£ 245,578$ & $£ 244,433$ & $-£ 1,145$ \\
\hline Royal Agricultural University & 6 & $£ 37,896$ & $£ 34,981$ & $-£ 2,915$ \\
\hline Royal Central School of Speech and Drama & 35 & $£ 540,795$ & $£ 565,046$ & $£ 24,251$ \\
\hline Royal College of Art & 34 & $£ 1,500,361$ & $£ 1,536,482$ & $£ 36,121$ \\
\hline Royal Veterinary College & 6 & $£ 3,016,980$ & $£ 3,052,544$ & $£ 35,564$ \\
\hline School of Oriental and African Studies & 19 & $£ 244,015$ & $£ 254,652$ & $£ 10,637$ \\
\hline School of Oriental and African Studies & 20 & $£ 381,994$ & $£ 366,011$ & $-£ 15,983$ \\
\hline School of Oriental and African Studies & 21 & $£ 388,670$ & $£ 399,116$ & $£ 10,446$ \\
\hline School of Oriental and African Studies & 24 & $£ 269,447$ & $£ 264,714$ & $-£ 4,733$ \\
\hline School of Oriental and African Studies & 24 & $£ 480,952$ & $£ 477,580$ & $-£ 3,372$ \\
\hline School of Oriental and African Studies & 27 & $£ 621,852$ & $£ 606,068$ & $-£ 15,784$ \\
\hline School of Oriental and African Studies & 28 & $£ 195,397$ & $£ 188,659$ & $-£ 6,738$ \\
\hline School of Oriental and African Studies & 30 & $£ 184,748$ & $£ 174,383$ & $-£ 10,365$ \\
\hline School of Oriental and African Studies & 33 & $£ 255,049$ & $£ 249,138$ & $-£ 5,911$ \\
\hline School of Oriental and African Studies & 34 & $£ 256,225$ & $£ 250,224$ & $-£ 6,001$ \\
\hline School of Oriental and African Studies & 35 & $£ 259,277$ & $£ 249,314$ & $-£ 9,963$ \\
\hline University of Bath & 3 & $£ 2,162,765$ & $£ 2,154,845$ & $-£ 7,920$ \\
\hline University of Bath & 5 & $£ 696,821$ & $£ 672,274$ & $-£ 24,547$ \\
\hline University of Bath & 8 & $£ 1,124,090$ & $£ 1,126,266$ & $£ 2,176$ \\
\hline University of Bath & 9 & $£ 730,623$ & $£ 745,181$ & $£ 14,558$ \\
\hline University of Bath & 10 & $£ 1,441,506$ & $£ 1,433,540$ & $-£ 7,966$ \\
\hline University of Bath & 11 & $£ 560,589$ & $£ 545,845$ & $-£ 14,744$ \\
\hline University of Bath & 12 & $£ 1,706,922$ & $£ 1,717,343$ & $£ 10,421$ \\
\hline University of Bath & 13 & $£ 537,368$ & $£ 533,041$ & $-£ 4,327$ \\
\hline University of Bath & 16 & $£ 955,070$ & $£ 971,756$ & $£ 16,686$ \\
\hline University of Bath & 19 & $£ 1,430,615$ & $£ 1,432,667$ & $£ 2,052$ \\
\hline University of Bath & 22 & $£ 802,019$ & $£ 827,436$ & $£ 25,417$ \\
\hline University of Bath & 26 & $£ 718,085$ & $£ 724,377$ & $£ 6,292$ \\
\hline University of Bath & 27 & $£ 380,419$ & $£ 389,704$ & $£ 9,285$ \\
\hline
\end{tabular}




\begin{tabular}{|c|c|c|c|c|}
\hline University of Birmingham & 1 & $£ 4,336,772$ & $£ 4,372,492$ & $£ 35,720$ \\
\hline University of Birmingham & 2 & $£ 1,293,919$ & $£ 1,297,628$ & $£ 3,709$ \\
\hline University of Birmingham & 3 & $£ 502,702$ & $£ 503,140$ & $£ 438$ \\
\hline University of Birmingham & 4 & $£ 1,455,534$ & $£ 1,448,721$ & $-£ 6,813$ \\
\hline University of Birmingham & 5 & $£ 1,445,563$ & $£ 1,384,230$ & $-£ 61,333$ \\
\hline University of Birmingham & 7 & $£ 763,475$ & $£ 744,816$ & $-£ 18,659$ \\
\hline University of Birmingham & 8 & $£ 716,206$ & $£ 688,591$ & $-£ 27,615$ \\
\hline University of Birmingham & 9 & $£ 1,218,776$ & $£ 1,182,362$ & $-£ 36,414$ \\
\hline University of Birmingham & 10 & $£ 1,067,124$ & $£ 1,022,366$ & $-£ 44,758$ \\
\hline University of Birmingham & 11 & $£ 1,394,621$ & $£ 1,394,315$ & $-£ 306$ \\
\hline University of Birmingham & 12 & $£ 539,212$ & $£ 525,944$ & $-£ 13,268$ \\
\hline University of Birmingham & 12 & $£ 1,014,187$ & $£ 1,042,818$ & $£ 28,631$ \\
\hline University of Birmingham & 13 & $£ 654,048$ & $£ 656,109$ & $£ 2,061$ \\
\hline University of Birmingham & 13 & $£ 987,480$ & $£ 988,993$ & $£ 1,513$ \\
\hline University of Birmingham & 14 & $£ 309,636$ & $£ 305,948$ & $-£ 3,688$ \\
\hline University of Birmingham & 17 & $£ 641,374$ & $£ 651,848$ & $£ 10,474$ \\
\hline University of Birmingham & 18 & $£ 265,404$ & $£ 268,442$ & $£ 3,038$ \\
\hline University of Birmingham & 19 & $£ 753,276$ & $£ 757,212$ & $£ 3,936$ \\
\hline University of Birmingham & 20 & $£ 567,874$ & $£ 553,942$ & $-£ 13,932$ \\
\hline University of Birmingham & 21 & $£ 657,164$ & $£ 674,964$ & $£ 17,800$ \\
\hline University of Birmingham & 22 & $£ 555,462$ & $£ 550,200$ & $-£ 5,262$ \\
\hline University of Birmingham & 25 & $£ 576,868$ & $£ 569,115$ & $-£ 7,753$ \\
\hline University of Birmingham & 26 & $£ 1,236,981$ & $£ 1,232,631$ & $-£ 4,350$ \\
\hline University of Birmingham & 27 & $£ 182,544$ & $£ 182,318$ & $-£ 226$ \\
\hline University of Birmingham & 28 & $£ 445,967$ & $£ 431,595$ & $-£ 14,372$ \\
\hline University of Birmingham & 29 & $£ 752,038$ & $£ 744,231$ & $-£ 7,807$ \\
\hline University of Birmingham & 30 & $£ 885,981$ & $£ 889,815$ & $£ 3,834$ \\
\hline University of Birmingham & 31 & $£ 417,682$ & $£ 419,888$ & $£ 2,206$ \\
\hline University of Birmingham & 32 & $£ 339,740$ & $£ 346,657$ & $£ 6,917$ \\
\hline University of Birmingham & 33 & $£ 226,060$ & $£ 225,876$ & $-£ 184$ \\
\hline University of Birmingham & 34 & $£ 157,344$ & $£ 157,353$ & $£ 9$ \\
\hline University of Birmingham & 35 & $£ 296,891$ & $£ 285,150$ & $-£ 11,741$ \\
\hline University of Birmingham & 35 & $£ 137,760$ & $£ 136,026$ & $-£ 1,734$ \\
\hline University of Bolton & 4 & $£ 30,875$ & $£ 29,956$ & $-£ 919$ \\
\hline University of Bolton & 15 & $£ 226,336$ & $£ 214,321$ & $-£ 12,015$ \\
\hline University of Bolton & 16 & $£ 16,558$ & $£ 15,284$ & $-£ 1,274$ \\
\hline University of Bolton & 22 & $£ 4,200$ & $£ 3,877$ & $-£ 323$ \\
\hline University of Bolton & 25 & $£ 27,340$ & $£ 27,055$ & $-£ 285$ \\
\hline University of Bolton & 29 & $£ 68,557$ & $£ 74,186$ & $£ 5,629$ \\
\hline University of Bolton & 36 & $£ 19,279$ & $£ 17,796$ & $-£ 1,483$ \\
\hline University of Bradford & 3 & $£ 1,394,711$ & $£ 1,367,050$ & $-£ 27,661$ \\
\hline University of Bradford & 12 & $£ 328,059$ & $£ 313,777$ & $-£ 14,282$ \\
\hline University of Bradford & 14 & $£ 155,073$ & $£ 150,956$ & $-£ 4,117$ \\
\hline University of Bradford & 17 & $£ 328,959$ & $£ 338,897$ & $£ 9,938$ \\
\hline University of Bradford & 19 & $£ 271,274$ & $£ 277,234$ & $£ 5,960$ \\
\hline University of Bradford & 21 & $£ 173,896$ & $£ 185,231$ & $£ 11,335$ \\
\hline University of Bradford & 22 & $£ 166,056$ & $£ 165,332$ & $-£ 724$ \\
\hline University of Chichester & 4 & $£ 33,919$ & $£ 31,310$ & $-£ 2,609$ \\
\hline
\end{tabular}




\begin{tabular}{|c|c|c|c|c|}
\hline University of Chichester & 26 & $£ 285,856$ & $£ 300,787$ & $£ 14,931$ \\
\hline University of Chichester & 29 & $£ 74,417$ & $£ 71,450$ & $-£ 2,967$ \\
\hline University of Chichester & 30 & $£ 54,877$ & $£ 52,181$ & $-£ 2,696$ \\
\hline University of Chichester & 35 & $£ 188,125$ & $£ 193,740$ & $£ 5,615$ \\
\hline University of Cumbria & 3 & $£ 39,796$ & $£ 37,715$ & $-£ 2,081$ \\
\hline University of Cumbria & 17 & $£ 9,936$ & $£ 9,172$ & $-£ 764$ \\
\hline University of Cumbria & 19 & $£ 25,969$ & $£ 24,951$ & $-£ 1,018$ \\
\hline University of Cumbria & 25 & $£ 13,058$ & $£ 12,604$ & $-£ 454$ \\
\hline University of Cumbria & 26 & $£ 63,865$ & $£ 58,952$ & $-£ 4,913$ \\
\hline University of Cumbria & 34 & $£ 44,944$ & $£ 46,671$ & $£ 1,727$ \\
\hline University of East Anglia & 1 & $£ 452,201$ & $£ 439,954$ & $-£ 12,247$ \\
\hline University of East Anglia & 2 & $£ 353,458$ & $£ 355,280$ & $£ 1,822$ \\
\hline University of East Anglia & 3 & $£ 565,408$ & $£ 544,755$ & $-£ 20,653$ \\
\hline University of East Anglia & 3 & $£ 484,499$ & $£ 473,474$ & $-£ 11,025$ \\
\hline University of East Anglia & 4 & $£ 342,334$ & $£ 343,814$ & $£ 1,480$ \\
\hline University of East Anglia & 5 & $£ 1,299,023$ & $£ 1,282,340$ & $-£ 16,683$ \\
\hline University of East Anglia & 6 & $£ 330,410$ & $£ 328,650$ & $-£ 1,760$ \\
\hline University of East Anglia & 7 & $£ 2,265,592$ & $£ 2,318,933$ & $£ 53,341$ \\
\hline University of East Anglia & 8 & $£ 738,753$ & $£ 726,770$ & $-£ 11,983$ \\
\hline University of East Anglia & 10 & $£ 517,165$ & $£ 495,699$ & $-£ 21,466$ \\
\hline University of East Anglia & 11 & $£ 604,899$ & $£ 590,308$ & $-£ 14,591$ \\
\hline University of East Anglia & 18 & $£ 224,089$ & $£ 219,326$ & $-£ 4,763$ \\
\hline University of East Anglia & 19 & $£ 460,304$ & $£ 461,831$ & $£ 1,527$ \\
\hline University of East Anglia & 20 & $£ 213,494$ & $£ 213,333$ & $-£ 161$ \\
\hline University of East Anglia & 21 & $£ 178,274$ & $£ 172,499$ & $-£ 5,775$ \\
\hline University of East Anglia & 22 & $£ 252,644$ & $£ 253,081$ & $£ 437$ \\
\hline University of East Anglia & 24 & $£ 455,648$ & $£ 459,765$ & $£ 4,117$ \\
\hline University of East Anglia & 25 & $£ 185,221$ & $£ 178,280$ & $-£ 6,941$ \\
\hline University of East Anglia & 27 & $£ 262,616$ & $£ 266,456$ & $£ 3,840$ \\
\hline University of East Anglia & 29 & $£ 416,975$ & $£ 419,831$ & $£ 2,856$ \\
\hline University of East Anglia & 30 & $£ 669,515$ & $£ 658,528$ & $-£ 10,987$ \\
\hline University of East Anglia & 32 & $£ 88,416$ & $£ 91,610$ & $£ 3,194$ \\
\hline University of East Anglia & 34 & $£ 340,699$ & $£ 360,220$ & $£ 19,521$ \\
\hline University of East Anglia & 36 & $£ 194,289$ & $£ 186,201$ & $-£ 8,088$ \\
\hline University of Essex & 4 & $£ 684,813$ & $£ 674,112$ & $-£ 10,701$ \\
\hline University of Essex & 5 & $£ 304,370$ & $£ 294,014$ & $-£ 10,356$ \\
\hline University of Essex & 11 & $£ 958,502$ & $£ 934,527$ & $-£ 23,975$ \\
\hline University of Essex & 18 & $£ 702,432$ & $£ 689,022$ & $-£ 13,410$ \\
\hline University of Essex & 19 & $£ 695,691$ & $£ 687,673$ & $-£ 8,018$ \\
\hline University of Essex & 20 & $£ 431,892$ & $£ 428,860$ & $-£ 3,032$ \\
\hline University of Essex & 21 & $£ 958,468$ & $£ 953,170$ & $-£ 5,298$ \\
\hline University of Essex & 23 & $£ 953,927$ & $£ 959,348$ & $£ 5,421$ \\
\hline University of Essex & 26 & $£ 110,580$ & $£ 116,390$ & $£ 5,810$ \\
\hline University of Essex & 28 & $£ 270,746$ & $£ 268,939$ & $-£ 1,807$ \\
\hline University of Essex & 29 & $£ 294,328$ & $£ 293,237$ & $-£ 1,091$ \\
\hline University of Essex & 30 & $£ 243,506$ & $£ 253,626$ & $£ 10,120$ \\
\hline University of Essex & 32 & $£ 190,287$ & $£ 190,690$ & $£ 403$ \\
\hline University of Essex & 34 & $£ 118,448$ & $£ 118,744$ & $£ 296$ \\
\hline
\end{tabular}




\begin{tabular}{|c|c|c|c|c|}
\hline University of Huddersfield & 3 & $£ 169,495$ & $£ 170,315$ & $£ 820$ \\
\hline University of Huddersfield & 5 & $£ 147,104$ & $£ 136,461$ & $-£ 10,643$ \\
\hline University of Huddersfield & 8 & $£ 224,804$ & $£ 217,972$ & $-£ 6,832$ \\
\hline University of Huddersfield & 9 & $£ 158,872$ & $£ 147,359$ & $-£ 11,513$ \\
\hline University of Huddersfield & 11 & $£ 208,870$ & $£ 198,352$ & $-£ 10,518$ \\
\hline University of Huddersfield & 15 & $£ 414,906$ & $£ 423,387$ & $£ 8,481$ \\
\hline University of Huddersfield & 19 & $£ 157,138$ & $£ 169,254$ & $£ 12,116$ \\
\hline University of Huddersfield & 22 & $£ 601,799$ & $£ 621,866$ & $£ 20,067$ \\
\hline University of Huddersfield & 25 & $£ 121,097$ & $£ 123,622$ & $£ 2,525$ \\
\hline University of Huddersfield & 29 & $£ 255,886$ & $£ 241,300$ & $-£ 14,586$ \\
\hline University of Huddersfield & 30 & $£ 159,210$ & $£ 159,206$ & $-£ 4$ \\
\hline University of Huddersfield & 34 & $£ 197,610$ & $£ 188,711$ & $-£ 8,899$ \\
\hline University of Huddersfield & 35 & $£ 509,062$ & $£ 529,407$ & $£ 20,345$ \\
\hline University of Hull & 3 & $£ 996,331$ & $£ 1,012,014$ & $£ 15,683$ \\
\hline University of Hull & 4 & $£ 350,807$ & $£ 352,784$ & $£ 1,977$ \\
\hline University of Hull & 8 & $£ 550,441$ & $£ 546,376$ & $-£ 4,065$ \\
\hline University of Hull & 11 & $£ 326,000$ & $£ 349,775$ & $£ 23,775$ \\
\hline University of Hull & 15 & $£ 329,335$ & $£ 312,685$ & $-£ 16,650$ \\
\hline University of Hull & 17 & $£ 788,015$ & $£ 826,239$ & $£ 38,224$ \\
\hline University of Hull & 19 & $£ 368,187$ & $£ 358,435$ & $-£ 9,752$ \\
\hline University of Hull & 20 & $£ 114,697$ & $£ 112,277$ & $-£ 2,420$ \\
\hline University of Hull & 21 & $£ 72,301$ & $£ 76,520$ & $£ 4,219$ \\
\hline University of Hull & 22 & $£ 243,075$ & $£ 242,451$ & $-£ 624$ \\
\hline University of Hull & 25 & $£ 107,958$ & $£ 101,240$ & $-£ 6,718$ \\
\hline University of Hull & 26 & $£ 107,288$ & $£ 107,429$ & $£ 141$ \\
\hline University of Hull & 29 & $£ 378,426$ & $£ 385,420$ & $£ 6,994$ \\
\hline University of Hull & 30 & $£ 337,972$ & $£ 333,007$ & $-£ 4,965$ \\
\hline University of Hull & 32 & $£ 27,998$ & $£ 28,418$ & $£ 420$ \\
\hline University of Hull & 35 & $£ 219,445$ & $£ 217,166$ & $-£ 2,279$ \\
\hline University of Kent & 3 & $£ 457,482$ & $£ 433,512$ & $-£ 23,970$ \\
\hline University of Kent & 4 & $£ 716,737$ & $£ 717,229$ & $£ 492$ \\
\hline University of Kent & 5 & $£ 624,464$ & $£ 610,998$ & $-£ 13,466$ \\
\hline University of Kent & 8 & $£ 399,344$ & $£ 390,903$ & $-£ 8,441$ \\
\hline University of Kent & 9 & $£ 153,463$ & $£ 155,651$ & $£ 2,188$ \\
\hline University of Kent & 10 & $£ 659,485$ & $£ 656,038$ & $-£ 3,447$ \\
\hline University of Kent & 11 & $£ 766,094$ & $£ 765,333$ & $-£ 761$ \\
\hline University of Kent & 15 & $£ 491,958$ & $£ 489,698$ & $-£ 2,260$ \\
\hline University of Kent & 16 & $£ 232,534$ & $£ 215,015$ & $-£ 17,519$ \\
\hline University of Kent & 18 & $£ 139,166$ & $£ 141,914$ & $£ 2,748$ \\
\hline University of Kent & 19 & $£ 599,053$ & $£ 602,127$ & $£ 3,074$ \\
\hline University of Kent & 20 & $£ 874,103$ & $£ 878,313$ & $£ 4,210$ \\
\hline University of Kent & 21 & $£ 365,783$ & $£ 379,010$ & $£ 13,227$ \\
\hline University of Kent & 22 & $£ 1,359,606$ & $£ 1,397,644$ & $£ 38,038$ \\
\hline University of Kent & 24 & $£ 274,466$ & $£ 272,070$ & $-£ 2,396$ \\
\hline University of Kent & 26 & $£ 144,160$ & $£ 149,148$ & $£ 4,988$ \\
\hline University of Kent & 28 & $£ 534,787$ & $£ 538,600$ & $£ 3,813$ \\
\hline University of Kent & 29 & $£ 687,633$ & $£ 692,717$ & $£ 5,084$ \\
\hline University of Kent & 30 & $£ 507,158$ & $£ 510,841$ & $£ 3,683$ \\
\hline
\end{tabular}




\begin{tabular}{|c|c|c|c|c|}
\hline University of Kent & 31 & $£ 176,262$ & $£ 184,787$ & $£ 8,525$ \\
\hline University of Kent & 32 & $£ 155,381$ & $£ 161,657$ & $£ 6,276$ \\
\hline University of Kent & 33 & $£ 157,226$ & $£ 160,433$ & $£ 3,207$ \\
\hline University of Kent & 35 & $£ 1,043,136$ & $£ 1,041,988$ & $-£ 1,148$ \\
\hline University of Lancaster & 3 & $£ 2,177,537$ & $£ 2,143,832$ & $-£ 33,705$ \\
\hline University of Lancaster & 4 & $£ 534,988$ & $£ 531,240$ & $-£ 3,748$ \\
\hline University of Lancaster & 7 & $£ 1,454,188$ & $£ 1,492,741$ & $£ 38,553$ \\
\hline University of Lancaster & 8 & $£ 362,505$ & $£ 353,319$ & $-£ 9,186$ \\
\hline University of Lancaster & 9 & $£ 1,098,331$ & $£ 1,061,482$ & $-£ 36,849$ \\
\hline University of Lancaster & 10 & $£ 1,011,328$ & $£ 1,021,321$ & $£ 9,993$ \\
\hline University of Lancaster & 11 & $£ 1,286,081$ & $£ 1,279,699$ & $-£ 6,382$ \\
\hline University of Lancaster & 15 & $£ 679,489$ & $£ 683,254$ & $£ 3,765$ \\
\hline University of Lancaster & 19 & $£ 2,626,973$ & $£ 2,636,058$ & $£ 9,085$ \\
\hline University of Lancaster & 20 & $£ 536,935$ & $£ 531,953$ & $-£ 4,982$ \\
\hline University of Lancaster & 23 & $£ 609,605$ & $£ 626,864$ & $£ 17,259$ \\
\hline University of Lancaster & 25 & $£ 189,858$ & $£ 185,916$ & $-£ 3,942$ \\
\hline University of Lancaster & 29 & $£ 1,071,806$ & $£ 1,106,750$ & $£ 34,944$ \\
\hline University of Lancaster & 30 & $£ 363,436$ & $£ 364,440$ & $£ 1,004$ \\
\hline University of Lancaster & 33 & $£ 456,411$ & $£ 477,675$ & $£ 21,264$ \\
\hline University of Lancaster & 34 & $£ 768,223$ & $£ 769,742$ & $£ 1,519$ \\
\hline University of Leeds & 1 & $£ 2,616,610$ & $£ 2,663,513$ & $£ 46,903$ \\
\hline University of Leeds & 2 & $£ 771,880$ & $£ 770,192$ & $-£ 1,688$ \\
\hline University of Leeds & 3 & $£ 1,459,739$ & $£ 1,481,390$ & $£ 21,651$ \\
\hline University of Leeds & 4 & $£ 1,014,483$ & $£ 1,014,868$ & $£ 385$ \\
\hline University of Leeds & 5 & $£ 1,913,439$ & $£ 1,938,455$ & $£ 25,016$ \\
\hline University of Leeds & 6 & $£ 369,389$ & $£ 378,627$ & $£ 9,238$ \\
\hline University of Leeds & 7 & $£ 2,967,430$ & $£ 2,962,378$ & $-£ 5,052$ \\
\hline University of Leeds & 8 & $£ 1,073,434$ & $£ 1,083,858$ & $£ 10,424$ \\
\hline University of Leeds & 9 & $£ 757,789$ & $£ 774,749$ & $£ 16,960$ \\
\hline University of Leeds & 10 & $£ 1,916,363$ & $£ 1,929,095$ & $£ 12,732$ \\
\hline University of Leeds & 11 & $£ 854,892$ & $£ 874,080$ & $£ 19,188$ \\
\hline University of Leeds & 12 & $£ 1,033,153$ & $£ 1,048,887$ & $£ 15,734$ \\
\hline University of Leeds & 13 & $£ 894,051$ & $£ 881,253$ & $-£ 12,798$ \\
\hline University of Leeds & 14 & $£ 1,332,798$ & $£ 1,315,763$ & $-£ 17,035$ \\
\hline University of Leeds & 15 & $£ 1,079,981$ & $£ 1,065,035$ & $-£ 14,946$ \\
\hline University of Leeds & 17 & $£ 1,280,516$ & $£ 1,274,434$ & $-£ 6,082$ \\
\hline University of Leeds & 19 & $£ 1,503,740$ & $£ 1,529,089$ & $£ 25,349$ \\
\hline University of Leeds & 20 & $£ 658,877$ & $£ 672,903$ & $£ 14,026$ \\
\hline University of Leeds & 21 & $£ 361,683$ & $£ 377,357$ & $£ 15,674$ \\
\hline University of Leeds & 22 & $£ 618,485$ & $£ 635,888$ & $£ 17,403$ \\
\hline University of Leeds & 25 & $£ 504,241$ & $£ 518,792$ & $£ 14,551$ \\
\hline University of Leeds & 26 & $£ 500,881$ & $£ 494,741$ & $-£ 6,140$ \\
\hline University of Leeds & 28 & $£ 1,063,231$ & $£ 1,073,662$ & $£ 10,431$ \\
\hline University of Leeds & 29 & $£ 669,444$ & $£ 676,359$ & $£ 6,915$ \\
\hline University of Leeds & 30 & $£ 632,881$ & $£ 638,187$ & $£ 5,306$ \\
\hline University of Leeds & 31 & $£ 75,452$ & $£ 74,059$ & $-£ 1,393$ \\
\hline University of Leeds & 32 & $£ 480,454$ & $£ 478,188$ & $-£ 2,266$ \\
\hline University of Leeds & 33 & $£ 211,765$ & $£ 206,830$ & $-£ 4,935$ \\
\hline
\end{tabular}




\begin{tabular}{|c|c|c|c|c|}
\hline University of Leeds & 34 & $£ 382,577$ & $£ 394,364$ & $£ 11,787$ \\
\hline University of Leeds & 34 & $£ 472,003$ & $£ 494,626$ & $£ 22,623$ \\
\hline University of Leeds & 35 & $£ 429,548$ & $£ 438,858$ & $£ 9,310$ \\
\hline University of Leeds & 35 & $£ 252,716$ & $£ 273,497$ & $£ 20,781$ \\
\hline University of Leeds & 36 & $£ 584,795$ & $£ 592,469$ & $£ 7,674$ \\
\hline University of Leicester & 1 & $£ 1,957,164$ & $£ 1,981,124$ & $£ 23,960$ \\
\hline University of Leicester & 2 & $£ 744,778$ & $£ 752,024$ & $£ 7,246$ \\
\hline University of Leicester & 4 & $£ 851,565$ & $£ 815,473$ & $-£ 36,092$ \\
\hline University of Leicester & 5 & $£ 1,147,942$ & $£ 1,133,487$ & $-£ 14,455$ \\
\hline University of Leicester & 7 & $£ 619,394$ & $£ 605,354$ & $-£ 14,040$ \\
\hline University of Leicester & 8 & $£ 483,855$ & $£ 489,913$ & $£ 6,058$ \\
\hline University of Leicester & 9 & $£ 1,305,981$ & $£ 1,326,745$ & $£ 20,764$ \\
\hline University of Leicester & 10 & $£ 379,280$ & $£ 373,328$ & $-£ 5,952$ \\
\hline University of Leicester & 11 & $£ 477,510$ & $£ 450,002$ & $-£ 27,508$ \\
\hline University of Leicester & 15 & $£ 762,071$ & $£ 736,143$ & $-£ 25,928$ \\
\hline University of Leicester & 17 & $£ 517,764$ & $£ 538,411$ & $£ 20,647$ \\
\hline University of Leicester & 17 & $£ 442,708$ & $£ 435,438$ & $-£ 7,270$ \\
\hline University of Leicester & 18 & $£ 258,611$ & $£ 243,597$ & $-£ 15,014$ \\
\hline University of Leicester & 19 & $£ 662,751$ & $£ 653,158$ & $-£ 9,593$ \\
\hline University of Leicester & 20 & $£ 515,841$ & $£ 508,215$ & $-£ 7,626$ \\
\hline University of Leicester & 21 & $£ 161,283$ & $£ 157,946$ & $-£ 3,337$ \\
\hline University of Leicester & 22 & $£ 132,498$ & $£ 130,050$ & $-£ 2,448$ \\
\hline University of Leicester & 23 & $£ 121,749$ & $£ 112,527$ & $-£ 9,222$ \\
\hline University of Leicester & 25 & $£ 270,883$ & $£ 261,217$ & $-£ 9,666$ \\
\hline University of Leicester & 28 & $£ 80,617$ & $£ 79,926$ & $-£ 691$ \\
\hline University of Leicester & 29 & $£ 524,130$ & $£ 519,795$ & $-£ 4,335$ \\
\hline University of Leicester & 30 & $£ 504,368$ & $£ 498,905$ & $-£ 5,463$ \\
\hline University of Leicester & 34 & $£ 129,781$ & $£ 133,477$ & $£ 3,696$ \\
\hline University of Leicester & 36 & $£ 457,209$ & $£ 459,359$ & $£ 2,150$ \\
\hline University of Leicester & 36 & $£ 278,247$ & $£ 286,430$ & $£ 8,183$ \\
\hline University of Liverpool & 1 & $£ 3,878,766$ & $£ 3,928,557$ & $£ 49,791$ \\
\hline University of Liverpool & 2 & $£ 905,283$ & $£ 936,045$ & $£ 30,762$ \\
\hline University of Liverpool & 4 & $£ 889,628$ & $£ 906,825$ & $£ 17,197$ \\
\hline University of Liverpool & 5 & $£ 421,621$ & $£ 402,350$ & $-£ 19,271$ \\
\hline University of Liverpool & 6 & $£ 1,809,359$ & $£ 1,815,870$ & $£ 6,511$ \\
\hline University of Liverpool & 7 & $£ 708,414$ & $£ 680,694$ & $-£ 27,720$ \\
\hline University of Liverpool & 8 & $£ 1,684,884$ & $£ 1,663,893$ & $-£ 20,991$ \\
\hline University of Liverpool & 9 & $£ 976,054$ & $£ 947,436$ & $-£ 28,618$ \\
\hline University of Liverpool & 10 & $£ 934,957$ & $£ 925,457$ & $-£ 9,500$ \\
\hline University of Liverpool & 11 & $£ 992,597$ & $£ 972,368$ & $-£ 20,229$ \\
\hline University of Liverpool & 13 & $£ 634,812$ & $£ 612,135$ & $-£ 22,677$ \\
\hline University of Liverpool & 15 & $£ 1,011,071$ & $£ 995,033$ & $-£ 16,038$ \\
\hline University of Liverpool & 16 & $£ 615,807$ & $£ 603,053$ & $-£ 12,754$ \\
\hline University of Liverpool & 17 & $£ 547,832$ & $£ 535,385$ & $-£ 12,447$ \\
\hline University of Liverpool & 17 & $£ 429,166$ & $£ 425,155$ & $-£ 4,011$ \\
\hline University of Liverpool & 19 & $£ 637,232$ & $£ 666,628$ & $£ 29,396$ \\
\hline University of Liverpool & 20 & $£ 259,907$ & $£ 253,317$ & $-£ 6,590$ \\
\hline University of Liverpool & 21 & $£ 53,131$ & $£ 55,292$ & $£ 2,161$ \\
\hline
\end{tabular}




\begin{tabular}{|c|c|c|c|c|}
\hline University of Liverpool & 22 & $£ 231,843$ & $£ 234,033$ & $£ 2,190$ \\
\hline University of Liverpool & 28 & $£ 336,339$ & $£ 330,387$ & $-£ 5,952$ \\
\hline University of Liverpool & 29 & $£ 586,339$ & $£ 582,246$ & $-£ 4,093$ \\
\hline University of Liverpool & 30 & $£ 435,176$ & $£ 437,687$ & $£ 2,511$ \\
\hline University of Liverpool & 31 & $£ 112,637$ & $£ 107,088$ & $-£ 5,549$ \\
\hline University of Liverpool & 32 & $£ 103,357$ & $£ 98,839$ & $-£ 4,518$ \\
\hline University of Liverpool & 35 & $£ 207,551$ & $£ 209,625$ & $£ 2,074$ \\
\hline University of Liverpool & 36 & $£ 92,831$ & $£ 95,972$ & $£ 3,141$ \\
\hline University of Manchester & 1 & $£ 4,259,113$ & $£ 4,279,047$ & $£ 19,934$ \\
\hline University of Manchester & 2 & $£ 653,084$ & $£ 635,827$ & $-£ 17,257$ \\
\hline University of Manchester & 3 & $£ 4,334,122$ & $£ 4,376,752$ & $£ 42,630$ \\
\hline University of Manchester & 4 & $£ 1,996,730$ & $£ 2,006,458$ & $£ 9,728$ \\
\hline University of Manchester & 5 & $£ 4,483,890$ & $£ 4,422,421$ & $-£ 61,469$ \\
\hline University of Manchester & 7 & $£ 1,432,790$ & $£ 1,434,486$ & $£ 1,696$ \\
\hline University of Manchester & 8 & $£ 1,907,796$ & $£ 1,913,293$ & $£ 5,497$ \\
\hline University of Manchester & 9 & $£ 2,445,744$ & $£ 2,507,892$ & $£ 62,148$ \\
\hline University of Manchester & 10 & $£ 2,100,604$ & $£ 2,106,394$ & $£ 5,790$ \\
\hline University of Manchester & 11 & $£ 1,995,473$ & $£ 2,011,697$ & $£ 16,224$ \\
\hline University of Manchester & 12 & $£ 1,147,103$ & $£ 1,162,876$ & $£ 15,773$ \\
\hline University of Manchester & 12 & $£ 1,070,773$ & $£ 1,091,284$ & $£ 20,511$ \\
\hline University of Manchester & 13 & $£ 1,554,343$ & $£ 1,553,825$ & $-£ 518$ \\
\hline University of Manchester & 13 & $£ 1,557,335$ & $£ 1,589,202$ & $£ 31,867$ \\
\hline University of Manchester & 14 & $£ 749,448$ & $£ 753,628$ & $£ 4,180$ \\
\hline University of Manchester & 16 & $£ 413,178$ & $£ 415,114$ & $£ 1,936$ \\
\hline University of Manchester & 17 & $£ 619,934$ & $£ 632,693$ & $£ 12,759$ \\
\hline University of Manchester & 17 & $£ 140,231$ & $£ 137,778$ & $-£ 2,453$ \\
\hline University of Manchester & 18 & $£ 453,005$ & $£ 463,356$ & $£ 10,351$ \\
\hline University of Manchester & 19 & $£ 2,372,600$ & $£ 2,406,208$ & $£ 33,608$ \\
\hline University of Manchester & 20 & $£ 615,107$ & $£ 622,860$ & $£ 7,753$ \\
\hline University of Manchester & 21 & $£ 523,335$ & $£ 522,118$ & $-£ 1,217$ \\
\hline University of Manchester & 23 & $£ 1,075,459$ & $£ 1,093,399$ & $£ 17,940$ \\
\hline University of Manchester & 24 & $£ 320,624$ & $£ 323,161$ & $£ 2,537$ \\
\hline University of Manchester & 24 & $£ 522,776$ & $£ 537,521$ & $£ 14,745$ \\
\hline University of Manchester & 25 & $£ 671,675$ & $£ 670,700$ & $-£ 975$ \\
\hline University of Manchester & 28 & $£ 1,542,537$ & $£ 1,546,681$ & $£ 4,144$ \\
\hline University of Manchester & 29 & $£ 716,406$ & $£ 722,525$ & $£ 6,119$ \\
\hline University of Manchester & 30 & $£ 567,116$ & $£ 563,923$ & $-£ 3,193$ \\
\hline University of Manchester & 31 & $£ 202,390$ & $£ 201,118$ & $-£ 1,272$ \\
\hline University of Manchester & 32 & $£ 178,510$ & $£ 182,047$ & $£ 3,537$ \\
\hline University of Manchester & 33 & $£ 239,397$ & $£ 246,465$ & $£ 7,068$ \\
\hline University of Manchester & 34 & $£ 337,818$ & $£ 331,191$ & $-£ 6,627$ \\
\hline University of Manchester & 35 & $£ 412,680$ & $£ 413,470$ & $£ 790$ \\
\hline University of Manchester & 35 & $£ 434,397$ & $£ 439,998$ & $£ 5,601$ \\
\hline University of Northampton & 3 & $£ 102,944$ & $£ 95,256$ & $-£ 7,688$ \\
\hline University of Northampton & 4 & $£ 5,122$ & $£ 4,850$ & $-£ 272$ \\
\hline University of Northampton & 12 & $£ 22,915$ & $£ 23,754$ & $£ 839$ \\
\hline University of Northampton & 17 & $£ 81,630$ & $£ 78,659$ & $-£ 2,971$ \\
\hline University of Northampton & 19 & $£ 25,390$ & $£ 24,813$ & $-£ 577$ \\
\hline
\end{tabular}




\begin{tabular}{|c|c|c|c|c|}
\hline University of Northampton & 25 & $£ 52,715$ & $£ 55,835$ & $£ 3,120$ \\
\hline University of Northampton & 29 & $£ 85,250$ & $£ 84,216$ & $-£ 1,034$ \\
\hline University of Northampton & 30 & $£ 108,201$ & $£ 103,784$ & $-£ 4,417$ \\
\hline University of Northampton & 34 & $£ 58,004$ & $£ 61,690$ & $£ 3,686$ \\
\hline University of Nottingham & 1 & $£ 2,979,566$ & $£ 3,039,192$ & $£ 59,626$ \\
\hline University of Nottingham & 2 & $£ 1,024,327$ & $£ 1,043,784$ & $£ 19,457$ \\
\hline University of Nottingham & 3 & $£ 1,728,252$ & $£ 1,753,847$ & $£ 25,595$ \\
\hline University of Nottingham & 3 & $£ 1,156,980$ & $£ 1,187,877$ & $£ 30,897$ \\
\hline University of Nottingham & 4 & $£ 1,499,198$ & $£ 1,497,578$ & $-£ 1,620$ \\
\hline University of Nottingham & 5 & $£ 2,085,593$ & $£ 2,109,271$ & $£ 23,678$ \\
\hline University of Nottingham & 6 & $£ 3,382,234$ & $£ 3,376,204$ & $-£ 6,030$ \\
\hline University of Nottingham & 8 & $£ 1,418,150$ & $£ 1,399,786$ & $-£ 18,364$ \\
\hline University of Nottingham & 9 & $£ 2,126,646$ & $£ 2,156,947$ & $£ 30,301$ \\
\hline University of Nottingham & 10 & $£ 1,920,300$ & $£ 1,899,480$ & $-£ 20,820$ \\
\hline University of Nottingham & 11 & $£ 1,592,794$ & $£ 1,596,629$ & $£ 3,835$ \\
\hline University of Nottingham & 15 & $£ 4,636,933$ & $£ 4,695,862$ & $£ 58,929$ \\
\hline University of Nottingham & 16 & $£ 317,056$ & $£ 317,064$ & $£ 8$ \\
\hline University of Nottingham & 17 & $£ 156,097$ & $£ 155,571$ & $-£ 526$ \\
\hline University of Nottingham & 17 & $£ 992,493$ & $£ 951,911$ & $-£ 40,582$ \\
\hline University of Nottingham & 18 & $£ 566,692$ & $£ 557,685$ & $-£ 9,007$ \\
\hline University of Nottingham & 19 & $£ 1,444,188$ & $£ 1,480,110$ & $£ 35,922$ \\
\hline University of Nottingham & 20 & $£ 922,471$ & $£ 936,925$ & $£ 14,454$ \\
\hline University of Nottingham & 21 & $£ 433,554$ & $£ 435,288$ & $£ 1,734$ \\
\hline University of Nottingham & 22 & $£ 697,693$ & $£ 707,341$ & $£ 9,648$ \\
\hline University of Nottingham & 25 & $£ 643,189$ & $£ 660,879$ & $£ 17,690$ \\
\hline University of Nottingham & 27 & $£ 341,180$ & $£ 352,614$ & $£ 11,434$ \\
\hline University of Nottingham & 27 & $£ 252,030$ & $£ 253,066$ & $£ 1,036$ \\
\hline University of Nottingham & 28 & $£ 909,604$ & $£ 921,371$ & $£ 11,767$ \\
\hline University of Nottingham & 29 & $£ 987,061$ & $£ 998,124$ & $£ 11,063$ \\
\hline University of Nottingham & 30 & $£ 482,591$ & $£ 479,003$ & $-£ 3,588$ \\
\hline University of Nottingham & 31 & $£ 293,838$ & $£ 292,696$ & $-£ 1,142$ \\
\hline University of Nottingham & 32 & $£ 144,056$ & $£ 142,808$ & $-£ 1,248$ \\
\hline University of Nottingham & 33 & $£ 280,208$ & $£ 274,035$ & $-£ 6,173$ \\
\hline University of Nottingham & 34 & $£ 170,065$ & $£ 159,728$ & $-£ 10,337$ \\
\hline University of Nottingham & 35 & $£ 323,102$ & $£ 315,512$ & $-£ 7,590$ \\
\hline University of Nottingham & 36 & $£ 345,068$ & $£ 340,877$ & $-£ 4,191$ \\
\hline University of Reading & 3 & $£ 585,972$ & $£ 553,073$ & $-£ 32,899$ \\
\hline University of Reading & 4 & $£ 966,308$ & $£ 986,235$ & $£ 19,927$ \\
\hline University of Reading & 5 & $£ 482,958$ & $£ 473,099$ & $-£ 9,859$ \\
\hline University of Reading & 6 & $£ 2,428,993$ & $£ 2,482,939$ & $£ 53,946$ \\
\hline University of Reading & 7 & $£ 2,351,464$ & $£ 2,390,967$ & $£ 39,503$ \\
\hline University of Reading & 8 & $£ 484,640$ & $£ 459,626$ & $-£ 25,014$ \\
\hline University of Reading & 10 & $£ 691,217$ & $£ 677,040$ & $-£ 14,177$ \\
\hline University of Reading & 13 & $£ 363,730$ & $£ 352,676$ & $-£ 11,054$ \\
\hline University of Reading & 16 & $£ 1,008,120$ & $£ 1,023,307$ & $£ 15,187$ \\
\hline University of Reading & 17 & $£ 513,846$ & $£ 495,921$ & $-£ 17,925$ \\
\hline University of Reading & 17 & $£ 247,062$ & $£ 237,909$ & $-£ 9,153$ \\
\hline University of Reading & 19 & $£ 746,319$ & $£ 764,167$ & $£ 17,848$ \\
\hline
\end{tabular}




\begin{tabular}{|c|c|c|c|c|}
\hline University of Reading & 20 & $£ 345,598$ & $£ 332,738$ & $-£ 12,860$ \\
\hline University of Reading & 21 & $£ 259,924$ & $£ 253,702$ & $-£ 6,222$ \\
\hline University of Reading & 25 & $£ 281,816$ & $£ 282,189$ & $£ 373$ \\
\hline University of Reading & 28 & $£ 347,931$ & $£ 368,490$ & $£ 20,559$ \\
\hline University of Reading & 29 & $£ 434,099$ & $£ 423,000$ & $-£ 11,099$ \\
\hline University of Reading & 30 & $£ 247,127$ & $£ 242,349$ & $-£ 4,778$ \\
\hline University of Reading & 31 & $£ 253,952$ & $£ 250,771$ & $-£ 3,181$ \\
\hline University of Reading & 32 & $£ 136,805$ & $£ 128,784$ & $-£ 8,021$ \\
\hline University of Reading & 34 & $£ 199,629$ & $£ 198,496$ & $-£ 1,133$ \\
\hline University of Reading & 34 & $£ 298,436$ & $£ 299,431$ & $£ 995$ \\
\hline University of Reading & 35 & $£ 184,818$ & $£ 179,069$ & $-£ 5,749$ \\
\hline University of Salford & 3 & $£ 594,197$ & $£ 582,888$ & $-£ 11,309$ \\
\hline University of Salford & 5 & $£ 262,088$ & $£ 253,159$ & $-£ 8,929$ \\
\hline University of Salford & 11 & $£ 117,110$ & $£ 120,249$ & $£ 3,139$ \\
\hline University of Salford & 13 & $£ 282,222$ & $£ 262,898$ & $-£ 19,324$ \\
\hline University of Salford & 16 & $£ 730,991$ & $£ 736,573$ & $£ 5,582$ \\
\hline University of Salford & 17 & $£ 112,688$ & $£ 114,843$ & $£ 2,155$ \\
\hline University of Salford & 19 & $£ 163,411$ & $£ 172,813$ & $£ 9,402$ \\
\hline University of Salford & 22 & $£ 97,293$ & $£ 103,896$ & $£ 6,603$ \\
\hline University of Salford & 28 & $£ 38,331$ & $£ 35,702$ & $-£ 2,629$ \\
\hline University of Salford & 29 & $£ 105,924$ & $£ 100,979$ & $-£ 4,945$ \\
\hline University of Salford & 34 & $£ 120,802$ & $£ 127,977$ & $£ 7,175$ \\
\hline University of Salford & 35 & $£ 118,513$ & $£ 111,711$ & $-£ 6,802$ \\
\hline University of Salford & 36 & $£ 247,518$ & $£ 242,680$ & $-£ 4,838$ \\
\hline University of Sheffield & 1 & $£ 1,834,560$ & $£ 1,859,823$ & $£ 25,263$ \\
\hline University of Sheffield & 2 & $£ 2,010,237$ & $£ 2,110,310$ & $£ 100,073$ \\
\hline University of Sheffield & 3 & $£ 1,025,471$ & $£ 1,000,857$ & $-£ 24,614$ \\
\hline University of Sheffield & 3 & $£ 2,744,975$ & $£ 2,752,508$ & $£ 7,533$ \\
\hline University of Sheffield & 4 & $£ 965,093$ & $£ 972,382$ & $£ 7,289$ \\
\hline University of Sheffield & 5 & $£ 1,777,342$ & $£ 1,752,012$ & $-£ 25,330$ \\
\hline University of Sheffield & 7 & $£ 656,516$ & $£ 648,448$ & $-£ 8,068$ \\
\hline University of Sheffield & 8 & $£ 960,133$ & $£ 938,421$ & $-£ 21,712$ \\
\hline University of Sheffield & 9 & $£ 971,447$ & $£ 936,743$ & $-£ 34,704$ \\
\hline University of Sheffield & 10 & $£ 991,330$ & $£ 992,865$ & $£ 1,535$ \\
\hline University of Sheffield & 11 & $£ 1,343,779$ & $£ 1,348,973$ & $£ 5,194$ \\
\hline University of Sheffield & 12 & $£ 1,339,124$ & $£ 1,326,875$ & $-£ 12,249$ \\
\hline University of Sheffield & 12 & $£ 838,060$ & $£ 830,057$ & $-£ 8,003$ \\
\hline University of Sheffield & 13 & $£ 1,136,891$ & $£ 1,146,153$ & $£ 9,262$ \\
\hline University of Sheffield & 13 & $£ 1,141,801$ & $£ 1,093,691$ & $-£ 48,110$ \\
\hline University of Sheffield & 14 & $£ 1,138,268$ & $£ 1,120,769$ & $-£ 17,499$ \\
\hline University of Sheffield & 15 & $£ 989,321$ & $£ 965,387$ & $-£ 23,934$ \\
\hline University of Sheffield & 16 & $£ 1,082,073$ & $£ 1,093,023$ & $£ 10,950$ \\
\hline University of Sheffield & 17 & $£ 398,119$ & $£ 405,882$ & $£ 7,763$ \\
\hline University of Sheffield & 17 & $£ 610,044$ & $£ 614,040$ & $£ 3,996$ \\
\hline University of Sheffield & 18 & $£ 164,936$ & $£ 168,631$ & $£ 3,695$ \\
\hline University of Sheffield & 19 & $£ 666,010$ & $£ 678,402$ & $£ 12,392$ \\
\hline University of Sheffield & 20 & $£ 507,413$ & $£ 499,997$ & $-£ 7,416$ \\
\hline University of Sheffield & 21 & $£ 484,589$ & $£ 485,814$ & $£ 1,225$ \\
\hline
\end{tabular}




\begin{tabular}{|c|c|c|c|c|}
\hline University of Sheffield & 22 & $£ 303,461$ & $£ 298,698$ & $-£ 4,763$ \\
\hline University of Sheffield & 25 & $£ 324,495$ & $£ 335,882$ & $£ 11,387$ \\
\hline University of Sheffield & 27 & $£ 166,631$ & $£ 160,539$ & $-£ 6,092$ \\
\hline University of Sheffield & 28 & $£ 577,412$ & $£ 590,008$ & $£ 12,596$ \\
\hline University of Sheffield & 28 & $£ 112,791$ & $£ 120,007$ & $£ 7,216$ \\
\hline University of Sheffield & 29 & $£ 810,233$ & $£ 823,867$ & $£ 13,634$ \\
\hline University of Sheffield & 30 & $£ 653,478$ & $£ 653,140$ & $-£ 338$ \\
\hline University of Sheffield & 32 & $£ 385,156$ & $£ 376,672$ & $-£ 8,484$ \\
\hline University of Sheffield & 33 & $£ 58,643$ & $£ 57,028$ & $-£ 1,615$ \\
\hline University of Sheffield & 35 & $£ 397,260$ & $£ 398,054$ & $£ 794$ \\
\hline University of Sheffield & 36 & $£ 416,110$ & $£ 431,441$ & $£ 15,331$ \\
\hline University of Surrey & 3 & $£ 2,478,290$ & $£ 2,452,731$ & $-£ 25,559$ \\
\hline University of Surrey & 4 & $£ 406,638$ & $£ 395,221$ & $-£ 11,417$ \\
\hline University of Surrey & 9 & $£ 833,025$ & $£ 835,471$ & $£ 2,446$ \\
\hline University of Surrey & 10 & $£ 702,567$ & $£ 664,264$ & $-£ 38,303$ \\
\hline University of Surrey & 11 & $£ 364,941$ & $£ 359,589$ & $-£ 5,352$ \\
\hline University of Surrey & 13 & $£ 2,233,180$ & $£ 2,208,780$ & $-£ 24,400$ \\
\hline University of Surrey & 15 & $£ 1,473,144$ & $£ 1,467,300$ & $-£ 5,844$ \\
\hline University of Surrey & 18 & $£ 334,895$ & $£ 322,140$ & $-£ 12,755$ \\
\hline University of Surrey & 19 & $£ 469,449$ & $£ 444,700$ & $-£ 24,749$ \\
\hline University of Surrey & 20 & $£ 73,860$ & $£ 70,243$ & $-£ 3,617$ \\
\hline University of Surrey & 21 & $£ 77,897$ & $£ 72,047$ & $-£ 5,850$ \\
\hline University of Surrey & 23 & $£ 300,640$ & $£ 294,243$ & $-£ 6,397$ \\
\hline University of Surrey & 26 & $£ 401,274$ & $£ 402,604$ & $£ 1,330$ \\
\hline University of Surrey & 29 & $£ 422,584$ & $£ 432,391$ & $£ 9,807$ \\
\hline University of Surrey & 35 & $£ 385,626$ & $£ 388,516$ & $£ 2,890$ \\
\hline University of Warwick & 1 & $£ 870,027$ & $£ 856,508$ & $-£ 13,519$ \\
\hline University of Warwick & 2 & $£ 1,017,165$ & $£ 1,024,641$ & $£ 7,476$ \\
\hline University of Warwick & 4 & $£ 670,604$ & $£ 656,995$ & $-£ 13,609$ \\
\hline University of Warwick & 5 & $£ 1,215,220$ & $£ 1,173,769$ & $-£ 41,451$ \\
\hline University of Warwick & 6 & $£ 489,725$ & $£ 493,222$ & $£ 3,497$ \\
\hline University of Warwick & 8 & $£ 1,342,087$ & $£ 1,317,208$ & $-£ 24,879$ \\
\hline University of Warwick & 9 & $£ 1,950,879$ & $£ 1,913,233$ & $-£ 37,646$ \\
\hline University of Warwick & 10 & $£ 4,442,423$ & $£ 4,399,619$ & $-£ 42,804$ \\
\hline University of Warwick & 11 & $£ 1,279,659$ & $£ 1,274,300$ & $-£ 5,359$ \\
\hline University of Warwick & 15 & $£ 3,250,816$ & $£ 3,282,669$ & $£ 31,853$ \\
\hline University of Warwick & 18 & $£ 1,076,180$ & $£ 1,070,114$ & $-£ 6,066$ \\
\hline University of Warwick & 19 & $£ 2,211,084$ & $£ 2,142,546$ & $-£ 68,538$ \\
\hline University of Warwick & 20 & $£ 674,652$ & $£ 670,734$ & $-£ 3,918$ \\
\hline University of Warwick & 21 & $£ 1,067,686$ & $£ 1,079,416$ & $£ 11,730$ \\
\hline University of Warwick & 23 & $£ 446,644$ & $£ 436,035$ & $-£ 10,609$ \\
\hline University of Warwick & 25 & $£ 642,382$ & $£ 645,183$ & $£ 2,801$ \\
\hline University of Warwick & 28 & $£ 644,546$ & $£ 630,817$ & $-£ 13,729$ \\
\hline University of Warwick & 29 & $£ 1,068,374$ & $£ 1,068,889$ & $£ 515$ \\
\hline University of Warwick & 30 & $£ 907,069$ & $£ 907,187$ & $£ 118$ \\
\hline University of Warwick & 31 & $£ 248,714$ & $£ 249,771$ & $£ 1,057$ \\
\hline University of Warwick & 32 & $£ 400,307$ & $£ 386,352$ & $-£ 13,955$ \\
\hline University of Warwick & 34 & $£ 310,809$ & $£ 302,367$ & $-£ 8,442$ \\
\hline
\end{tabular}




\begin{tabular}{|c|c|c|c|c|}
\hline University of Warwick & 35 & $£ 896,914$ & $£ 895,895$ & $-£ 1,019$ \\
\hline University of West London & 3 & $£ 139,157$ & $£ 133,002$ & $-£ 6,155$ \\
\hline University of West London & 11 & $£ 17,668$ & $£ 16,309$ & $-£ 1,359$ \\
\hline University of West London & 25 & $£ 19,690$ & $£ 18,175$ & $-£ 1,515$ \\
\hline University of West London & 35 & $£ 32,198$ & $£ 29,780$ & $-£ 2,418$ \\
\hline University of West London & 36 & $£ 32,671$ & $£ 30,158$ & $-£ 2,513$ \\
\hline University of Westminster & 3 & $£ 528,145$ & $£ 515,218$ & $-£ 12,927$ \\
\hline University of Westminster & 4 & $£ 160,984$ & $£ 157,949$ & $-£ 3,035$ \\
\hline University of Westminster & 11 & $£ 111,857$ & $£ 105,770$ & $-£ 6,087$ \\
\hline University of Westminster & 16 & $£ 462,667$ & $£ 469,519$ & $£ 6,852$ \\
\hline University of Westminster & 19 & $£ 140,032$ & $£ 139,139$ & $-£ 893$ \\
\hline University of Westminster & 20 & $£ 147,976$ & $£ 142,411$ & $-£ 5,565$ \\
\hline University of Westminster & 21 & $£ 136,702$ & $£ 133,801$ & $-£ 2,901$ \\
\hline University of Westminster & 27 & $£ 62,895$ & $£ 59,272$ & $-£ 3,623$ \\
\hline University of Westminster & 28 & $£ 17,032$ & $£ 16,680$ & $-£ 352$ \\
\hline University of Westminster & 29 & $£ 348,634$ & $£ 349,875$ & $£ 1,241$ \\
\hline University of Westminster & 30 & $£ 48,205$ & $£ 45,776$ & $-£ 2,429$ \\
\hline University of Westminster & 34 & $£ 751,336$ & $£ 759,528$ & $£ 8,192$ \\
\hline University of Westminster & 36 & $£ 460,532$ & $£ 468,969$ & $£ 8,437$ \\
\hline Trinity Laban Conservatoire of Music and Dance & 35 & $£ 199,222$ & $£ 200,088$ & $£ 866$ \\
\hline University College London & 1 & $£ 14,246,231$ & $£ 14,614,358$ & $£ 368,127$ \\
\hline University College London & 2 & $£ 5,446,382$ & $£ 5,525,570$ & $£ 79,188$ \\
\hline University College London & 3 & $£ 945,615$ & $£ 957,066$ & $£ 11,451$ \\
\hline University College London & 3 & $£ 1,719,674$ & $£ 1,721,883$ & $£ 2,209$ \\
\hline University College London & 4 & $£ 9,692,031$ & $£ 9,711,104$ & $£ 19,073$ \\
\hline University College London & 5 & $£ 6,370,239$ & $£ 6,252,969$ & $-£ 117,270$ \\
\hline University College London & 7 & $£ 1,271,196$ & $£ 1,277,285$ & $£ 6,089$ \\
\hline University College London & 8 & $£ 2,396,862$ & $£ 2,412,389$ & $£ 15,527$ \\
\hline University College London & 9 & $£ 3,449,228$ & $£ 3,413,753$ & $-£ 35,475$ \\
\hline University College London & 10 & $£ 2,040,955$ & $£ 1,971,060$ & $-£ 69,895$ \\
\hline University College London & 11 & $£ 3,808,294$ & $£ 3,789,219$ & $-£ 19,075$ \\
\hline University College London & 12 & $£ 1,726,239$ & $£ 1,714,940$ & $-£ 11,299$ \\
\hline University College London & 13 & $£ 1,650,901$ & $£ 1,622,652$ & $-£ 28,249$ \\
\hline University College London & 14 & $£ 693,057$ & $£ 678,510$ & $-£ 14,547$ \\
\hline University College London & 15 & $£ 2,263,907$ & $£ 2,237,352$ & $-£ 26,555$ \\
\hline University College London & 16 & $£ 4,153,756$ & $£ 4,156,256$ & $£ 2,500$ \\
\hline University College London & 17 & $£ 1,800,967$ & $£ 1,813,060$ & $£ 12,093$ \\
\hline University College London & 17 & $£ 1,264,086$ & $£ 1,282,270$ & $£ 18,184$ \\
\hline University College London & 18 & $£ 1,366,647$ & $£ 1,357,104$ & $-£ 9,543$ \\
\hline University College London & 19 & $£ 313,689$ & $£ 304,660$ & $-£ 9,029$ \\
\hline University College London & 20 & $£ 1,149,383$ & $£ 1,178,457$ & $£ 29,074$ \\
\hline University College London & 21 & $£ 695,664$ & $£ 694,463$ & $-£ 1,201$ \\
\hline University College London & 22 & $£ 241,003$ & $£ 253,597$ & $£ 12,594$ \\
\hline University College London & 24 & $£ 624,968$ & $£ 625,953$ & $£ 985$ \\
\hline University College London & 25 & $£ 5,106,613$ & $£ 5,207,259$ & $£ 100,646$ \\
\hline University College London & 25 & $£ 90,201$ & $£ 93,235$ & $£ 3,034$ \\
\hline University College London & 27 & $£ 779,414$ & $£ 812,996$ & $£ 33,582$ \\
\hline University College London & 28 & $£ 857,786$ & $£ 879,012$ & $£ 21,226$ \\
\hline
\end{tabular}




\begin{tabular}{|c|c|c|c|c|}
\hline University College London & 29 & $£ 735,518$ & $£ 733,199$ & $-£ 2,319$ \\
\hline University College London & 30 & $£ 915,070$ & $£ 912,245$ & $-£ 2,825$ \\
\hline University College London & 31 & $£ 210,557$ & $£ 212,807$ & $£ 2,250$ \\
\hline University College London & 32 & $£ 533,665$ & $£ 547,201$ & $£ 13,536$ \\
\hline University College London & 33 & $£ 141,524$ & $£ 142,009$ & $£ 485$ \\
\hline University College London & 34 & $£ 471,813$ & $£ 469,174$ & $-£ 2,639$ \\
\hline University College London & 34 & $£ 375,643$ & $£ 376,070$ & $£ 427$ \\
\hline University College London & 36 & $£ 286,894$ & $£ 288,762$ & $£ 1,868$ \\
\hline University for the Creative Arts & 34 & $£ 334,081$ & $£ 345,091$ & $£ 11,010$ \\
\hline University of Bedfordshire & 3 & $£ 622,967$ & $£ 626,405$ & $£ 3,438$ \\
\hline University of Bedfordshire & 7 & $£ 14,831$ & $£ 14,615$ & $-£ 216$ \\
\hline University of Bedfordshire & 11 & $£ 403,270$ & $£ 388,916$ & $-£ 14,354$ \\
\hline University of Bedfordshire & 19 & $£ 99,882$ & $£ 93,189$ & $-£ 6,693$ \\
\hline University of Bedfordshire & 20 & $£ 16,409$ & $£ 15,147$ & $-£ 1,262$ \\
\hline University of Bedfordshire & 22 & $£ 261,067$ & $£ 266,114$ & $£ 5,047$ \\
\hline University of Bedfordshire & 25 & $£ 77,590$ & $£ 71,622$ & $-£ 5,968$ \\
\hline University of Bedfordshire & 26 & $£ 210,994$ & $£ 197,973$ & $-£ 13,021$ \\
\hline University of Bedfordshire & 29 & $£ 201,587$ & $£ 209,650$ & $£ 8,063$ \\
\hline University of Bedfordshire & 35 & $£ 54,966$ & $£ 50,827$ & $-£ 4,139$ \\
\hline University of Bedfordshire & 36 & $£ 106,116$ & $£ 102,887$ & $-£ 3,229$ \\
\hline University of Brighton & 3 & $£ 814,711$ & $£ 838,136$ & $£ 23,425$ \\
\hline University of Brighton & 7 & $£ 181,482$ & $£ 188,662$ & $£ 7,180$ \\
\hline University of Brighton & 11 & $£ 186,886$ & $£ 194,326$ & $£ 7,440$ \\
\hline University of Brighton & 12 & $£ 158,469$ & $£ 151,448$ & $-£ 7,021$ \\
\hline University of Brighton & 19 & $£ 248,325$ & $£ 260,468$ & $£ 12,143$ \\
\hline University of Brighton & 22 & $£ 299,659$ & $£ 309,565$ & $£ 9,906$ \\
\hline University of Brighton & 25 & $£ 62,537$ & $£ 60,037$ & $-£ 2,500$ \\
\hline University of Brighton & 26 & $£ 453,234$ & $£ 452,445$ & $-£ 789$ \\
\hline University of Brighton & 34 & $£ 1,359,880$ & $£ 1,412,864$ & $£ 52,984$ \\
\hline University of Brighton & 36 & $£ 235,982$ & $£ 243,106$ & $£ 7,124$ \\
\hline University of Bristol & 1 & $£ 2,245,065$ & $£ 2,348,290$ & $£ 103,225$ \\
\hline University of Bristol & 2 & $£ 2,743,130$ & $£ 2,804,163$ & $£ 61,033$ \\
\hline University of Bristol & 3 & $£ 547,152$ & $£ 553,207$ & $£ 6,055$ \\
\hline University of Bristol & 4 & $£ 2,005,313$ & $£ 2,039,089$ & $£ 33,776$ \\
\hline University of Bristol & 5 & $£ 1,982,114$ & $£ 1,937,930$ & $-£ 44,184$ \\
\hline University of Bristol & 6 & $£ 1,079,392$ & $£ 1,094,097$ & $£ 14,705$ \\
\hline University of Bristol & 7 & $£ 1,800,271$ & $£ 1,767,410$ & $-£ 32,861$ \\
\hline University of Bristol & 8 & $£ 2,405,488$ & $£ 2,391,562$ & $-£ 13,926$ \\
\hline University of Bristol & 9 & $£ 1,321,946$ & $£ 1,304,413$ & $-£ 17,533$ \\
\hline University of Bristol & 10 & $£ 3,391,260$ & $£ 3,417,189$ & $£ 25,929$ \\
\hline University of Bristol & 11 & $£ 1,439,529$ & $£ 1,453,279$ & $£ 13,750$ \\
\hline University of Bristol & 15 & $£ 4,814,466$ & $£ 4,871,641$ & $£ 57,175$ \\
\hline University of Bristol & 17 & $£ 1,682,908$ & $£ 1,682,348$ & $-£ 560$ \\
\hline University of Bristol & 17 & $£ 62,644$ & $£ 58,789$ & $-£ 3,855$ \\
\hline University of Bristol & 18 & $£ 426,813$ & $£ 442,686$ & $£ 15,873$ \\
\hline University of Bristol & 19 & $£ 444,011$ & $£ 461,625$ & $£ 17,614$ \\
\hline University of Bristol & 20 & $£ 860,775$ & $£ 876,302$ & $£ 15,527$ \\
\hline University of Bristol & 21 & $£ 304,091$ & $£ 304,426$ & $£ 335$ \\
\hline
\end{tabular}




\begin{tabular}{|c|c|c|c|c|}
\hline University of Bristol & 22 & $£ 756,800$ & $£ 756,240$ & $-£ 560$ \\
\hline University of Bristol & 23 & $£ 311,243$ & $£ 319,000$ & $£ 7,757$ \\
\hline University of Bristol & 25 & $£ 782,284$ & $£ 786,123$ & $£ 3,839$ \\
\hline University of Bristol & 26 & $£ 278,456$ & $£ 279,848$ & $£ 1,392$ \\
\hline University of Bristol & 28 & $£ 505,424$ & $£ 495,699$ & $-£ 9,725$ \\
\hline University of Bristol & 29 & $£ 232,805$ & $£ 227,540$ & $-£ 5,265$ \\
\hline University of Bristol & 30 & $£ 298,258$ & $£ 287,354$ & $-£ 10,904$ \\
\hline University of Bristol & 31 & $£ 269,454$ & $£ 262,793$ & $-£ 6,661$ \\
\hline University of Bristol & 32 & $£ 265,399$ & $£ 263,744$ & $-£ 1,655$ \\
\hline University of Bristol & 33 & $£ 123,902$ & $£ 118,311$ & $-£ 5,591$ \\
\hline University of Bristol & 34 & $£ 107,855$ & $£ 109,238$ & $£ 1,383$ \\
\hline University of Bristol & 35 & $£ 317,130$ & $£ 324,780$ & $£ 7,650$ \\
\hline University of Bristol & 35 & $£ 222,745$ & $£ 219,690$ & $-£ 3,055$ \\
\hline University of Cambridge & 1 & $£ 8,179,134$ & $£ 8,170,078$ & $-£ 9,056$ \\
\hline University of Cambridge & 2 & $£ 2,404,324$ & $£ 2,330,395$ & $-£ 73,929$ \\
\hline University of Cambridge & 4 & $£ 3,003,284$ & $£ 2,971,654$ & $-£ 31,630$ \\
\hline University of Cambridge & 5 & $£ 7,576,690$ & $£ 7,544,540$ & $-£ 32,150$ \\
\hline University of Cambridge & 6 & $£ 1,282,562$ & $£ 1,280,708$ & $-£ 1,854$ \\
\hline University of Cambridge & 7 & $£ 1,775,225$ & $£ 1,764,760$ & $-£ 10,465$ \\
\hline University of Cambridge & 8 & $£ 3,268,947$ & $£ 3,236,041$ & $-£ 32,906$ \\
\hline University of Cambridge & 9 & $£ 5,942,527$ & $£ 5,920,482$ & $-£ 22,045$ \\
\hline University of Cambridge & 10 & $£ 6,367,522$ & $£ 6,276,768$ & $-£ 90,754$ \\
\hline University of Cambridge & 11 & $£ 2,452,186$ & $£ 2,474,594$ & $£ 22,408$ \\
\hline University of Cambridge & 12 & $£ 1,486,251$ & $£ 1,461,182$ & $-£ 25,069$ \\
\hline University of Cambridge & 13 & $£ 1,984,020$ & $£ 1,963,949$ & $-£ 20,071$ \\
\hline University of Cambridge & 15 & $£ 8,574,081$ & $£ 8,547,813$ & $-£ 26,268$ \\
\hline University of Cambridge & 16 & $£ 1,307,765$ & $£ 1,313,676$ & $£ 5,911$ \\
\hline University of Cambridge & 17 & $£ 1,148,087$ & $£ 1,158,410$ & $£ 10,323$ \\
\hline University of Cambridge & 17 & $£ 1,512,554$ & $£ 1,523,405$ & $£ 10,851$ \\
\hline University of Cambridge & 18 & $£ 737,982$ & $£ 724,270$ & $-£ 13,712$ \\
\hline University of Cambridge & 19 & $£ 1,126,919$ & $£ 1,135,553$ & $£ 8,634$ \\
\hline University of Cambridge & 20 & $£ 1,801,318$ & $£ 1,806,059$ & $£ 4,741$ \\
\hline University of Cambridge & 21 & $£ 546,729$ & $£ 545,312$ & $-£ 1,417$ \\
\hline University of Cambridge & 23 & $£ 271,701$ & $£ 273,135$ & $£ 1,434$ \\
\hline University of Cambridge & 24 & $£ 639,348$ & $£ 650,139$ & $£ 10,791$ \\
\hline University of Cambridge & 25 & $£ 876,401$ & $£ 887,126$ & $£ 10,725$ \\
\hline University of Cambridge & 27 & $£ 562,271$ & $£ 556,238$ & $-£ 6,033$ \\
\hline University of Cambridge & 28 & $£ 2,081,317$ & $£ 2,066,362$ & $-£ 14,955$ \\
\hline University of Cambridge & 29 & $£ 1,339,343$ & $£ 1,295,362$ & $-£ 43,981$ \\
\hline University of Cambridge & 30 & $£ 2,593,755$ & $£ 2,595,551$ & $£ 1,796$ \\
\hline University of Cambridge & 31 & $£ 1,005,378$ & $£ 1,014,029$ & $£ 8,651$ \\
\hline University of Cambridge & 32 & $£ 325,656$ & $£ 318,561$ & $-£ 7,095$ \\
\hline University of Cambridge & 32 & $£ 748,245$ & $£ 768,651$ & $£ 20,406$ \\
\hline University of Cambridge & 33 & $£ 463,631$ & $£ 474,542$ & $£ 10,911$ \\
\hline University of Cambridge & 35 & $£ 551,658$ & $£ 533,495$ & $-£ 18,163$ \\
\hline University of Central Lancashire & 3 & $£ 792,071$ & $£ 786,940$ & $-£ 5,131$ \\
\hline University of Central Lancashire & 4 & $£ 225,559$ & $£ 238,303$ & $£ 12,744$ \\
\hline University of Central Lancashire & 9 & $£ 348,658$ & $£ 333,144$ & $-£ 15,514$ \\
\hline
\end{tabular}




\begin{tabular}{|c|c|c|c|c|}
\hline University of Central Lancashire & 13 & $£ 84,045$ & $£ 77,715$ & $-£ 6,330$ \\
\hline University of Central Lancashire & 15 & $£ 183,256$ & $£ 170,430$ & $-£ 12,826$ \\
\hline University of Central Lancashire & 16 & $£ 65,336$ & $£ 60,630$ & $-£ 4,706$ \\
\hline University of Central Lancashire & 17 & $£ 52,683$ & $£ 48,763$ & $-£ 3,920$ \\
\hline University of Central Lancashire & 19 & $£ 84,615$ & $£ 91,221$ & $£ 6,606$ \\
\hline University of Central Lancashire & 20 & $£ 61,416$ & $£ 61,182$ & $-£ 234$ \\
\hline University of Central Lancashire & 22 & $£ 236,178$ & $£ 240,081$ & $£ 3,903$ \\
\hline University of Central Lancashire & 26 & $£ 188,154$ & $£ 177,342$ & $-£ 10,812$ \\
\hline University of Central Lancashire & 28 & $£ 146,826$ & $£ 143,230$ & $-£ 3,596$ \\
\hline University of Central Lancashire & 29 & $£ 65,721$ & $£ 64,784$ & $-£ 937$ \\
\hline University of Central Lancashire & 30 & $£ 67,554$ & $£ 65,690$ & $-£ 1,864$ \\
\hline University of Central Lancashire & 34 & $£ 116,320$ & $£ 120,942$ & $£ 4,622$ \\
\hline University of Central Lancashire & 36 & $£ 125,581$ & $£ 120,262$ & $-£ 5,319$ \\
\hline University of Chester & 3 & $£ 199,608$ & $£ 201,235$ & $£ 1,627$ \\
\hline University of Chester & 4 & $£ 118,138$ & $£ 127,453$ & $£ 9,315$ \\
\hline University of Chester & 10 & $£ 38,172$ & $£ 35,886$ & $-£ 2,286$ \\
\hline University of Chester & 11 & $£ 4,252$ & $£ 3,925$ & $-£ 327$ \\
\hline University of Chester & 17 & $£ 66,038$ & $£ 60,958$ & $-£ 5,080$ \\
\hline University of Chester & 17 & $£ 48,688$ & $£ 44,943$ & $-£ 3,745$ \\
\hline University of Chester & 19 & $£ 10,622$ & $£ 9,805$ & $-£ 817$ \\
\hline University of Chester & 22 & $£ 2,295$ & $£ 2,118$ & $-£ 177$ \\
\hline University of Chester & 25 & $£ 38,726$ & $£ 35,747$ & $-£ 2,979$ \\
\hline University of Chester & 26 & $£ 71,499$ & $£ 70,360$ & $-£ 1,139$ \\
\hline University of Chester & 27 & $£ 55,323$ & $£ 54,091$ & $-£ 1,232$ \\
\hline University of Chester & 29 & $£ 91,274$ & $£ 85,605$ & $-£ 5,669$ \\
\hline University of Chester & 30 & $£ 31,017$ & $£ 29,737$ & $-£ 1,280$ \\
\hline University of Chester & 33 & $£ 75,034$ & $£ 70,502$ & $-£ 4,532$ \\
\hline University of Chester & 34 & $£ 51,248$ & $£ 47,306$ & $-£ 3,942$ \\
\hline University of Chester & 35 & $£ 41,674$ & $£ 42,830$ & $£ 1,156$ \\
\hline University of Derby & 4 & $£ 131,935$ & $£ 141,562$ & $£ 9,627$ \\
\hline University of Derby & 5 & $£ 21,447$ & $£ 19,797$ & $-£ 1,650$ \\
\hline University of Derby & 7 & $£ 41,426$ & $£ 38,239$ & $-£ 3,187$ \\
\hline University of Derby & 11 & $£ 92,175$ & $£ 85,085$ & $-£ 7,090$ \\
\hline University of Derby & 15 & $£ 52,502$ & $£ 53,473$ & $£ 971$ \\
\hline University of Derby & 19 & $£ 26,628$ & $£ 29,070$ & $£ 2,442$ \\
\hline University of Derby & 20 & $£ 22,137$ & $£ 21,388$ & $-£ 749$ \\
\hline University of Derby & 25 & $£ 44,505$ & $£ 41,082$ & $-£ 3,423$ \\
\hline University of Derby & 34 & $£ 79,482$ & $£ 80,573$ & $£ 1,091$ \\
\hline University of Derby & 36 & $£ 183,699$ & $£ 178,450$ & $-£ 5,249$ \\
\hline University of Durham & 4 & $£ 573,658$ & $£ 576,644$ & $£ 2,986$ \\
\hline University of Durham & 5 & $£ 933,828$ & $£ 958,710$ & $£ 24,882$ \\
\hline University of Durham & 7 & $£ 1,120,297$ & $£ 1,134,931$ & $£ 14,634$ \\
\hline University of Durham & 8 & $£ 1,573,951$ & $£ 1,595,896$ & $£ 21,945$ \\
\hline University of Durham & 9 & $£ 2,722,069$ & $£ 2,705,857$ & $-£ 16,212$ \\
\hline University of Durham & 10 & $£ 1,571,489$ & $£ 1,607,043$ & $£ 35,554$ \\
\hline University of Durham & 11 & $£ 408,412$ & $£ 402,645$ & $-£ 5,767$ \\
\hline University of Durham & 15 & $£ 908,444$ & $£ 944,975$ & $£ 36,531$ \\
\hline University of Durham & 17 & $£ 709,471$ & $£ 707,576$ & $-£ 1,895$ \\
\hline
\end{tabular}




\begin{tabular}{|c|c|c|c|c|}
\hline University of Durham & 17 & $£ 1,996,693$ & $£ 2,004,870$ & $£ 8,177$ \\
\hline University of Durham & 19 & $£ 801,390$ & $£ 787,884$ & $-£ 13,506$ \\
\hline University of Durham & 20 & $£ 572,031$ & $£ 583,156$ & $£ 11,125$ \\
\hline University of Durham & 21 & $£ 342,073$ & $£ 347,045$ & $£ 4,972$ \\
\hline University of Durham & 22 & $£ 375,123$ & $£ 372,651$ & $-£ 2,472$ \\
\hline University of Durham & 24 & $£ 447,169$ & $£ 453,668$ & $£ 6,499$ \\
\hline University of Durham & 25 & $£ 588,345$ & $£ 609,068$ & $£ 20,723$ \\
\hline University of Durham & 28 & $£ 553,097$ & $£ 549,108$ & $-£ 3,989$ \\
\hline University of Durham & 29 & $£ 886,102$ & $£ 886,036$ & $-£ 66$ \\
\hline University of Durham & 30 & $£ 592,738$ & $£ 596,053$ & $£ 3,315$ \\
\hline University of Durham & 31 & $£ 325,163$ & $£ 326,392$ & $£ 1,229$ \\
\hline University of Durham & 32 & $£ 253,948$ & $£ 252,833$ & $-£ 1,115$ \\
\hline University of Durham & 33 & $£ 609,816$ & $£ 621,692$ & $£ 11,876$ \\
\hline University of Durham & 35 & $£ 510,367$ & $£ 517,616$ & $£ 7,249$ \\
\hline University of East London & 3 & $£ 382,768$ & $£ 373,432$ & $-£ 9,336$ \\
\hline University of East London & 4 & $£ 281,363$ & $£ 300,938$ & $£ 19,575$ \\
\hline University of East London & 11 & $£ 45,039$ & $£ 41,574$ & $-£ 3,465$ \\
\hline University of East London & 15 & $£ 66,804$ & $£ 61,665$ & $-£ 5,139$ \\
\hline University of East London & 16 & $£ 83,952$ & $£ 79,633$ & $-£ 4,319$ \\
\hline University of East London & 19 & $£ 15,207$ & $£ 15,743$ & $£ 536$ \\
\hline University of East London & 20 & $£ 92,921$ & $£ 93,070$ & $£ 149$ \\
\hline University of East London & 22 & $£ 86,773$ & $£ 88,280$ & $£ 1,507$ \\
\hline University of East London & 23 & $£ 235,338$ & $£ 244,728$ & $£ 9,390$ \\
\hline University of East London & 25 & $£ 84,978$ & $£ 83,059$ & $-£ 1,919$ \\
\hline University of East London & 34 & $£ 155,264$ & $£ 147,213$ & $-£ 8,051$ \\
\hline University of East London & 35 & $£ 99,749$ & $£ 105,775$ & $£ 6,026$ \\
\hline University of East London & 36 & $£ 284,211$ & $£ 281,365$ & $-£ 2,846$ \\
\hline University of Exeter & 1 & $£ 839,737$ & $£ 842,549$ & $£ 2,812$ \\
\hline University of Exeter & 2 & $£ 648,532$ & $£ 648,229$ & $-£ 303$ \\
\hline University of Exeter & 4 & $£ 966,502$ & $£ 947,885$ & $-£ 18,617$ \\
\hline University of Exeter & 5 & $£ 1,644,995$ & $£ 1,634,383$ & $-£ 10,612$ \\
\hline University of Exeter & 7 & $£ 1,103,452$ & $£ 1,084,045$ & $-£ 19,407$ \\
\hline University of Exeter & 9 & $£ 1,271,721$ & $£ 1,249,265$ & $-£ 22,456$ \\
\hline University of Exeter & 10 & $£ 926,183$ & $£ 919,184$ & $-£ 6,999$ \\
\hline University of Exeter & 11 & $£ 306,400$ & $£ 294,186$ & $-£ 12,214$ \\
\hline University of Exeter & 15 & $£ 1,475,981$ & $£ 1,451,664$ & $-£ 24,317$ \\
\hline University of Exeter & 17 & $£ 1,359,340$ & $£ 1,325,223$ & $-£ 34,117$ \\
\hline University of Exeter & 17 & $£ 257,462$ & $£ 267,005$ & $£ 9,543$ \\
\hline University of Exeter & 18 & $£ 319,839$ & $£ 315,063$ & $-£ 4,776$ \\
\hline University of Exeter & 19 & $£ 694,347$ & $£ 691,217$ & $-£ 3,130$ \\
\hline University of Exeter & 20 & $£ 252,420$ & $£ 253,299$ & $£ 879$ \\
\hline University of Exeter & 21 & $£ 455,173$ & $£ 457,222$ & $£ 2,049$ \\
\hline University of Exeter & 23 & $£ 385,144$ & $£ 388,463$ & $£ 3,319$ \\
\hline University of Exeter & 25 & $£ 610,367$ & $£ 599,962$ & $-£ 10,405$ \\
\hline University of Exeter & 26 & $£ 631,225$ & $£ 634,978$ & $£ 3,753$ \\
\hline University of Exeter & 27 & $£ 325,595$ & $£ 339,944$ & $£ 14,349$ \\
\hline University of Exeter & 28 & $£ 527,710$ & $£ 514,790$ & $-£ 12,920$ \\
\hline University of Exeter & 29 & $£ 1,016,666$ & $£ 1,025,361$ & $£ 8,695$ \\
\hline
\end{tabular}




\begin{tabular}{|c|c|c|c|c|}
\hline University of Exeter & 30 & $£ 937,076$ & $£ 930,001$ & $-£ 7,075$ \\
\hline University of Exeter & 31 & $£ 329,163$ & $£ 332,753$ & $£ 3,590$ \\
\hline University of Exeter & 33 & $£ 174,892$ & $£ 174,253$ & $-£ 639$ \\
\hline University of Exeter & 35 & $£ 367,144$ & $£ 368,349$ & $£ 1,205$ \\
\hline University of Gloucestershire & 16 & $£ 170,611$ & $£ 161,522$ & $-£ 9,089$ \\
\hline University of Gloucestershire & 17 & $£ 104,250$ & $£ 98,164$ & $-£ 6,086$ \\
\hline University of Gloucestershire & 26 & $£ 215,627$ & $£ 228,397$ & $£ 12,770$ \\
\hline University of Gloucestershire & 29 & $£ 48,334$ & $£ 46,853$ & $-£ 1,481$ \\
\hline University of Gloucestershire & 30 & $£ 21,479$ & $£ 20,417$ & $-£ 1,062$ \\
\hline University of Gloucestershire & 33 & $£ 24,045$ & $£ 23,605$ & $-£ 440$ \\
\hline University of Greenwich & 3 & $£ 56,133$ & $£ 53,192$ & $-£ 2,941$ \\
\hline University of Greenwich & 3 & $£ 135,206$ & $£ 128,519$ & $-£ 6,687$ \\
\hline University of Greenwich & 4 & $£ 110,028$ & $£ 103,144$ & $-£ 6,884$ \\
\hline University of Greenwich & 6 & $£ 406,125$ & $£ 444,185$ & $£ 38,060$ \\
\hline University of Greenwich & 8 & $£ 169,138$ & $£ 167,226$ & $-£ 1,912$ \\
\hline University of Greenwich & 10 & $£ 67,580$ & $£ 62,863$ & $-£ 4,717$ \\
\hline University of Greenwich & 11 & $£ 190,544$ & $£ 192,303$ & $£ 1,759$ \\
\hline University of Greenwich & 12 & $£ 227,676$ & $£ 227,016$ & $-£ 660$ \\
\hline University of Greenwich & 13 & $£ 181,000$ & $£ 169,389$ & $-£ 11,611$ \\
\hline University of Greenwich & 15 & $£ 138,825$ & $£ 152,424$ & $£ 13,599$ \\
\hline University of Greenwich & 16 & $£ 46,119$ & $£ 42,765$ & $-£ 3,354$ \\
\hline University of Greenwich & 19 & $£ 186,095$ & $£ 190,549$ & $£ 4,454$ \\
\hline University of Greenwich & 20 & $£ 23,211$ & $£ 21,426$ & $-£ 1,785$ \\
\hline University of Greenwich & 24 & $£ 57,299$ & $£ 61,982$ & $£ 4,683$ \\
\hline University of Greenwich & 25 & $£ 30,080$ & $£ 27,766$ & $-£ 2,314$ \\
\hline University of Greenwich & 28 & $£ 16,857$ & $£ 15,959$ & $-£ 898$ \\
\hline University of Greenwich & 29 & $£ 66,255$ & $£ 64,108$ & $-£ 2,147$ \\
\hline University of Greenwich & 30 & $£ 38,837$ & $£ 37,010$ & $-£ 1,827$ \\
\hline University of Greenwich & 34 & $£ 49,647$ & $£ 45,828$ & $-£ 3,819$ \\
\hline University of Hertfordshire & 3 & $£ 345,653$ & $£ 333,463$ & $-£ 12,190$ \\
\hline University of Hertfordshire & 3 & $£ 358,226$ & $£ 360,193$ & $£ 1,967$ \\
\hline University of Hertfordshire & 4 & $£ 123,067$ & $£ 125,147$ & $£ 2,080$ \\
\hline University of Hertfordshire & 6 & $£ 174,490$ & $£ 161,468$ & $-£ 13,022$ \\
\hline University of Hertfordshire & 9 & $£ 586,675$ & $£ 560,101$ & $-£ 26,574$ \\
\hline University of Hertfordshire & 11 & $£ 395,913$ & $£ 387,730$ & $-£ 8,183$ \\
\hline University of Hertfordshire & 15 & $£ 188,874$ & $£ 176,020$ & $-£ 12,854$ \\
\hline University of Hertfordshire & 19 & $£ 62,174$ & $£ 57,391$ & $-£ 4,783$ \\
\hline University of Hertfordshire & 29 & $£ 75,742$ & $£ 73,357$ & $-£ 2,385$ \\
\hline University of Hertfordshire & 30 & $£ 276,086$ & $£ 287,361$ & $£ 11,275$ \\
\hline University of Hertfordshire & 32 & $£ 126,493$ & $£ 127,738$ & $£ 1,245$ \\
\hline University of Hertfordshire & 34 & $£ 120,326$ & $£ 115,477$ & $-£ 4,849$ \\
\hline University of Hertfordshire & 35 & $£ 26,306$ & $£ 29,009$ & $£ 2,703$ \\
\hline University of Keele & 2 & $£ 296,490$ & $£ 302,241$ & $£ 5,751$ \\
\hline University of Keele & 3 & $£ 1,544,127$ & $£ 1,553,645$ & $£ 9,518$ \\
\hline University of Keele & 4 & $£ 163,540$ & $£ 169,104$ & $£ 5,564$ \\
\hline University of Keele & 5 & $£ 149,584$ & $£ 155,560$ & $£ 5,976$ \\
\hline University of Keele & 7 & $£ 127,320$ & $£ 125,989$ & $-£ 1,331$ \\
\hline University of Keele & 9 & $£ 266,680$ & $£ 250,920$ & $-£ 15,760$ \\
\hline
\end{tabular}




\begin{tabular}{|c|c|c|c|c|}
\hline University of Keele & 10 & $£ 184,288$ & $£ 174,842$ & $-£ 9,446$ \\
\hline University of Keele & 11 & $£ 58,974$ & $£ 56,364$ & $-£ 2,610$ \\
\hline University of Keele & 15 & $£ 994,806$ & $£ 975,940$ & $-£ 18,866$ \\
\hline University of Keele & 19 & $£ 137,386$ & $£ 131,417$ & $-£ 5,969$ \\
\hline University of Keele & 20 & $£ 277,048$ & $£ 282,074$ & $£ 5,026$ \\
\hline University of Keele & 21 & $£ 185,412$ & $£ 196,770$ & $£ 11,358$ \\
\hline University of Keele & 22 & $£ 391,596$ & $£ 389,041$ & $-£ 2,555$ \\
\hline University of Keele & 29 & $£ 186,205$ & $£ 179,973$ & $-£ 6,232$ \\
\hline University of Keele & 30 & $£ 204,744$ & $£ 198,331$ & $-£ 6,413$ \\
\hline University of Keele & 32 & $£ 42,149$ & $£ 47,505$ & $£ 5,356$ \\
\hline University of Keele & 35 & $£ 173,888$ & $£ 173,479$ & $-£ 409$ \\
\hline University of Lincoln & 3 & $£ 562,726$ & $£ 550,971$ & $-£ 11,755$ \\
\hline University of Lincoln & 4 & $£ 135,408$ & $£ 140,813$ & $£ 5,405$ \\
\hline University of Lincoln & 6 & $£ 439,809$ & $£ 426,441$ & $-£ 13,368$ \\
\hline University of Lincoln & 11 & $£ 243,164$ & $£ 224,459$ & $-£ 18,705$ \\
\hline University of Lincoln & 15 & $£ 198,126$ & $£ 186,556$ & $-£ 11,570$ \\
\hline University of Lincoln & 16 & $£ 34,378$ & $£ 31,934$ & $-£ 2,444$ \\
\hline University of Lincoln & 19 & $£ 95,499$ & $£ 98,569$ & $£ 3,070$ \\
\hline University of Lincoln & 20 & $£ 20,034$ & $£ 20,067$ & $£ 33$ \\
\hline University of Lincoln & 21 & $£ 35,986$ & $£ 33,734$ & $-£ 2,252$ \\
\hline University of Lincoln & 22 & $£ 80,180$ & $£ 74,805$ & $-£ 5,375$ \\
\hline University of Lincoln & 25 & $£ 58,965$ & $£ 58,442$ & $-£ 523$ \\
\hline University of Lincoln & 26 & $£ 94,687$ & $£ 90,170$ & $-£ 4,517$ \\
\hline University of Lincoln & 29 & $£ 86,719$ & $£ 83,084$ & $-£ 3,635$ \\
\hline University of Lincoln & 30 & $£ 163,976$ & $£ 154,287$ & $-£ 9,689$ \\
\hline University of Lincoln & 34 & $£ 178,323$ & $£ 180,969$ & $£ 2,646$ \\
\hline University of Lincoln & 35 & $£ 64,437$ & $£ 60,668$ & $-£ 3,769$ \\
\hline University of Lincoln & 36 & $£ 69,668$ & $£ 68,757$ & $-£ 911$ \\
\hline University of London Institute in Paris & 28 & $£ 7,668$ & $£ 7,078$ & $-£ 590$ \\
\hline University of Newcastle upon Tyne & 1 & $£ 4,551,691$ & $£ 4,637,498$ & $£ 85,807$ \\
\hline University of Newcastle upon Tyne & 2 & $£ 643,462$ & $£ 649,686$ & $£ 6,224$ \\
\hline University of Newcastle upon Tyne & 3 & $£ 633,272$ & $£ 642,071$ & $£ 8,799$ \\
\hline University of Newcastle upon Tyne & 4 & $£ 1,739,098$ & $£ 1,758,125$ & $£ 19,027$ \\
\hline University of Newcastle upon Tyne & 5 & $£ 1,275,981$ & $£ 1,249,155$ & $-£ 26,826$ \\
\hline University of Newcastle upon Tyne & 6 & $£ 533,600$ & $£ 528,816$ & $-£ 4,784$ \\
\hline University of Newcastle upon Tyne & 7 & $£ 732,953$ & $£ 756,532$ & $£ 23,579$ \\
\hline University of Newcastle upon Tyne & 8 & $£ 503,729$ & $£ 510,028$ & $£ 6,299$ \\
\hline University of Newcastle upon Tyne & 10 & $£ 702,236$ & $£ 701,800$ & $-£ 436$ \\
\hline University of Newcastle upon Tyne & 11 & $£ 1,133,840$ & $£ 1,159,706$ & $£ 25,866$ \\
\hline University of Newcastle upon Tyne & 12 & $£ 1,270,400$ & $£ 1,240,798$ & $-£ 29,602$ \\
\hline University of Newcastle upon Tyne & 13 & $£ 1,052,491$ & $£ 1,037,840$ & $-£ 14,651$ \\
\hline University of Newcastle upon Tyne & 14 & $£ 1,375,333$ & $£ 1,377,090$ & $£ 1,757$ \\
\hline University of Newcastle upon Tyne & 16 & $£ 988,695$ & $£ 997,764$ & $£ 9,069$ \\
\hline University of Newcastle upon Tyne & 17 & $£ 156,964$ & $£ 149,868$ & $-£ 7,096$ \\
\hline University of Newcastle upon Tyne & 17 & $£ 814,811$ & $£ 825,884$ & $£ 11,073$ \\
\hline University of Newcastle upon Tyne & 19 & $£ 750,441$ & $£ 743,314$ & $-£ 7,127$ \\
\hline University of Newcastle upon Tyne & 20 & $£ 275,809$ & $£ 265,291$ & $-£ 10,518$ \\
\hline University of Newcastle upon Tyne & 21 & $£ 213,611$ & $£ 207,855$ & $-£ 5,756$ \\
\hline
\end{tabular}




\begin{tabular}{|c|c|c|c|c|}
\hline University of Newcastle upon Tyne & 23 & $£ 285,704$ & $£ 291,483$ & $£ 5,779$ \\
\hline University of Newcastle upon Tyne & 25 & $£ 247,840$ & $£ 248,598$ & $£ 758$ \\
\hline University of Newcastle upon Tyne & 28 & $£ 942,370$ & $£ 963,348$ & $£ 20,978$ \\
\hline University of Newcastle upon Tyne & 29 & $£ 870,671$ & $£ 893,573$ & $£ 22,902$ \\
\hline University of Newcastle upon Tyne & 30 & $£ 335,638$ & $£ 317,880$ & $-£ 17,758$ \\
\hline University of Newcastle upon Tyne & 31 & $£ 181,762$ & $£ 180,407$ & $-£ 1,355$ \\
\hline University of Newcastle upon Tyne & 34 & $£ 359,553$ & $£ 350,454$ & $-£ 9,099$ \\
\hline University of Newcastle upon Tyne & 35 & $£ 344,664$ & $£ 333,461$ & $-£ 11,203$ \\
\hline University of Newcastle upon Tyne & 36 & $£ 315,053$ & $£ 315,573$ & $£ 520$ \\
\hline University of Northumbria at Newcastle & 3 & $£ 1,238,836$ & $£ 1,251,804$ & $£ 12,968$ \\
\hline University of Northumbria at Newcastle & 4 & $£ 314,149$ & $£ 333,856$ & $£ 19,707$ \\
\hline University of Northumbria at Newcastle & 10 & $£ 197,518$ & $£ 187,196$ & $-£ 10,322$ \\
\hline University of Northumbria at Newcastle & 11 & $£ 177,398$ & $£ 166,257$ & $-£ 11,141$ \\
\hline University of Northumbria at Newcastle & 15 & $£ 514,509$ & $£ 485,389$ & $-£ 29,120$ \\
\hline University of Northumbria at Newcastle & 16 & $£ 199,374$ & $£ 202,212$ & $£ 2,838$ \\
\hline University of Northumbria at Newcastle & 17 & $£ 232,340$ & $£ 224,402$ & $-£ 7,938$ \\
\hline University of Northumbria at Newcastle & 19 & $£ 193,199$ & $£ 202,506$ & $£ 9,307$ \\
\hline University of Northumbria at Newcastle & 20 & $£ 89,840$ & $£ 86,007$ & $-£ 3,833$ \\
\hline University of Northumbria at Newcastle & 22 & $£ 231,304$ & $£ 222,930$ & $-£ 8,374$ \\
\hline University of Northumbria at Newcastle & 26 & $£ 88,125$ & $£ 84,330$ & $-£ 3,795$ \\
\hline University of Northumbria at Newcastle & 29 & $£ 488,125$ & $£ 462,695$ & $-£ 25,430$ \\
\hline University of Northumbria at Newcastle & 30 & $£ 313,384$ & $£ 296,604$ & $-£ 16,780$ \\
\hline University of Northumbria at Newcastle & 34 & $£ 768,945$ & $£ 770,566$ & $£ 1,621$ \\
\hline University of Northumbria at Newcastle & 36 & $£ 223,788$ & $£ 214,870$ & $-£ 8,918$ \\
\hline University of Northumbria at Newcastle & 36 & $£ 55,754$ & $£ 55,930$ & $£ 176$ \\
\hline University of Oxford & 1 & $£ 9,699,827$ & $£ 9,726,023$ & $£ 26,196$ \\
\hline University of Oxford & 2 & $£ 2,064,913$ & $£ 2,064,013$ & $-£ 900$ \\
\hline University of Oxford & 4 & $£ 4,349,133$ & $£ 4,303,364$ & $-£ 45,769$ \\
\hline University of Oxford & 5 & $£ 8,724,276$ & $£ 8,644,250$ & $-£ 80,026$ \\
\hline University of Oxford & 7 & $£ 1,618,683$ & $£ 1,565,352$ & $-£ 53,331$ \\
\hline University of Oxford & 8 & $£ 3,965,768$ & $£ 3,921,472$ & $-£ 44,296$ \\
\hline University of Oxford & 9 & $£ 5,311,767$ & $£ 5,228,962$ & $-£ 82,805$ \\
\hline University of Oxford & 10 & $£ 7,717,641$ & $£ 7,743,086$ & $£ 25,445$ \\
\hline University of Oxford & 11 & $£ 3,584,633$ & $£ 3,531,388$ & $-£ 53,245$ \\
\hline University of Oxford & 13 & $£ 1,821,085$ & $£ 1,822,171$ & $£ 1,086$ \\
\hline University of Oxford & 15 & $£ 4,687,968$ & $£ 4,697,898$ & $£ 9,930$ \\
\hline University of Oxford & 17 & $£ 1,043,617$ & $£ 1,041,572$ & $-£ 2,045$ \\
\hline University of Oxford & 17 & $£ 1,679,363$ & $£ 1,667,930$ & $-£ 11,433$ \\
\hline University of Oxford & 18 & $£ 2,328,137$ & $£ 2,319,356$ & $-£ 8,781$ \\
\hline University of Oxford & 19 & $£ 1,108,269$ & $£ 1,093,181$ & $-£ 15,088$ \\
\hline University of Oxford & 20 & $£ 2,375,603$ & $£ 2,401,573$ & $£ 25,970$ \\
\hline University of Oxford & 21 & $£ 1,944,496$ & $£ 1,986,362$ & $£ 41,866$ \\
\hline University of Oxford & 22 & $£ 995,989$ & $£ 994,185$ & $-£ 1,804$ \\
\hline University of Oxford & 23 & $£ 672,776$ & $£ 682,137$ & $£ 9,361$ \\
\hline University of Oxford & 24 & $£ 816,871$ & $£ 829,993$ & $£ 13,122$ \\
\hline University of Oxford & 24 & $£ 926,420$ & $£ 941,058$ & $£ 14,638$ \\
\hline University of Oxford & 25 & $£ 1,216,550$ & $£ 1,219,073$ & $£ 2,523$ \\
\hline University of Oxford & 27 & $£ 1,398,393$ & $£ 1,393,181$ & $-£ 5,212$ \\
\hline
\end{tabular}




\begin{tabular}{|c|c|c|c|c|}
\hline University of Oxford & 28 & $£ 1,932,911$ & $£ 1,903,000$ & $-£ 29,911$ \\
\hline University of Oxford & 29 & $£ 1,889,427$ & $£ 1,927,802$ & $£ 38,375$ \\
\hline University of Oxford & 30 & $£ 2,978,251$ & $£ 2,976,794$ & $-£ 1,457$ \\
\hline University of Oxford & 31 & $£ 1,599,428$ & $£ 1,622,204$ & $£ 22,776$ \\
\hline University of Oxford & 32 & $£ 1,773,696$ & $£ 1,775,939$ & $£ 2,243$ \\
\hline University of Oxford & 33 & $£ 627,577$ & $£ 620,403$ & $-£ 7,174$ \\
\hline University of Oxford & 34 & $£ 178,490$ & $£ 177,061$ & $-£ 1,429$ \\
\hline University of Oxford & 35 & $£ 713,058$ & $£ 702,784$ & $-£ 10,274$ \\
\hline University of Plymouth & 1 & $£ 519,672$ & $£ 501,513$ & $-£ 18,159$ \\
\hline University of Plymouth & 3 & $£ 666,502$ & $£ 636,249$ & $-£ 30,253$ \\
\hline University of Plymouth & 4 & $£ 687,534$ & $£ 680,717$ & $-£ 6,817$ \\
\hline University of Plymouth & 6 & $£ 373,757$ & $£ 381,368$ & $£ 7,611$ \\
\hline University of Plymouth & 7 & $£ 1,142,542$ & $£ 1,125,080$ & $-£ 17,462$ \\
\hline University of Plymouth & 10 & $£ 233,075$ & $£ 219,672$ & $-£ 13,403$ \\
\hline University of Plymouth & 11 & $£ 328,357$ & $£ 316,612$ & $-£ 11,745$ \\
\hline University of Plymouth & 13 & $£ 155,753$ & $£ 169,227$ & $£ 13,474$ \\
\hline University of Plymouth & 15 & $£ 321,933$ & $£ 309,252$ & $-£ 12,681$ \\
\hline University of Plymouth & 16 & $£ 136,891$ & $£ 126,988$ & $-£ 9,903$ \\
\hline University of Plymouth & 17 & $£ 544,943$ & $£ 548,180$ & $£ 3,237$ \\
\hline University of Plymouth & 19 & $£ 268,393$ & $£ 261,989$ & $-£ 6,404$ \\
\hline University of Plymouth & 22 & $£ 278,042$ & $£ 279,253$ & $£ 1,211$ \\
\hline University of Plymouth & 25 & $£ 221,546$ & $£ 214,855$ & $-£ 6,691$ \\
\hline University of Plymouth & 29 & $£ 153,050$ & $£ 143,630$ & $-£ 9,420$ \\
\hline University of Plymouth & 30 & $£ 102,774$ & $£ 98,346$ & $-£ 4,428$ \\
\hline University of Plymouth & 34 & $£ 235,449$ & $£ 230,639$ & $-£ 4,810$ \\
\hline University of Plymouth & 35 & $£ 152,896$ & $£ 157,380$ & $£ 4,484$ \\
\hline University of Portsmouth & 2 & $£ 56,077$ & $£ 59,257$ & $£ 3,180$ \\
\hline University of Portsmouth & 3 & $£ 657,364$ & $£ 655,525$ & $-£ 1,839$ \\
\hline University of Portsmouth & 4 & $£ 378,344$ & $£ 386,278$ & $£ 7,934$ \\
\hline University of Portsmouth & 7 & $£ 498,305$ & $£ 493,282$ & $-£ 5,023$ \\
\hline University of Portsmouth & 9 & $£ 474,401$ & $£ 456,586$ & $-£ 17,815$ \\
\hline University of Portsmouth & 10 & $£ 185,667$ & $£ 180,697$ & $-£ 4,970$ \\
\hline University of Portsmouth & 11 & $£ 321,016$ & $£ 324,642$ & $£ 3,626$ \\
\hline University of Portsmouth & 12 & $£ 210,602$ & $£ 203,072$ & $-£ 7,530$ \\
\hline University of Portsmouth & 17 & $£ 128,908$ & $£ 130,484$ & $£ 1,576$ \\
\hline University of Portsmouth & 19 & $£ 479,894$ & $£ 512,736$ & $£ 32,842$ \\
\hline University of Portsmouth & 22 & $£ 198,751$ & $£ 193,583$ & $-£ 5,168$ \\
\hline University of Portsmouth & 26 & $£ 79,164$ & $£ 87,896$ & $£ 8,732$ \\
\hline University of Portsmouth & 27 & $£ 592,201$ & $£ 603,169$ & $£ 10,968$ \\
\hline University of Portsmouth & 29 & $£ 139,953$ & $£ 131,995$ & $-£ 7,958$ \\
\hline University of Portsmouth & 36 & $£ 183,590$ & $£ 190,717$ & $£ 7,127$ \\
\hline University of Southampton & 1 & $£ 3,489,941$ & $£ 3,557,769$ & $£ 67,828$ \\
\hline University of Southampton & 2 & $£ 374,959$ & $£ 367,512$ & $-£ 7,447$ \\
\hline University of Southampton & 3 & $£ 1,382,656$ & $£ 1,402,109$ & $£ 19,453$ \\
\hline University of Southampton & 4 & $£ 978,586$ & $£ 990,984$ & $£ 12,398$ \\
\hline University of Southampton & 5 & $£ 816,623$ & $£ 817,242$ & $£ 619$ \\
\hline University of Southampton & 7 & $£ 2,845,676$ & $£ 2,844,092$ & $-£ 1,584$ \\
\hline University of Southampton & 8 & $£ 1,606,865$ & $£ 1,597,521$ & $-£ 9,344$ \\
\hline
\end{tabular}




\begin{tabular}{|c|c|c|c|c|}
\hline University of Southampton & 9 & $£ 1,267,880$ & $£ 1,271,847$ & $£ 3,967$ \\
\hline University of Southampton & 10 & $£ 1,655,640$ & $£ 1,648,905$ & $-£ 6,735$ \\
\hline University of Southampton & 11 & $£ 1,758,763$ & $£ 1,791,981$ & $£ 33,218$ \\
\hline University of Southampton & 13 & $£ 3,257,854$ & $£ 3,245,573$ & $-£ 12,281$ \\
\hline University of Southampton & 15 & $£ 6,874,491$ & $£ 6,917,638$ & $£ 43,147$ \\
\hline University of Southampton & 17 & $£ 517,708$ & $£ 528,233$ & $£ 10,525$ \\
\hline University of Southampton & 17 & $£ 903,094$ & $£ 890,023$ & $-£ 13,071$ \\
\hline University of Southampton & 18 & $£ 273,853$ & $£ 265,313$ & $-£ 8,540$ \\
\hline University of Southampton & 19 & $£ 506,868$ & $£ 519,279$ & $£ 12,411$ \\
\hline University of Southampton & 20 & $£ 284,993$ & $£ 269,202$ & $-£ 15,791$ \\
\hline University of Southampton & 21 & $£ 250,781$ & $£ 238,919$ & $-£ 11,862$ \\
\hline University of Southampton & 22 & $£ 928,957$ & $£ 914,445$ & $-£ 14,512$ \\
\hline University of Southampton & 25 & $£ 397,339$ & $£ 412,681$ & $£ 15,342$ \\
\hline University of Southampton & 28 & $£ 519,647$ & $£ 524,950$ & $£ 5,303$ \\
\hline University of Southampton & 29 & $£ 527,054$ & $£ 516,066$ & $-£ 10,988$ \\
\hline University of Southampton & 30 & $£ 709,746$ & $£ 712,569$ & $£ 2,823$ \\
\hline University of Southampton & 32 & $£ 163,560$ & $£ 153,915$ & $-£ 9,645$ \\
\hline University of Southampton & 34 & $£ 226,128$ & $£ 215,371$ & $-£ 10,757$ \\
\hline University of Southampton & 35 & $£ 912,458$ & $£ 924,275$ & $£ 11,817$ \\
\hline University of Sunderland & 3 & $£ 316,521$ & $£ 303,811$ & $-£ 12,710$ \\
\hline University of Sunderland & 11 & $£ 33,037$ & $£ 35,505$ & $£ 2,468$ \\
\hline University of Sunderland & 12 & $£ 82,540$ & $£ 76,191$ & $-£ 6,349$ \\
\hline University of Sunderland & 19 & $£ 4,014$ & $£ 5,017$ & $£ 1,003$ \\
\hline University of Sunderland & 20 & $£ 2,524$ & $£ 2,330$ & $-£ 194$ \\
\hline University of Sunderland & 22 & $£ 33,850$ & $£ 31,246$ & $-£ 2,604$ \\
\hline University of Sunderland & 25 & $£ 68,736$ & $£ 76,591$ & $£ 7,855$ \\
\hline University of Sunderland & 26 & $£ 26,191$ & $£ 24,273$ & $-£ 1,918$ \\
\hline University of Sunderland & 29 & $£ 74,584$ & $£ 69,983$ & $-£ 4,601$ \\
\hline University of Sunderland & 30 & $£ 22,913$ & $£ 21,432$ & $-£ 1,481$ \\
\hline University of Sunderland & 34 & $£ 188,763$ & $£ 180,819$ & $-£ 7,944$ \\
\hline University of Sunderland & 35 & $£ 8,854$ & $£ 9,445$ & $£ 591$ \\
\hline University of Sunderland & 36 & $£ 192,051$ & $£ 192,194$ & $£ 143$ \\
\hline University of Sussex & 3 & $£ 0$ & $£ 0$ & $£ 0$ \\
\hline University of Sussex & 4 & $£ 1,395,609$ & $£ 1,399,093$ & $£ 3,484$ \\
\hline University of Sussex & 5 & $£ 1,909,255$ & $£ 1,861,061$ & $-£ 48,194$ \\
\hline University of Sussex & 8 & $£ 347,059$ & $£ 323,647$ & $-£ 23,412$ \\
\hline University of Sussex & 9 & $£ 670,198$ & $£ 638,879$ & $-£ 31,319$ \\
\hline University of Sussex & 10 & $£ 456,750$ & $£ 434,861$ & $-£ 21,889$ \\
\hline University of Sussex & 11 & $£ 388,083$ & $£ 374,456$ & $-£ 13,627$ \\
\hline University of Sussex & 15 & $£ 332,240$ & $£ 328,684$ & $-£ 3,556$ \\
\hline University of Sussex & 17 & $£ 519,804$ & $£ 541,696$ & $£ 21,892$ \\
\hline University of Sussex & 18 & $£ 231,210$ & $£ 234,909$ & $£ 3,699$ \\
\hline University of Sussex & 19 & $£ 629,535$ & $£ 628,192$ & $-£ 1,343$ \\
\hline University of Sussex & 20 & $£ 343,004$ & $£ 343,705$ & $£ 701$ \\
\hline University of Sussex & 21 & $£ 374,864$ & $£ 380,299$ & $£ 5,435$ \\
\hline University of Sussex & 22 & $£ 167,636$ & $£ 173,423$ & $£ 5,787$ \\
\hline University of Sussex & 23 & $£ 178,893$ & $£ 181,152$ & $£ 2,259$ \\
\hline University of Sussex & 24 & $£ 273,392$ & $£ 283,242$ & $£ 9,850$ \\
\hline
\end{tabular}




\begin{tabular}{|c|c|c|c|c|}
\hline University of Sussex & 25 & $£ 264,454$ & $£ 261,634$ & $-£ 2,820$ \\
\hline University of Sussex & 27 & $£ 194,235$ & $£ 186,309$ & $-£ 7,926$ \\
\hline University of Sussex & 29 & $£ 812,433$ & $£ 796,831$ & $-£ 15,602$ \\
\hline University of Sussex & 30 & $£ 443,049$ & $£ 432,485$ & $-£ 10,564$ \\
\hline University of Sussex & 32 & $£ 175,493$ & $£ 168,739$ & $-£ 6,754$ \\
\hline University of Sussex & 34 & $£ 158,502$ & $£ 149,199$ & $-£ 9,303$ \\
\hline University of Sussex & 35 & $£ 69,578$ & $£ 69,960$ & $£ 382$ \\
\hline University of Sussex & 36 & $£ 523,937$ & $£ 536,228$ & $£ 12,291$ \\
\hline University of the Arts, London & 34 & $£ 2,681,420$ & $£ 2,711,377$ & $£ 29,957$ \\
\hline University of the West of England, Bristol & 3 & $£ 1,170,548$ & $£ 1,187,454$ & $£ 16,906$ \\
\hline University of the West of England, Bristol & 6 & $£ 243,928$ & $£ 248,468$ & $£ 4,540$ \\
\hline University of the West of England, Bristol & 11 & $£ 322,558$ & $£ 318,152$ & $-£ 4,406$ \\
\hline University of the West of England, Bristol & 15 & $£ 323,700$ & $£ 304,026$ & $-£ 19,674$ \\
\hline University of the West of England, Bristol & 16 & $£ 392,797$ & $£ 401,613$ & $£ 8,816$ \\
\hline University of the West of England, Bristol & 17 & $£ 118,012$ & $£ 122,132$ & $£ 4,120$ \\
\hline University of the West of England, Bristol & 19 & $£ 320,046$ & $£ 324,117$ & $£ 4,071$ \\
\hline University of the West of England, Bristol & 20 & $£ 85,114$ & $£ 84,630$ & $-£ 484$ \\
\hline University of the West of England, Bristol & 21 & $£ 52,865$ & $£ 54,047$ & $£ 1,182$ \\
\hline University of the West of England, Bristol & 22 & $£ 131,626$ & $£ 129,659$ & $-£ 1,967$ \\
\hline University of the West of England, Bristol & 25 & $£ 129,415$ & $£ 131,484$ & $£ 2,069$ \\
\hline University of the West of England, Bristol & 28 & $£ 76,632$ & $£ 73,902$ & $-£ 2,730$ \\
\hline University of the West of England, Bristol & 29 & $£ 200,066$ & $£ 201,194$ & $£ 1,128$ \\
\hline University of the West of England, Bristol & 30 & $£ 139,977$ & $£ 150,815$ & $£ 10,838$ \\
\hline University of the West of England, Bristol & 32 & $£ 48,328$ & $£ 51,736$ & $£ 3,408$ \\
\hline University of the West of England, Bristol & 34 & $£ 391,572$ & $£ 408,516$ & $£ 16,944$ \\
\hline University of the West of England, Bristol & 36 & $£ 289,120$ & $£ 287,785$ & $-£ 1,335$ \\
\hline University of Winchester & 4 & $£ 45,844$ & $£ 43,485$ & $-£ 2,359$ \\
\hline University of Winchester & 17 & $£ 29,830$ & $£ 27,535$ & $-£ 2,295$ \\
\hline University of Winchester & 23 & $£ 16,982$ & $£ 15,676$ & $-£ 1,306$ \\
\hline University of Winchester & 25 & $£ 72,993$ & $£ 69,042$ & $-£ 3,951$ \\
\hline University of Winchester & 30 & $£ 103,351$ & $£ 99,788$ & $-£ 3,563$ \\
\hline University of Winchester & 33 & $£ 51,993$ & $£ 55,905$ & $£ 3,912$ \\
\hline University of Winchester & 35 & $£ 135,373$ & $£ 133,533$ & $-£ 1,840$ \\
\hline University of Winchester & 36 & $£ 148,574$ & $£ 144,182$ & $-£ 4,392$ \\
\hline University of Wolverhampton & 3 & $£ 536,851$ & $£ 500,136$ & $-£ 36,715$ \\
\hline University of Wolverhampton & 12 & $£ 66,346$ & $£ 62,904$ & $-£ 3,442$ \\
\hline University of Wolverhampton & 16 & $£ 85,067$ & $£ 78,959$ & $-£ 6,108$ \\
\hline University of Wolverhampton & 19 & $£ 49,444$ & $£ 49,463$ & $£ 19$ \\
\hline University of Wolverhampton & 20 & $£ 45,734$ & $£ 42,216$ & $-£ 3,518$ \\
\hline University of Wolverhampton & 25 & $£ 60,328$ & $£ 57,834$ & $-£ 2,494$ \\
\hline University of Wolverhampton & 26 & $£ 69,861$ & $£ 72,429$ & $£ 2,568$ \\
\hline University of Wolverhampton & 27 & $£ 28,532$ & $£ 27,268$ & $-£ 1,264$ \\
\hline University of Wolverhampton & 28 & $£ 94,444$ & $£ 93,683$ & $-£ 761$ \\
\hline University of Wolverhampton & 29 & $£ 40,093$ & $£ 37,009$ & $-£ 3,084$ \\
\hline University of Wolverhampton & 30 & $£ 110,303$ & $£ 110,131$ & $-£ 172$ \\
\hline University of Wolverhampton & 34 & $£ 244,398$ & $£ 234,146$ & $-£ 10,252$ \\
\hline University of Wolverhampton & 36 & $£ 173,694$ & $£ 174,489$ & $£ 795$ \\
\hline University of Worcester & 3 & $£ 82,314$ & $£ 78,559$ & $-£ 3,755$ \\
\hline
\end{tabular}




\begin{tabular}{|c|c|c|c|c|}
\hline University of Worcester & 4 & $£ 70,017$ & $£ 67,965$ & $-£ 2,052$ \\
\hline University of Worcester & 5 & $£ 130,363$ & $£ 128,258$ & $-£ 2,105$ \\
\hline University of Worcester & 17 & $£ 60,890$ & $£ 58,121$ & $-£ 2,769$ \\
\hline University of Worcester & 19 & $£ 9,182$ & $£ 8,983$ & $-£ 199$ \\
\hline University of Worcester & 25 & $£ 88,965$ & $£ 85,458$ & $-£ 3,507$ \\
\hline University of Worcester & 26 & $£ 94,731$ & $£ 98,511$ & $£ 3,780$ \\
\hline University of Worcester & 29 & $£ 45,879$ & $£ 47,109$ & $£ 1,230$ \\
\hline University of Worcester & 30 & $£ 52,719$ & $£ 51,116$ & $-£ 1,603$ \\
\hline University of Worcester & 34 & $£ 65,578$ & $£ 62,227$ & $-£ 3,351$ \\
\hline University of Worcester & 35 & $£ 21,207$ & $£ 20,336$ & $-£ 871$ \\
\hline University of York & 2 & $£ 1,688,658$ & $£ 1,726,605$ & $£ 37,947$ \\
\hline University of York & 4 & $£ 931,487$ & $£ 911,939$ & $-£ 19,548$ \\
\hline University of York & 5 & $£ 1,670,015$ & $£ 1,685,935$ & $£ 15,920$ \\
\hline University of York & 7 & $£ 520,250$ & $£ 529,172$ & $£ 8,922$ \\
\hline University of York & 8 & $£ 1,629,816$ & $£ 1,618,064$ & $-£ 11,752$ \\
\hline University of York & 9 & $£ 969,386$ & $£ 960,424$ & $-£ 8,962$ \\
\hline University of York & 10 & $£ 799,972$ & $£ 786,253$ & $-£ 13,719$ \\
\hline University of York & 11 & $£ 1,440,011$ & $£ 1,462,287$ & $£ 22,276$ \\
\hline University of York & 13 & $£ 454,196$ & $£ 442,808$ & $-£ 11,388$ \\
\hline University of York & 17 & $£ 549,034$ & $£ 563,246$ & $£ 14,212$ \\
\hline University of York & 18 & $£ 401,987$ & $£ 407,536$ & $£ 5,549$ \\
\hline University of York & 19 & $£ 339,419$ & $£ 345,410$ & $£ 5,991$ \\
\hline University of York & 20 & $£ 246,706$ & $£ 250,042$ & $£ 3,336$ \\
\hline University of York & 21 & $£ 478,156$ & $£ 482,863$ & $£ 4,707$ \\
\hline University of York & 22 & $£ 869,965$ & $£ 894,784$ & $£ 24,819$ \\
\hline University of York & 23 & $£ 443,333$ & $£ 460,111$ & $£ 16,778$ \\
\hline University of York & 25 & $£ 502,534$ & $£ 512,684$ & $£ 10,150$ \\
\hline University of York & 28 & $£ 323,546$ & $£ 327,273$ & $£ 3,727$ \\
\hline University of York & 29 & $£ 1,029,112$ & $£ 1,029,933$ & $£ 821$ \\
\hline University of York & 30 & $£ 789,985$ & $£ 791,931$ & $£ 1,946$ \\
\hline University of York & 32 & $£ 216,162$ & $£ 205,113$ & $-£ 11,049$ \\
\hline University of York & 34 & $£ 559,930$ & $£ 581,280$ & $£ 21,350$ \\
\hline University of York & 35 & $£ 300,703$ & $£ 296,888$ & $-£ 3,815$ \\
\hline University of York & 35 & $£ 228,523$ & $£ 218,042$ & $-£ 10,481$ \\
\hline Writtle University College & 6 & $£ 35,832$ & $£ 33,076$ & $-£ 2,756$ \\
\hline Writtle University College & 34 & $£ 5,389$ & $£ 4,974$ & $-£ 415$ \\
\hline York St John University & 3 & $£ 45,668$ & $£ 45,559$ & $-£ 109$ \\
\hline York St John University & 4 & $£ 65,622$ & $£ 68,127$ & $£ 2,505$ \\
\hline York St John University & 19 & $£ 6,659$ & $£ 6,147$ & $-£ 512$ \\
\hline York St John University & 25 & $£ 26,965$ & $£ 24,891$ & $-£ 2,074$ \\
\hline York St John University & 26 & $£ 57,654$ & $£ 53,219$ & $-£ 4,435$ \\
\hline York St John University & 29 & $£ 84,629$ & $£ 81,683$ & $-£ 2,946$ \\
\hline York St John University & 33 & $£ 25,443$ & $£ 23,986$ & $-£ 1,457$ \\
\hline York St John University & 35 & $£ 104,617$ & $£ 111,503$ & $£ 6,886$ \\
\hline York St John University & 36 & $£ 34,818$ & $£ 32,877$ & $-£ 1,941$ \\
\hline \multicolumn{5}{|c|}{$\begin{array}{l}\text { Notes: "Mainstream QR funding with 15-20-65" column offers total QR funding distributed across UOAs based on the } 15 \%, 20 \% \text {, and } 65 \% \text { weights } \\
\text { to the environment, impact and output, respectively. "Mainstream QR funding with 15-25-60" column offers total QR funding distributed across } \\
\text { UOAs based on the } 15 \%, 25 \% \text {, and } 60 \% \text { weights to the environment, impact and output, respectively. "Additional gains/losses" column gives the } \\
\text { difference between two alternative QR funding distributions. }\end{array}$} \\
\hline
\end{tabular}

